\title{
AN ANALYSIS OF THE RELATIONSHIP BETWEEN INFORMATION AND COMMUNICATION TECHNOLOGY (ICT) AND SCIENTIFIC LITERACY IN CANADA AND AUSTRALIA
}

by

King Luu

A thesis submitted to the Faculty of Education

in conformity with the requirements for

the degree of Master of Education

\author{
Queen's University \\ Kingston, Ontario, Canada
}

August, 2009

Copyright C King Luu, 2009 


\begin{abstract}
Despite the lack of substantial evidence for improvement in the quality of teaching and learning with information and communication technology (ICT), governmental organizations, including those of Canada and Australia, have made large investments into ICT. This investment has been largely predicated on the hypothesized relationship between ICT and science achievement, and the need for ICT as a means of providing broad-scale training to meet the demand for a skilled workforce.

To better understand this possible relationship, this study used data from the 2006 administration of the Programme for International Student Assessment (PISA 2006) to determine the extent to which scientific literacy is predicted by student- and school-level variables related to ICT, after adjusting for student demographic characteristics and school characteristics.

The findings suggest that, once student demographic characteristics and school characteristics have been accounted for, students with prior experience with ICT, who browse the Internet more frequently, and who are confident with basic ICT tasks earned higher scientific literacy scores. Gender differences existed with respect to types of productivity and entertainment software used; this difference may be attributed to personal choice and initiative to learn ICT. Finally, differences in ICT use between Canada and Australia, particularly with school use, may be due to initiatives in Australia (e.g., National Goals of Schooling for the Twenty-first Century) that promote the increased use of ICT in classrooms.
\end{abstract}




\section{ACKNOWLEDGEMENTS}

First, I wish to express my gratitude towards my thesis supervisor, Dr. John Freeman, who immediately adopted me upon our first encounter two summers ago and has since meticulously led me through each step of the program. John, through every page read, every presentation attended, and every meeting held, your guidance was instrumental in my successes. Thank you.

Second, I would like to thank Dr. Don Klinger, who served as my thesis committee member. He was helpful when it came to tabulating the data and interpreting the statistics. Don, your tireless devotion to educational research inspires me. Thank you for your indispensable advice.

Third, I am grateful to fellow graduate students, dear professors, as well as the library and administrative staff at the Faculty of Education. I would especially like to thank my colleagues, Shaljan Areepattamannil and Hana Saab, for helping me getting started with (what turned out to be) a tortuous - yet intellectually satisfying — field of research.

Last, I would like to thank my parents and my sister for their continuous encouragement throughout all my years in school. Their support has helped me attain personal goals I once considered well beyond my reach. 


\section{TABLE OF CONTENTS}

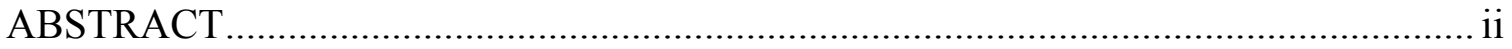

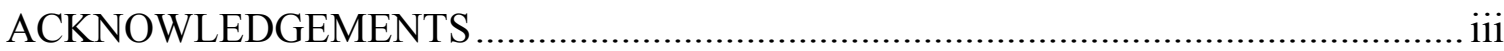

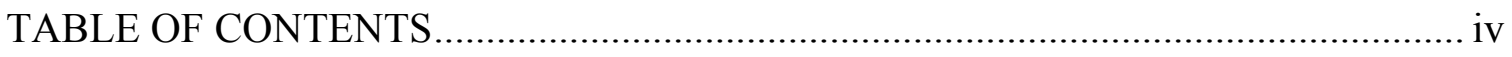

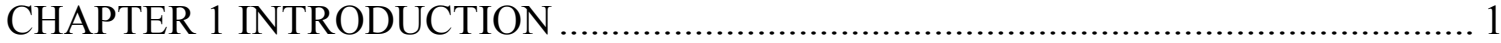

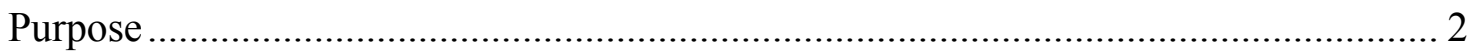

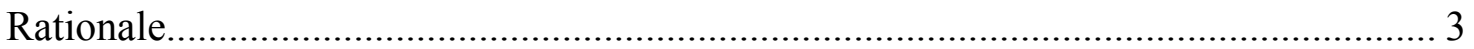

Organization of the Thesis .................................................................................... 5

CHAPTER 2 REVIEW OF THE LITERATURE .......................................................... 6

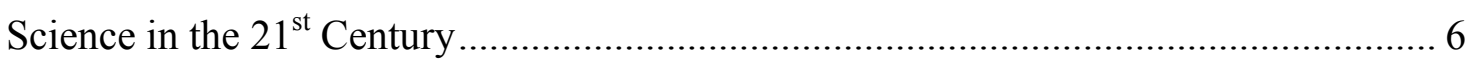

Information and Communication Technology (ICT) ……………............................ 11

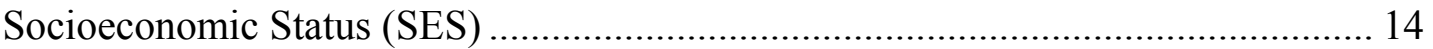

Immigrants and Indigenous Populations ............................................................. 15

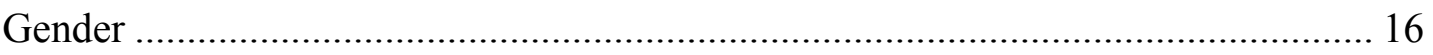

Access and Frequency of Use ..................................................................... 16

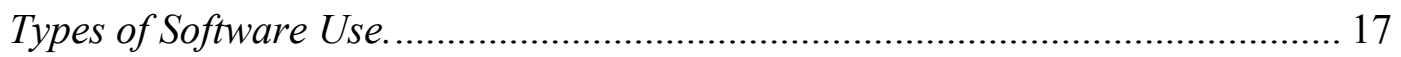

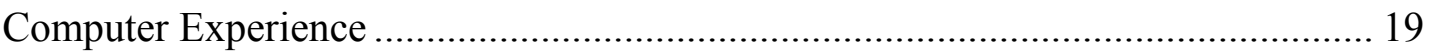

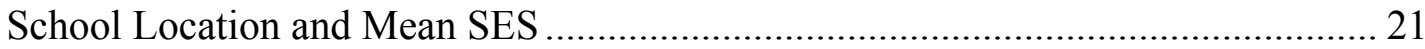

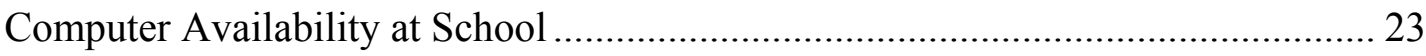

The State of ICT in Canada and Australia............................................................... 24

Changing Nature of ICT in Science Education ....................................................... 27

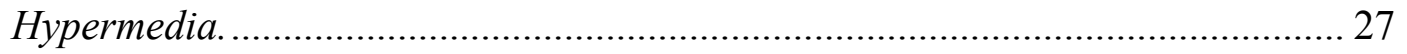

Computer-mediated Communication ............................................................... 28

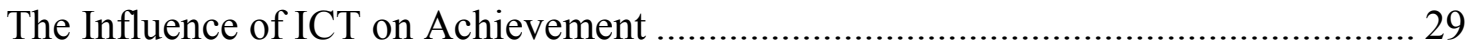

Access and Frequency of Use.......................................................................... 30

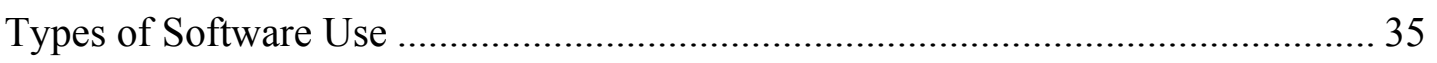

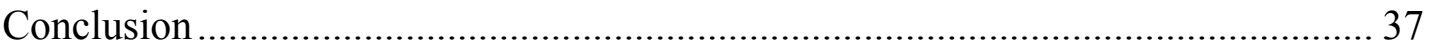

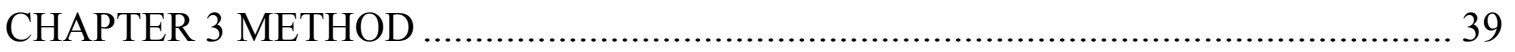

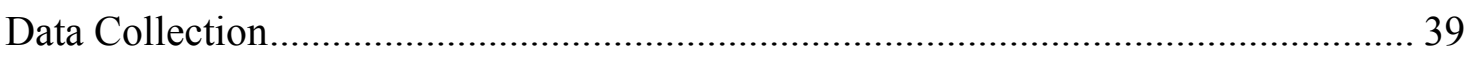

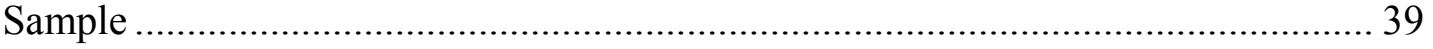


Canada. 40

Australia. 41

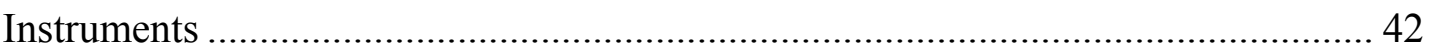

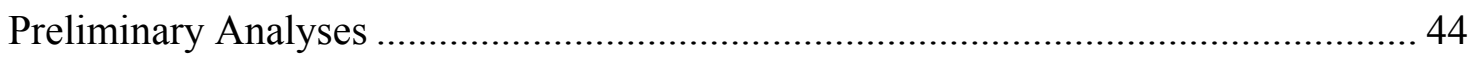

Handling of Missing Data, Weighting, and Estimation Methods............................... 45

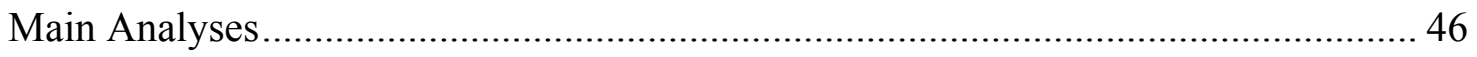

To what extent do students in Canada and Australia differ in their access to, use of, and confidence with information and communication technology (ICT)?................ 46 To what extent are differences in scientific literacy predicted by student-level and school-level characteristics in Canada and Australia? ............................................... 48

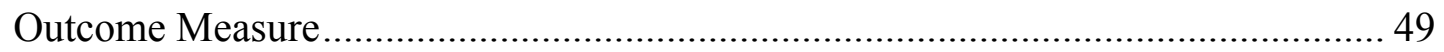

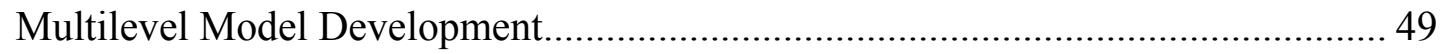

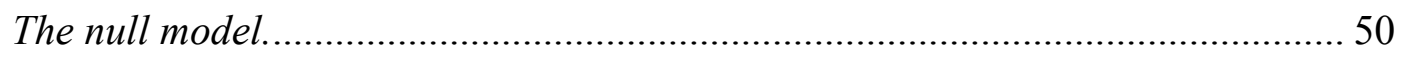

Addition of student-level predictors (level-1 fixed effects)................................... 50

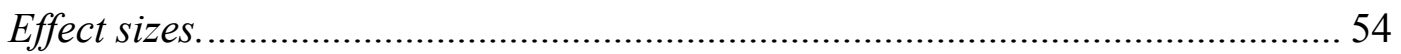

Supplementary Analysis for Second Research Question .............................................. 54

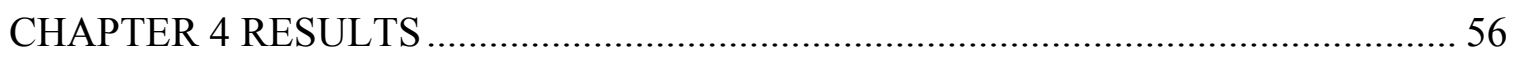

To what extent do students in Canada and Australia differ in their access to, use of, and confidence with information and communication technology (ICT)? .......................... 56

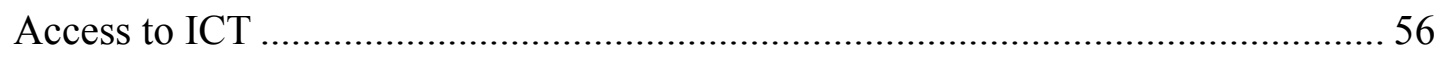

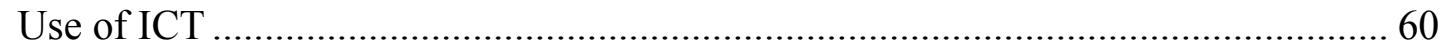

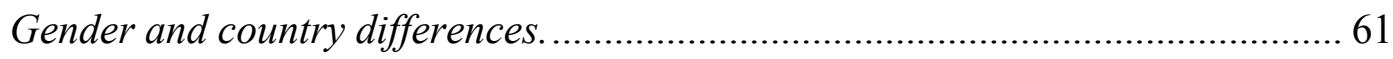

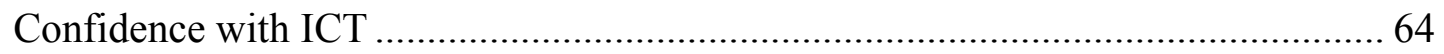

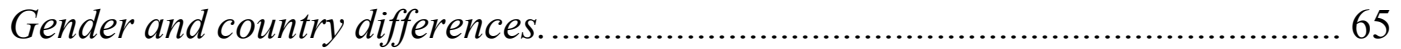

To what extent are differences in scientific literacy predicted by student-level and school-level characteristics in Canada and Australia? ................................................... 67

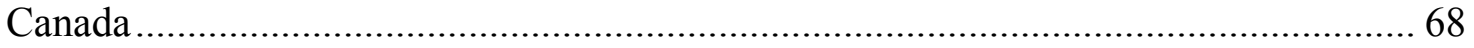

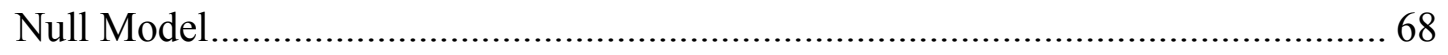

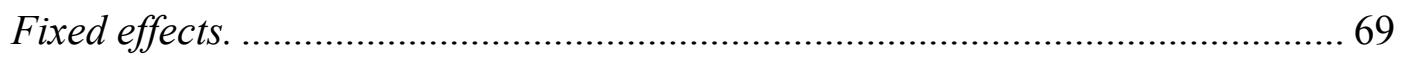

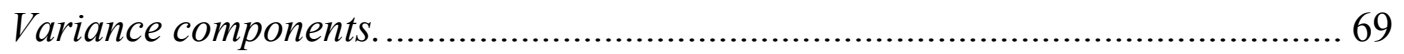




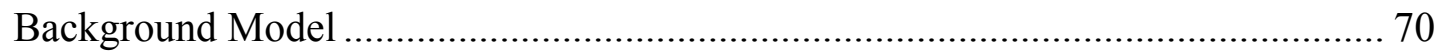

Relative Effects Model .................................................................................... 71

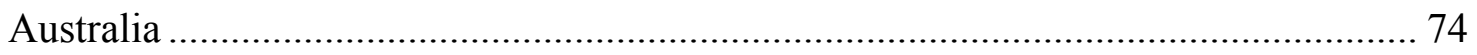

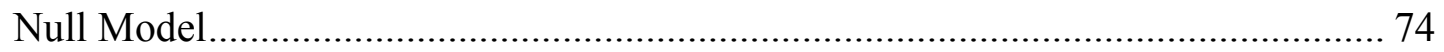

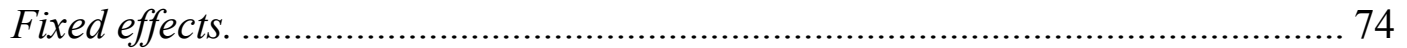

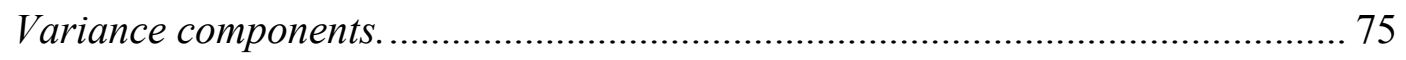

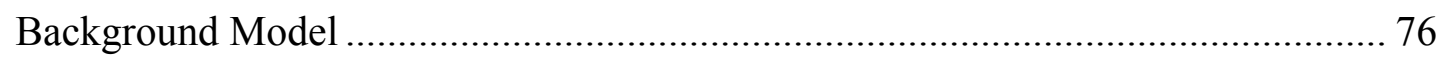

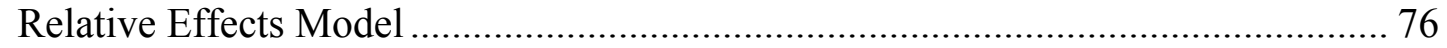

ICT Profiles and Scientific Literacy..................................................................... 79

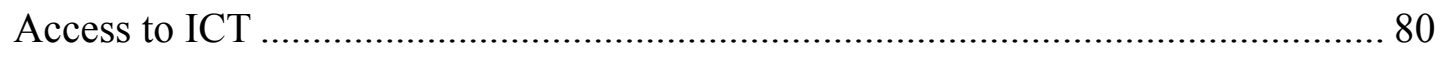

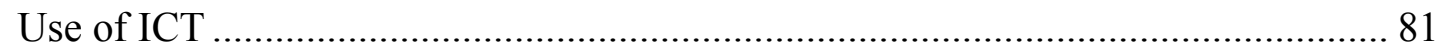

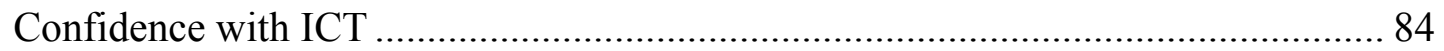

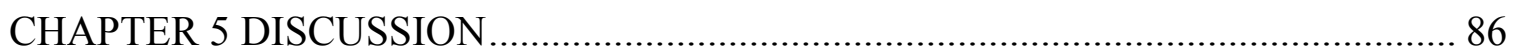

To what extent do students in Canada and Australia differ in their access to, use of, and confidence with information and communication technology (ICT)? .......................... 86

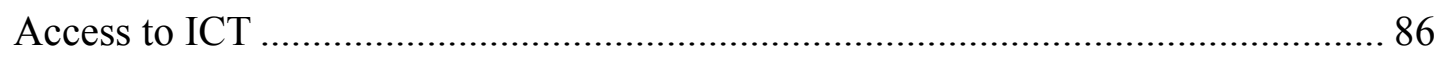

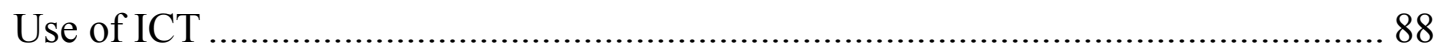

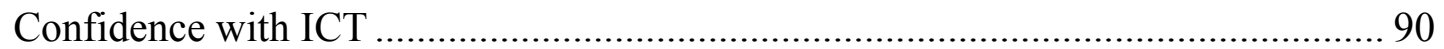

To what extent are differences in scientific literacy predicted by student-level and school-level characteristics in Canada and Australia? ................................................... 91

Student Characteristics ....................................................................................... 91

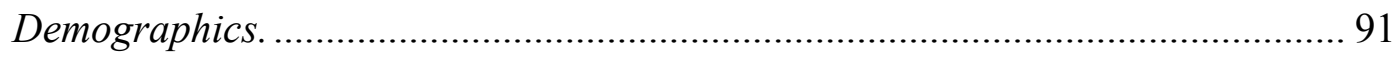

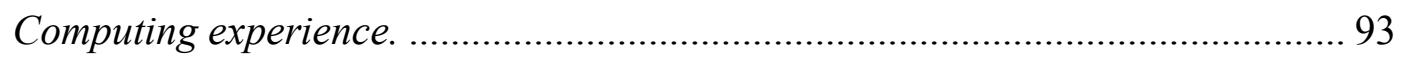

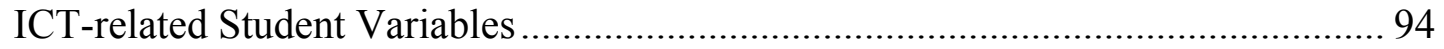

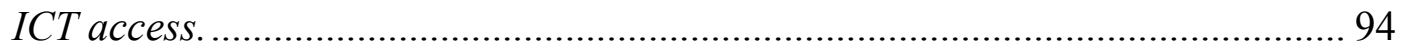

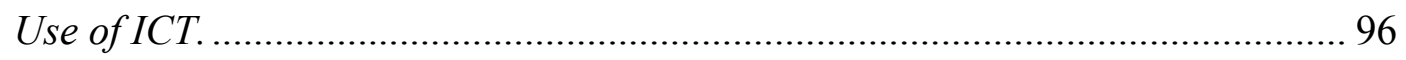

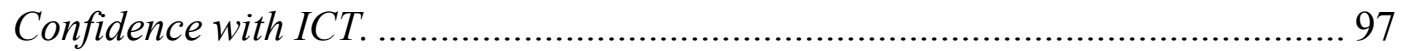

School-level Factors .......................................................................................... 99

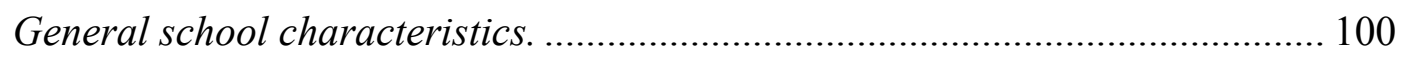

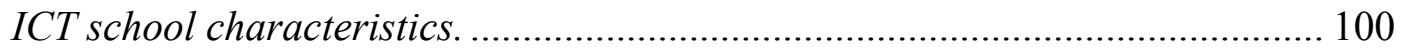




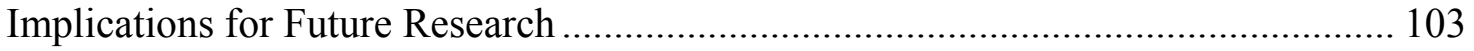

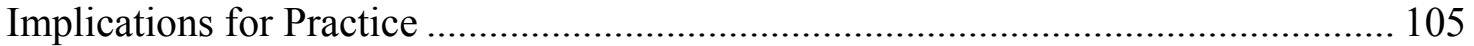

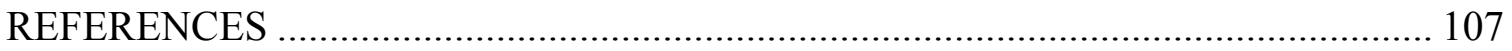

APPENDIX A VARIABLES USED IN MULTILEVEL LINEAR MODELING ........ 117 APPENDIX B DESCRIPTIVE STATISTICS FOR ICT USE AND CONFIDENCE

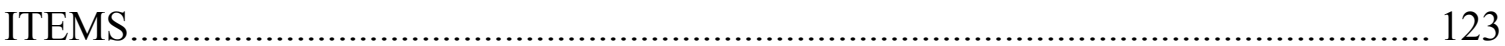

APPENDIX C MULTILEVEL MODELING EQUATIONS...................................... 126

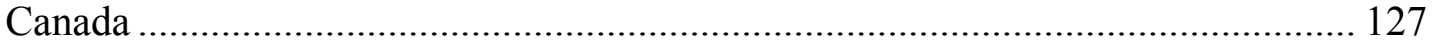

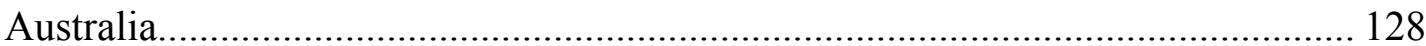

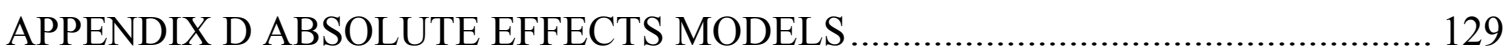




\section{CHAPTER 1}

INTRODUCTION

This thesis centres on the association between information and communication technology (ICT) variables and scientific literacy of students in Canada and Australia. Both ICT and science have been deemed essential by provincial and national governments in these countries for economic growth and development in the $21 \mathrm{st}$ century. These governments have increased their investments for training and equipment in these areas accordingly. Furthermore, similarities between ICT and science (e.g., cognitive processes and curricular outcomes) indicate the possibilities inherent in promoting the integration of ICT in science education.

Scientific literacy is defined as an "understanding of scientific concepts, as well as the ability to apply a scientific perspective and to think scientifically about evidence" (Organisation for Economic Co-operation and Development [OECD], 2007b, p. 21). This definition is centred upon four interrelated aspects: (a) scientific knowledge and use of that knowledge to identify questions, to acquire new knowledge, to explain scientific phenomena, and to draw evidence-based conclusions about science-related issues; (b) understanding the characteristic features of science as a form of human knowledge and enquiry; (c) awareness of how science and technology shape our material, intellectual, and cultural environments; and (d) willingness to engage in science-related issues and with the ideas of science, as a reflective citizen. 
To measure these concepts, OECD sponsors a large-scale international assessment, the Programme for International Student Assessment (PISA). The purpose of PISA is to measure how well 15-year-old students approaching the end of formal schooling are prepared to meet the challenges of today's knowledge societies (OECD, 2009). To that end, the results are used by participating countries to identify potential strategies and improve system outputs (OECD, 2006a).

In the 2006 administration of PISA, 57 countries participated in the study, including all 30 member countries; however, this thesis focuses on the countries of Canada and Australia, since the two nations share a number of economic, social, and cultural factors. These factors include the reliance on natural resource exports to maintain standards of living, a strong immigrant population to sustain their economies, large proportions of the population residing in urbanized areas, and similar levels of socioeconomic status (Corbett \& Willms, 2002). These national demographics guide decisions made by their respective federal governments, including the purposes of their education systems, and the types of learning resources that are provided to schools. In addition, relative to other participating countries, the two countries scored well above average in science achievement. OECD (2007b) reported that Canada scored 534 (third overall), while Australia was eighth overall, with a score of 527 (the mean score of all 57 countries participating in PISA 2006 was 500 with a standard deviation of 100).

\section{Purpose}

The primary purpose of this study was to determine the extent to which ICTrelated student- and school-level variables could predict scientific literacy in Australia 
and Canada in the presence of student- and school-level demographic variables. A secondary purpose was to understand the differences in ICT access, usage, and confidence in the two countries, as moderated by gender.

Two research questions guided the study:

1. To what extent do students in Canada and Australia differ in their access to, use of, and confidence with information and communication technology (ICT)?

2. To what extent are differences in scientific literacy predicted by student-level and school-level characteristics in Canada and Australia?

\section{Rationale}

Investments in information and communication technology (ICT) have increased in recent years (Pelgrum \& Plomp, 2002), with the perception that increased student use of computers and other electronic forms of media may have a positive impact on student achievement (OECD, 2001). In addition, students' use of technology ${ }^{1}$ is considered an important indicator of their preparedness to succeed and excel at school (Corbett \& Willms, 2002), although the benefits of using ICT for learning are still being studied (e.g., Wittwer \& Senkbeil, 2008).

OECD (2009) defines ICT as "the use of any equipment or software for processing or transmitting digital information that performs diverse general functions whose options can be specified or programmed by its user" (p. 59). PISA 2006 collected data from countries that opted to administer a short questionnaire on students' familiarity

\footnotetext{
${ }^{1}$ The term technology, whenever used in citations, refers to computer hardware and software as tools to support teaching and learning processes, rather than the design of products.
} 
with ICT, as well as a school questionnaire for administrators. In the ICT questionnaire, students were asked about their familiarity with ICT, with respect to availability and frequency of ICT use, and comfort performing activities related to ICT. Administrators were asked about the number of computers in their school; of those, how many were connected to the Internet; and the ratio of computers to students at the school. In that both Australia and Canada asked students to complete the ICT questionnaire, they are countries for which ICT questions related to achievement can be posed.

Canada and Australia are also appropriate countries for examining ICT with respect to achievement because of their similar resources. Countries with similar resources according to the gross national product (now defined as gross national income, or GNI) per capita are suitable for studies involving academic achievement (Raudenbush, Cheong, \& Fotiu, 1995). According to World Bank (2008) estimates, the GNI per capita for Canada was 35,310 international dollars after adjustment for purchasing power parity in 2007, while for Australia it was 33,340 international dollars. However, despite similarities in GNI per capita, the two countries differ in allocation of resources across schools. According to the TIMSS (Trends in Mathematics and Science Study) 1994 and 1999 data, Australia had low levels of between-school resource inequality (including computer hardware and software), while Canada was a nation with average levels of inequality (Baker \& LeTendre, 2005). These differences in inequality may have an effect on mathematics and science achievement and the ways schools are resourced to achieve academic success (Baker \& LeTendre), if a connection between ICT resources and achievement exists. 
Organization of the Thesis

The thesis contains five chapters. Chapter 1 provided definitions of important terms; gave information about PISA 2006; situated the economic and educational context of the two countries in the study, Canada and Australia; and described the rationale for this thesis. Chapter 2 is a review of the literature relating to students' use of ICT, the importance of science education in the 21 st century, and the use of ICT to promote learning and achievement. Chapter 3 describes the methods by which the data were collected, and the statistical techniques used to address the research questions in this thesis. Chapter 4 presents the results of the analyses, which include: (a) a comparison of ICT use and attitudes with respect to gender and by country, and (b) separate multilevel linear models for Canada and Australia. Lastly, a discussion of the findings takes place in Chapter 5, along with the implications for research and practice. 


\section{CHAPTER 2}

\section{REVIEW OF THE LITERATURE}

This chapter is organized into three sections. The first section describes how science education has emerged into an important subject for national prosperity and personal growth. The subsequent section outlines student-level and school-level variables related to ICT. Student-level variables include demographic variables (socioeconomic status [SES], ethnicity, and gender) and ICT-specific variables (types of computer activities, computer experience, and frequency of computer use). School-level variables include contextual variables (school size, school mean SES, and urbanicity) and ICTspecific variables (computer availability and ICT programs in the curriculum). The final section presents studies describing the impact of ICT use on achievement in a variety of contexts with an emphasis on science.

\section{Science in the $21^{\text {st }}$ Century}

Heightened attention has been given to science education in the past quartercentury because of the growing shift towards knowledge-based economies, which require a supply of workers well-prepared in the sciences to ensure continued innovation and development. Canada's future prosperity and quality of life are directly related to its ability to thrive and compete in the global economy in which science and technology play a pivotal role (Knox \& Schmidt, 2006; Lupart \& Cannon, 2002). Similarly, Australia’s success as a knowledge economy is "dependent on a highly skilled, informed and scientifically literate workforce who receive a strong foundation of SET [science, 
engineering, and technology] knowledge throughout their primary and secondary schooling" (Batterham, 2000, p. 49).

The challenge to develop a knowledge-based economy through a revised secondary science curriculum during this time was a priority in other countries as well. A document from the U.S. National Research Council linked science education to national economic development through a causal chain, described as follows:

Several implicit causal assumptions underlie public and political interest in crossnational studies of mathematics and science: (1) increased and improved curricular emphasis in precollegiate education for all students will result in greater achievement for a greater number of students; (2) this will result in a greater number of better prepared students entering the natural sciences and engineering; and (3) this will in turn lead to a greater number of more productive scientists and engineers in the labor force. A final assumption is that more and better scientists and engineers will increase economic growth or productivity. Each of these premises has its critics and each should be systematically evaluated. (Guilford, cited in Ramirez, Luo, Schofer, \& Meyer, 2006, p. 5)

To test the economic argument for the value of science education, Ramirez et al. (2006) conducted a cross-national longitudinal analysis to examine the relationship between student achievement in science and mathematics and national economic growth. Using aggregate data from the 1970-1990 and 1980-2000 periods, the authors regressed national economic growth on student achievement over a 20 -year period. They found that countries with high science and mathematics achievement scores tended to grow somewhat more rapidly than other countries, but this effect was tempered when the four Asian Tiger countries, South Korea, Singapore, Hong Kong, and Taiwan, which all experienced high economic growth and high scores during these periods, were excluded. The authors thus suggested that the relationship might not be causal, but rather outcomes of a regime, a regime where schooling is organized and chartered to produce human- 
capital development (Ramirez et al.). Furthermore, linking science education with economic growth "presupposes a world of enormous variation with respect to curriculum, teaching, and achievement [in science]" (Ramirez et al., p. 7), although research shows less variation in these areas than would be expected in policy discourse. Finally, in countries where students' science education is "less grounded in their test scores and more attuned to individual personal tastes" (p. 22), a smaller achievement impact on the economy would be expected.

This final point indicates that, even should these arguments promoting science as a mechanism through which countries maintain economic growth prove problematic, arguments focusing on cognitive growth may still provide reasons to focus on science education. Scientific literacy ${ }^{2}$ builds problem-solving, communication, and critical team skills, all of which are important not only for scientists and engineers, but also for collaborative teamwork (Knox \& Schmidt, 2006). Science education helps develop habits of mind, which encompass "higher-order thinking skills, critical and scientific reasoning skills, problem-solving skills, communication and decision-making skills, and metacognition - being aware of your own thinking” (Llewellyn, 2005, p. 2). Finally, Linn (2003) adds that preparing students for today's society means "engaging students in carrying out complex projects that connect advances in technology with important science topics" (p. 753), which will not only provide students with the ability to

\footnotetext{
${ }^{2}$ Scientific literacy (also known as science literacy) may also include information management and problem solving, and helps students make links among science, technology, innovation, the economy, and society (Knox \& Schmidt, 2006).
} 
understand and interpret scientific information, but also the opportunity to apply technology-enhanced solutions to everyday problems.

As a result of these two types of arguments (economic and cognitive), scientific literacy has been promoted as a vital requirement to national prosperity in the 21 st century, with the rationale that students need to develop the knowledge, skills, and habits of mind promoted in secondary school science classes (American Association for the Advancement of Science [AAAS], 1998; Council of Ministers of Education, Canada [CMEC], 1997). This valuation of scientific knowledge as a commodity has influenced educational reforms in Canada (O'Sullivan, 1999) and Australia (Batterham, 2000). For example, in Canada, the notions of scientific literacy encompassed within CMEC's Common Framework of Science Learning Outcomes document have elicited changes to the Grade K-12 science curricula across the country. This document built on earlier policy statements that targeted science education, such as the one issued in 1984 by the Science Council of Canada.

Prior to the scientific literacy framework established by CMEC in 1997, one of the most apposite policy documents for science education in Canada was a report entitled Science for Every Citizen, published in 1984 by the Science Council of Canada (cited in Fensham, 1992), which listed the following priorities for school science:

1. To develop citizens able to participate fully in political and social choices facing a technological society;

2. To train those with special interest in science and technology education for further study; 
3. To provide an appropriate preparation for modern fields of work; and

4. To stimulate intellectual and moral growth of students.

Generalist science education has two broad aims, as identified by the first two objectives, which are (a) to foster a public understanding of science and (b) to attract students into scientific careers (Norris \& Phillips, 2009). The third objective acknowledges the increasing importance of science and technology in the economy; and the last one links the intellectual and moral growth of students with their ability to participate democratically as educated citizens (Fensham, 1992; Smith \& Gunstone, 2009).

Despite this long-standing educational attention to science education, there remains, however, limited employment in science- and technology-based sectors because of insufficient student enrolments in secondary and post-secondary science courses, with only a small proportion of students pursuing a science- or technology-based career (Osborne, Simon, \& Collins, 2003; Tytler, 2007). For example, at the turn of the 21st century, the rate of participation in mathematics, science, and technology in Australia had been decreasing over the past decade, despite increasing school enrolments (Batterham, 2000). Declining student interest through successive grade levels may be a contributing factor to students' avoidance of science and mathematics in college (Osborne et al.).

In addition, the results from Canadian assessments in 2004 suggest that the revised curricula have not led to increased science achievement, since approximately onethird of students were performing below expected levels, a drop in performance compared to five years prior (Knox \& Schmidt, 2006). It is unclear which assessment 
results they examined. Regardless, the authors found little difference in achievement between males and females, indicating that efforts to raise science awareness among females might be having a positive effect on the gender gap.

To help the initiatives meant to increase the supply of Canadians with science skills and knowledge, Knox and Schmidt (2006) suggest fostering the importance of scientific literacy in students early, and reinforcing it throughout life. This process can be done through interactive programs that build science skills as well as promoting positive attitudes towards science. In a similar vein, Bybee and Fuchs (2006) indicate that, if K-12 science education is to achieve the desired workplace competencies, it needs to be valued as essential as literacy and mathematics. Instructional activities should be designed to provide students with practice in science and technological design. These recommendations strongly suggest the integration of science with ICT.

\section{Information and Communication Technology (ICT)}

The emergence of the knowledge-based economy means an ever-increasing demand for a well-educated and skilled workforce, including skills in Information and Communication Technology, or ICT (Government of Canada, 2002). Public education is one avenue where broad-scale training can be offered to meet this demand, but the integration of ICT in education may also "enhance the quality and effectiveness of the learning process" (Organisation for Economic Co-operation and Development [OECD], 2001, p. 9). Accordingly, OECD has identified three rationales for the integration of ICT in education: 
1. economic, where ICT is viewed as an aspect of employability, since the use of ICT is increasing in many areas of employment, with the aforementioned skills benefiting the national economic well-being;

2. social, as ICT is "becoming a prerequisite for participation in society and the workplace" (p. 10), perceiving ICT as essential a skill as reading and writing for daily life; therefore, educators should provide such opportunities to support students who may have opportunities to access ICT outside of school; and 3. pedagogical, which focuses on the role of ICT in teaching and learning, as accessibility to resources through ICT not only increases the richness of learning, but also supports the development of higher-order thinking skills in Bloom's taxonomy, including analysis and synthesis.

The reported potential of integration of ICT on student learning has led educational policymakers, in Canada and abroad, to incorporate ICT into existing programs. One of the most intriguing questions for policymakers is "what the added value of ICT use is [as compared to instruction without ICT]" (Pelgrum \& Plomp, 2002, p. 323). Furthermore, optimism about computer skills contributing to student achievement and employability assumes that the integration of ICT into the school curriculum would not be affected by prior patterns of inequality or would improve the effect of these patterns (Lowe, Krahn, $\&$ Sosteric, 2003).

In this contentious issue, education stakeholders have aligned themselves into one of two groups, optimist-rhetoric or pessimist-rhetoric. The optimist-rhetoric group, composed of "politicians, industrialists, policy makers, civil servants, local government 
advisory services, the media, related ICT support bodies and national agencies” (Reynolds, Treharne, \& Tripp, 2003, p. 151), have supported large government investments into ICT since the 1970s, despite the lack of substantial evidence for improvement in the quality of teaching and learning with ICT, as well as a plan for longterm curriculum development and research into the effectiveness of ICT. Conversely, the pessimist-rhetoric group, consisting of parents and teachers who oppose the use of ICT at school, claims that ICT distracts parents and teachers from the basic needs of children (Reynolds et al.).

Reports and publications suggest that OECD, the sponsor of the Programme for International Student Assessment (PISA), views ICT from an optimist-rhetoric lens (see OECD, 2001, 2005). The resources and communication mechanisms of ICT (e.g., email, Web access, and software) are seen as links that connect the learning experiences of students in school (e.g., curriculum, assessment, organization, leadership) to their lives out of school (e.g., community facilities, home study and support; OECD, 2001). Hence ICT would change the role of teachers in the classroom, and, with this change, enhance the learning environment. Finally, ICT would also increase channels of communication within the community, thereby making access more equitable to all students.

Currently, research on the impact on ICT on teaching and learning has been inconclusive (Reynolds et al., 2003). One reason is the lack of agreement as to what should be measured, or even whether or not it can be measured, to quantify success; there is no systematic methodology in place at institutions that have adopted ICT (Reynard, 2009). Using data from PISA, differences in accessibility to and use of ICT that exist at 
the student level (e.g., socioeconomic status, ethnicity, gender, computer experience) and at the school level (e.g., national programs, computer availability) may partially explain ICT's effects on academic achievement.

\section{Socioeconomic Status (SES)}

Canadian and Australian students in previous PISA studies were more likely to have an Internet connection at home than students in other participating countries (OECD, 2005), although SES, even in countries like Canada and Australia, has an effect on students' access to ICT. This differential access has been termed the digital divide, which is the gap between individuals and households at different socioeconomic levels with regards to opportunities to access ICT and use the Internet (Becker, 2000; Looker \& Thiessen, 2003; Willis \& Tranter, 2006). The Australian Bureau of Statistics (2008) found that socioeconomic characteristics continue to influence the rate of computer, Internet, and broadband connectivity across Australia. Households located in exmetropolitan or remote areas and/or having lower household incomes are less likely to be connected to the Internet.

Sociodemographic characteristics may influence how frequently a student uses ICT at home, since computer ownership may be dependent on a family's ability to afford one. SES is one of the best predictors of student academic success; up to $45 \%$ of the variation in achievement is explained by social class variables (Lytton \& Pyryt, 1998). Low achievement may be attributed to the paucity of resources available to students in low-income families, which is associated with low levels of parental education, lowstatus parental occupation, large family size, and absence of one parent (AAAS, 1998). 
Additionally, students in low-SES families may have less access to ICT from home due to economic issues or lack of parental interest in technology (Corbett \& Willms, 2002). Although there was a strong relationship in Australia between parents' occupational status and having a computer in the home, the gap between the highest quarter and lowest quarter is narrowing (Thomson \& De Bortoli, 2007). Similarly, Lupart and Cannon (2002) found that $96 \%$ of Canadian students in a 2000 survey either owned, or their family owned, a computer. In the two aforementioned studies, the shift was attributed to dramatic declines in the price of a computer relative to the average income, thereby allowing households at lower levels of SES to afford a computer. Although socioeconomic background may affect a student's frequency of access to ICT, this inequality does not appear to affect his or her choice of activities or self-confidence using computers (Thomson \& De Bortoli, 2007, 2008).

\section{Immigrants and Indigenous Populations}

OECD recognizes that the digital divide also exists among minority ethnic populations (i.e., immigrants) and persons residing in rural and remote regions (Looker \& Thiessen, 2003). For example, in Australia, which has a large Indigenous population, Indigenous students have less experience using computers (approximately one-half of the population have been using computers for more than five years, compared to $70 \%$ of nonIndigenous students), but it is still higher than the OECD average of $37 \%$ (Thomson \& De Bortoli, 2007).

Ethnicity and immigrant status effects on computer use at home may persist, independent of other student-level factors. For example, computer use at home for 
African-American students lags behind those of White and Asian students, even after controlling for poverty and other demographic factors, such as mother's marital status and her educational level (AAAS, 1998).

\section{Gender}

There are two aspects to ICT that have been described in the literature with respect to gender: access and frequency of use; and types of software use. The former refers to the locations where ICT is used, and how often it is used, while the latter relates to the interface that students used to complete their activities.

Access and Frequency of Use. The traditional gap between genders in computer use has largely disappeared, which may be attributable to recent focused efforts to increase opportunities for girls (Willis \& Tranter, 2006). Physical access to ICT for boys and girls is similar - after all, boys and girls live in the same households and attend the same schools (Looker \& Thiessen, 2003). Lupart and Cannon (2002) did not find significant differences in computer ownership between boys and girls, either. As well, students are generally interested in using computers, regardless of where the computers are located (Looker \& Thiessen).

In a recent meta-analysis of empirical research spanning the past decade, Kay (2008) found that, although males still report higher computer use, there has been a marked decrease in the gender gap over the past decade. Differences have been observed with respect to frequency of computer use at home (in 55\% of studies reviewed, males reported more use at home from 2005 to 2007, from 86\% for the period between 1997 to 2000), but no differences were observed in terms of use at school (Kay). What remains 
disparate between genders is interest in computers, with girls less likely than boys to use computers, and when girls do use them, they do so for shorter periods of time. When Lupart and Cannon (2002) looked at how much time students spent in front of the computer per day, most girls in the study spent less than 30 minutes per day, but most boys spent over 1 hour per day.

Furthermore, Lupart and Cannon (2002) also found that, while most students first started using computers between ages 6 and 10, boys in general were significantly younger than girls when they began to use computers (e.g., before age 5 or younger). This differential, however, appears to be narrowing as students in the younger group (Grade 7) in their study had more girls beginning to use computers at an earlier age than their peers in Grade 10. To support this finding, gender-based differences in the length of time students in Australia have been using a computer were negligible. Thomson and De Bortoli (2007) calculated that the gender gap was no more than $6 \%$ within any one Australian state. Therefore, gender differences that remain may be based more on biases of software than with accessibility to ICT.

Types of Software Use. Computer activities are determined primarily by the types of software available for student use, and may be a factor in explaining differences in computer use relating to gender, particularly interest, attitudes, and confidence. Kay (2008) found that entertainment software (e.g., games) were most gender-biased (towards boys) and application software (e.g., word processors, spreadsheets, presentations) were least gender-biased. As a result, gender biases in software may be inadvertently exacerbating the gender gap in regards to interest in ICT. For example, $76 \%$ of boys 
reported using computers out of interest, while only $58 \%$ of girls reported likewise (Looker \& Thiessen, 2003). Thomson and De Bortoli (2007) found that the largest gender divisions were in games and downloading software from the Internet, with male students dominating in both areas. All programs and software other than word processing were also used more frequently by male students, particularly programming software.

Socially-constituted practices have also encouraged boys to become more competent at ICT than girls through improved ICT skills, use of ICT for entertainment, and having the initiative to learn about ICT (Ilomäki \& Rantanen, 2007). Three-fifths of boys surveyed in the General Social Survey - Cycle 14 (Canada) cited personal interest as the reason for their acquisition of computer skills, while girls cited the other option, for school/study purposes, by virtually the same proportion (Looker \& Thiessen, 2003). Similarly, on survey items regarding perceived ability when using a computer and the affinity they have for computers, Lupart and Cannon (2002) found that, in general, boys liked computers significantly more than girls.

The lack of personal interest in ICT by girls may also be related to attitudes that they have when using the computer. In a study involving secondary-level students from schools in the Netherlands, Volman, van Eck, Heemskerk, and Kuiper (2005) found that the attitudes towards computers taken by girls were less positive than those taken by boys. In a similar vein, girls also took on different tasks while working at the computer than boys. Although computer use by both genders was equally intensive, girls tended to use the computers for email communication, while boys played games. Furthermore, in 
this same study, girls preferred an explanation of how to perform a task on the computer, whereas boys preferred to explore on their own.

Differences in confidence between genders also exist for high-level tasks, with girls being less confident than boys. In PISA 2003, a larger proportion of boys were comfortable doing high-level technical activities characteristic of their sex than were girls (e.g., using anti-virus software, creating multimedia, using spreadsheets and databases; see OECD, 2005; Thomson \& De Bortoli, 2007). This higher confidence may result in more complex uses of ICT. For example, in Ilomäki and Rantanen's (2007) study, boys became experts with technical aspects of ICT, whereas girls with high competence were oriented towards human and social uses of ICT, and towards communication and media.

In summary, although gains have been made in reducing gendered socialization of ICT in Canada and Australia, boys' tendency to have more positive attitudes towards ICT regardless of familiarity may prevent complete gender equity. Recent findings have suggested that accessibility to computers is no longer a limiting factor to student computer use. Gender differences remain with respect to frequency of ICT use and types of software use; however, differences in these areas may be a matter of choice rather than of opportunity.

\section{Computer Experience}

Students' prior experience using computers may affect how frequently and how confidently they use computers. Three member countries from the PISA 2003 cycleAustralia, Canada, and the United States - reported having over $60 \%$ of students with more than five years of computing experience (OECD, 2005). If the measure was 
expanded to include students with three to five years' experience, Australia and Canada led all OECD members and partner countries, with approximately $90 \%$ of students reporting having three or more years' experience. This experience may be attributed to computer ownership, as $90 \%$ of Canadian students and $87 \%$ of Australian students use computers at home at least a few times each week (OECD, 2005).

Computer use by youth can be generalized into two categories: (a) Internet/entertainment use, which includes playing games, email, and listening to music; and (b) program/software use, such as productivity and educational software (OECD, 2005). Differences in the reported frequency of use by students had effects on achievement. When the cases for each construct were organized into quartiles, OECD found that, in Canada, the second and third quarters of users for program/software performed better in mathematics than the first and fourth quarters of users (i.e., students who used these types of software moderately scored higher). In Australia, users in the second quarter scored highest among the quarters.

An Internet-connected computer broadens the genre of computer activities that users can perform. As computing power increases and access to the Internet becomes more affordable and accessible, the ways in which students communicate change as well. Word processing, browsing the Internet, and electronic communication were found to be the most frequently used software in Australia and Canada (Thomson \& De Bortoli, 2007); furthermore, a large proportion of students use the Internet frequently for communicating, in the form of instant messaging, blogging, and social networking tools (e.g., MySpace, Facebook). 
Computing experience and interest in ICT also influence the types of computer activities users can perform. Students had more difficulty undertaking high-level tasks by themselves than routine computer or Internet tasks (Ainley et al., 2008). As a result, these tasks may be less frequently used. Students from Australia and Canada were among the most confident with the three types of tasks measured in PISA 2003: routine computer tasks (e.g., opening, saving, and deleting files), routine Internet tasks, and high-level tasks (e.g., creating a multimedia presentation, constructing a web page). For routine tasks, non-Indigenous students were more confident than Indigenous students (Thomson \& De Bortoli, 2007).

\section{School Location and Mean SES}

School-level factors may also be related to ICT use; therefore, the community in which a school is located is also an important consideration in the discussion of school resources. Schools located in rural or remote areas may not necessarily have the same access to ICT as their urban counterparts. Rural schools and rural communities often have a weaker economic base, and since they may be located large distances from an urban centre, access to the Internet or technical support may be difficult (Looker \& Thiessen, 2003). Furthermore, funding for education by the provinces may be based on student enrolment numbers, thus placing smaller rural schools at a disadvantage. However, governments have attempted to offset the differential needs (e.g., by SES, demographic, or rural factors) among school districts by offering categorical funding grants. The grants may also be directed towards particular provincial initiatives, including investments in ICT (Wallin, Anderson, \& Penner, 2009). 
Connectivity and use of ICT may actually be higher in rural areas to provide access to specialized learning programs that would otherwise be available only to urban students, which is the case in Australia (see Thomson \& De Bortoli, 2007). More students living in remote areas $(76 \%)$ reported having used computers for more than five years compared to metropolitan $(70 \%)$ or provincial $^{3}(68 \%)$ areas (Thomson \& De Bortoli). Moreover, previous studies have found that geographical location was not a primary cause of Internet inequality in Australia (e.g., Wills \& Tranter, 2006), suggesting that schools remain important places for rural students to access the Internet.

Looker and Thiessen (2003) found that households in smaller Canadian communities were somewhat less likely than urban ones to have a computer, a consequence of the digital divide. However, students in rural areas reported spending more time on computers at places other than the home, signifying that smaller communities have been able to provide accessibility to ICT to students who may not have direct access in their own homes (Looker \& Thiessen).

In lower socioeconomic areas, where families may not be able to afford a computer, students may be more heavily dependent on publicly-accessible computers. Schools play a critical role in ensuring equal opportunity for low-SES children by providing them with enriching experiences that are generally dependent on wealth, including computer access (Becker, 2000; OECD, 2001); therefore, it is not unusual that

\footnotetext{
${ }^{3}$ In Australia, provincial refers to cities and other non-remote provincial areas. They are outside mainland state capital cities and major urban districts. $27 \%$ of Australian schools are located in provincial areas, compared to $70 \%$ in urban areas and $3 \%$ in remote areas (Thomson \& De Bortoli, 2007).
} 
teachers working in low-SES schools reported more frequent use of computers by students than those in more advantaged schools.

Furthermore, the ways in which students used computers were different between schools located in communities with different SES. According to Becker (2000), computer use in low-SES schools focused on traditional beliefs about student learning (e.g., remediation and mastery of skills), whereas computer use in high-SES schools focused on higher-level competencies and "more constructivist and innovative teaching strategies ... such as written expression, making presentations to an audience, and analyzing information" (p. 55). This difference may reflect the greater access that higher SES students have to home computers, which, in turn, may influence computer use patterns both at home and at school (Lowe et al., 2003). Since access to ICT at school may be restricted by demand from other students, the nature of access also needs to be considered (Ainley et al., 2008).

\section{Computer Availability at School}

Little variability in student access to computers at home and at school exists in Canada and Australia, as reported in PISA 2003. Both countries are approaching universal accessibility at school, $99 \%$ of students in Canada and $100 \%$ of students in Australia (see OECD, 2005; Thomson \& De Bortoli, 2007). At the school level in Canada, there was, on average, one computer for every five students (a ratio of 0.22 computers per student), and $98 \%$ of schools were equipped with an Internet connection (Ainley, Enger, \& Searle, 2008; Council of Ministers of Education, Canada [CMEC], 2008). In Australia, the ratio is even higher; at 0.28 computers per student; it is second 
only to the United States (Ainley et al.). Based on TIMSS 2003 data, $96 \%$ of Year 8 Australian students reported having access to a computer at home; $83 \%$ used computers at home and at school, 10\% reported using it only at home, and 5\% reported using it only at school (Mullis, Martin, Gonzalez, \& Chrostowski, 2004).

Despite these strong indicators of computer availability, McFarlane and Sakellariou (2002) argued that previous studies that have been conducted on the role of ICT in education have been oversimplified, since most treat ICT and educational outcomes as uniform entities with an attempt to make a direct correlation between the two, deriving conclusions unsuitable for policy. They present as an example, "the prominence given to the national reporting of computer:pupil ratios or number of schools connected to the Internet, with any improvement seen as clear evidence of progress" ( $\mathrm{p}$. 219). Furthermore, there is evidence of disconnect between availability and use. Pelgrum and Plomp (2002) found that, despite increasing availability of computers in countries participating in TIMSS, ICT was marginally used at the secondary level, and hardly changed between 1995 and 1999. (Despite their limitations, PISA 2006 continued to collect data based on such indicators as measures of a school's ICT resources.)

\section{The State of ICT in Canada and Australia}

National programs play an important role in providing access to ICT, particularly in rural or remote areas of the country and regions of lower socioeconomic status, as a form of addressing inequities in accessibility to ICT. For example, in Canada, federal programs (e.g., Canada's SchoolNet) were established nationwide to provide access in every school, with optimism that academic performance, equity among students, and 
students' ability to use and apply technology in their careers would be improved (Corbett $\&$ Willms, 2002). The purpose of SchoolNet was to encourage the integration of information technology into Canada's education system to help students acquire digital literacy skills and experience in using the Internet for research and communication (Mappin, 1995). It appears that this program has been successful in bringing Internet access to Canadian schools. Pelgrum and Anderson (cited in Pelgrum, 2001) reported that all 3,043 schools in Canada sampled by the Institution of Economic Affairs (IEA) for the 1998 Second International Technology in Education Study (SITES) had access to the Internet, including 786 upper secondary schools. The authors warned that a connected school, however, did not necessarily mean that students regularly accessed the Internet. In Canada, ICT has become an oft-mentioned component of traditional curricula, but there are no standards in the way it is implemented across the country. With education being the responsibility of individual provinces and territories, ICT in education thus consists of provincial, territorial, and federal e-learning networks, educational providers (public and private), and targeted initiatives (Canadian Council on Learning, 2009). The result is duplicated efforts, fragmented goals and objectives, and sporadic and short-term initiatives. These varying approaches to ICT in the curriculum may influence student achievement in science courses, where development and understanding is heavily dependent on advances in technology, as well as student interest in the subject, depending on future careers available to them.

In Australia, while education is also the responsibility of the states, educational systems cooperate on the development of national curriculum statements. Familiarity and 
competence with ICT was first identified as an important part of the country's National Goals for Schooling for the Twenty-first Century (Ministerial Council on Education, Employment, Training and Youth Affairs [MCEETYA], 1999; OECD, 2001). According to the declaration, graduates should be able to understand the impact of ICT on society, and have the "capacity for, and skills in, analysis and problem solving; ability to communicate ideas and to collaborate with others; employment-related skills and positive attitudes towards lifelong learning" (OECD, p. 20). Recently, the declaration was superseded by a new one, the National Declaration on the Educational Goals for Young Australians, which states that "learners become creative and productive users of technology" and also reiterates the importance of ICT as a "foundation for success in all learning areas" (MCEETYA, 2008, p. 8). The framework for ICT was developed collaboratively across jurisdictions and has been attributed to the country's economic and social development (Canadian Council for Learning, 2009). While these skills can be readily attained through ICT, they also align with the goals of science education.

In Australia, national sample assessments in ICT are administered in Years 6 and 10 to monitor progress in student ICT literacy (Thomson \& De Bortoli, 2008). The different emphasis placed on ICT in curriculum programs across the two countries may explain the differences in frequency of use in PISA 2003. For example, 59\% of students reported using computers at school at least a few times per week in Australia, compared to $40 \%$ in Canada (see OECD, 2005). This gap in computer use at school may also account for student differences in science achievement at the country level, a premise that is examined in this thesis. 


\section{Changing Nature of ICT in Science Education}

ICT has been an important factor in changing science education, from the first appearance of personal computers in the late 1960s, to the development of communications networks such as the Internet in the late 20th century. The latter, in particular, has enabled science-related collaborative activities to take place in teaching and learning processes.

The first applications of ICT to science education focused on cognitive benefits to the learner (e.g., the transmission of predefined content knowledge), but the goals of science education found in modern curricula centre on inquiry-based learning where developments in ICT have been most beneficial (Linn, 2003; Osborne \& Hennessy, 2003). The emergence of the Internet, for example, has brought science learning by students outside of the school (AAAS, 1998).

Two applications of ICT relevant to science education were identified by Dobson and Willinsky (2009): hypermedia and computer-mediated communication. The former includes interactive elements that allow the user to make connections between pieces of information, while the latter provides a medium to transfer information regardless of time and location.

Hypermedia. As a medium that links text to images, media, and sound, hypermedia is seen as a way to improve comprehension and motivation of learning because it mimics the associative processes of the mind. One aspect of scientific literacy is the ability to explain scientific phenomena (OECD, 2007b). Students who learn through hypermedia may benefit from the representations of scientific phenomena, 
simulations, and complex visualizations not realizable in textbook diagrams (Gobert, 2005; Linn, 2003). These enhancements include graphical representations, abstract representations (e.g., data maps and graphs), and interactive Web sites that allow students to practice scientific skills. Hence students are able to learn about worldwide scientific issues and access scientific data that are more authentic, thus allowing them to make more meaningful inquiries into the practice of science (Gobert; McFarlane, \& Sakellariou, 2002). However, others have argued that there is no evidence supporting the hypothesis that facilitating associative thinking might improve comprehension; indeed it may actually increase user disorientation (see Dobson \& Willinsky, 2009). Thus the effects of hypermedia on learning may require further study.

Computer-mediated Communication. There are different traditional forms of computer-mediated communication that arose with the public uptake of the Internet: email, bulletin boards, web pages, wikis, and chat rooms; in addition, instant messaging and blogs (a contraction of the term weblog) are social software applications that have emerged mostly in the last five years that are dependent on computer networks (Dobson \& Willinsky, 2009).

McFarlane and Sakellariou's (2002) model suggests how ICT could be used in the iterative process of science inquiry. To ask questions, make predictions, and hypothesize, students could use online research tools to collect information. To observe, measure, and manipulate variables, students could use data-logging software and organize, present, and record data using spreadsheets and database software. Finally, to interpret their results and evaluate scientific evidence, students could access the Internet for recent scientific 
findings. Throughout the inquiry process, collected data and the analysis of results could be entered into word processing software. Students would thereby be able to learn about scientific theory and process simultaneously (McFarlane \& Sakellariou). Therefore, ICT has the potential to emphasize scientific skills and thinking by "diminishing the mechanical aspects of collecting data and plotting graphs ... while enhancing the use of graphs for interpreting data, spending more time on observation and focused discussion, and developing investigative and analytic skills" (Osborne \& Hennessy, 2003, p. 23).

Assertions regarding the use of ICT in teaching and learning need to be taken with caution. Reynolds et al. (2003) found literature that described how electronic research tools can provide highly motivating access to information and ways to communicate that information in science classes. For example, there have been claims that ICT is intrinsically more interesting and exciting to pupils than using other resources, thereby increasing their motivation to learn (see Osborne \& Hennessy, 2003, for examples of such studies); however, a relationship between motivation and learning is an assertion without adequate proof (Reynolds et al.), and more support may be required to justify increased use of ICT in science education.

\section{The Influence of ICT on Achievement}

ICT is perceived as a potential way to enhance students' educational experiences; however, generalizations about the overall impact of ICT on achievement have been difficult to make (e.g., Pelgrum \& Plomp, 2002; Reynolds et al., 2003). Much like studies of gender differences in ICT, previous studies on the effects of ICT-related factors on achievement (e.g., OECD, 2005; Thompson \& De Bortoli, 2007) have primarily focused 
on access and frequency of use or specific types of software. Hence, to provide a context for the current examination of ICT and achievement, findings from studies in both of these areas are described.

Access and Frequency of Use

Achievement may differ between students who have different levels of experience with ICT, based on where they use it and how frequently they use it. For example, home use may not have as important a role as school use. Wittwer and Senkbeil (2008) analyzed PISA 2003 data to determine whether or not home computer availability was associated with German students' mathematics literacy, after accounting for the influence of other determinants of school performance (e.g., SES, gender, immigrant status, cognitive abilities, reading, and watching television). Latent class analysis was used to analyze how students differed in their ICT use at home. Students were classified into one of four profiles: (a) smart users, who had high interest and confidence in using computers, and used it for a variety of applications; (b) rational users, who used the computer mostly for school-related learning activities, but not for playing games or communicating with other people; (c) recreational users, who mainly used the computer for playing games, watching movies, or listening to music; and (d) indifferent users, who had low interest in using computers and rarely used them. Using multilevel modeling, the authors found that there was a slightly positive effect on problem solving and mathematics literacy for students in the 'smart user' and 'rational user' categories (which comprised $35 \%$ and $36 \%$ of the sample, respectively). The authors concluded that students' computer-related behaviour at home marginally predicted mathematics 
achievement; however, variables such as students' cognitive abilities, immigration background, or leisure activities were found to be far better predictors. Their findings suggest the importance of including student demographic variables in achievement studies. Unfortunately, PISA 2006 did not collect student ICT profile information in such detail.

OECD (2005) concluded that, of all the individual background and contextual factors examined in PISA 2003, access to a computer at home had the largest impact on mathematics literacy (the major domain for PISA 2003). Students who had access to a computer at home outperformed students who did not have access to a computer by one proficiency level after accounting for socioeconomic background effects, a finding that was statistically significant for Canada and Australia. On a related note, students with more computer experience in PISA 2003 also scored better in mathematics (OECD).

While higher scores in mathematics were also attained by students who frequently used computers at home, a non-linear relationship was found for students who frequently used computers at school (OECD, 2005). In Canada and Australia, frequent users at school scored lower than moderate users (i.e., students who used the computer at school between once a week and once a month), regardless of the type of activities that students performed while at the computer (OECD). Also, while the finding was the same for computer access at school, only in Canada was the difference statistically significant (OECD). These findings suggest students who use ICT at school in moderation may have higher achievement. 
Although OECD (2005) cautions that "associating computer access and usage with performance cannot provide evidence of computers on learning, since the PISA data do not demonstrate causation" (p. 53), it does raise issues for further investigation. With virtually universal accessibility to computers in Canada and Australia, an analysis of achievement based on software use and confidence with ICT would provide conclusions to support or refute this conclusion.

Using data from the 1999 TIMSS, Pelgrum and Plomp (2002) found results that contrasted those of OECD (2005). The authors classified students as high ICT users (i.e., students who have used ICT almost always or very often for mathematics) or low ICT users (i.e., students who used computers never or once in a while). High ICT users had lower achievement scores than low ICT users in every participating country; in Canada, the score differential represented approximately 1.5 years of achievement growth. Thus computers in classrooms may negatively affect mathematics scores. Of importance was the school student-to-computer ratio, where a higher availability of computers and corresponding higher student use of computers during mathematics class resulted in lower scores on achievement tests.

Pelgrum and Plomp (2002) posited that a selection bias may be present, since in one of their previous studies (i.e., Pelgrum \& Plomp, 1993), they found that computer users tended to be lower-achieving students who were given student-centred activities (e.g., drill-and-practice exercises). However, classroom applications of ICT have changed in recent years; faster connectivity to the Internet, more multimedia applications available for use, and an increased number of computers in schools (thus allowing more students to 
access computers at one time) suggest that there may be other factors that influence student achievement. Thus this study highlights the importance of both student-level and school-level factors in achievement.

Fuchs and Woessmann (2004) also found results that differed from OECD (2005). Analyzing data from PISA 2000 and 2003, the authors attempted to determine the effects of ICT use at home and at school on student achievement. There was a positive correlation between student achievement and availability of computer at home and at school; however, once variables for family background and school characteristics were accounted for, the relationship became negative for availability at home and not significant for availability at school. Although the effects of availability were negative, measures of student use of ICT at home showed that it was beneficial to achievement, particularly for Internet-based activities (e.g., accessing emails and Web pages). The relationship of use at school was curvilinear, with achievement peaking at use between a few times a year and several times a month, a level that is incongruent with current practices of the integration of ICT in education.

Another study looked at relationships between student achievement and ICT use at home and school. Papanastasiou, Zembylas, and Vrasidas (2005) generated regression models using PISA 2000 data from the U.S. and Germany, including variables relating to availability of computers, frequency of computer use, students' comfort level with computers, and types of computer activities performed. After controlling for SES, students in the U.S. who were comfortable with activities such as writing papers were more likely to have higher levels of scientific literacy. In terms of computer activities, 
students in both the U.S. and Germany who used the computer to access the Internet were likely to attain greater scientific achievement (Papanastasiou et al.). As there are a variety of purposes that can be accomplished on the Internet, it would be of interest to determine the types of activities that students are doing, in addition to the impact of student confidence with digital literacy applications such as word processing.

As a secondary data analysis, the study was not experimental, thus it was not possible to determine any cause-effect relationships between technological variables and scientific literacy. Moreover, the models did not account for possible interactions between the student-level variables nested within related school-level variables, an issue that could be addressed in a multilevel linear modeling study. Finally, while describing itself as a comparative analysis, the study did not attempt to explain differences in the models for the two countries.

Using data from the Iowa Tests of Basic Skills and Test of Academic Proficiency (ITBS/TAP) from Grades 8 and 11 students in the state of Idaho, Ravitz, Mergendoller, and Rush (2002) found a negative relationship between school use of computers and school-wide achievement in mathematics, reading, and language arts. However, computer use was more prevalent in smaller, poorly performing schools, typically in rural, lower income areas where the computer:student ratio was lower (i.e., more computers per student). Although the authors did not find any relationship between achievement and SES, they did find that students from rural areas relied on computer use at school to a greater extent than their urban peers. To minimize this bias in their study, the authors analyzed software capability instead (i.e., combining the effects of computer use at home 
and at school) and found a positive relationship with achievement and test score gains. Therefore, they reasoned that the lack of access to computers at home was a greater barrier to achievement than the lack of access at school. These results suggest that, while increased computer use may benefit achievement in the above-mentioned subjects, user competence with software and the types of software use need to be considered as well. Types of Software Use

The association between ICT and achievement may be dependent on the type of ICT examined. With a variety of computer software available for use, some programs may benefit achievement more than others. For example, Kulik (1994) aggregated the findings from over 500 individual studies of computer-based instruction (e.g., tutorial, drill-and-practice). The studies included settings ranging from Kindergarten through twelfth grade. Kulik found that computer tutoring applications were attributed to positive effects on student achievement tests, whereas other applications had only minimal effects; however, this meta-analysis did not consider specific subjects or grades.

Interactive multimedia and presentation software could improve achievement in a secondary school classroom. Siegle and Foster (2001) arranged a quasi-experimental design using two classes of the Anatomy \& Physiology course. One class had access to multimedia software for the first term, and were given laptops to use as well midway during this term, while the other class had access to another multimedia software product loaded onto the classroom computers. (Access to laptops implies computer use at home and at school.) Academic achievement was measured through students' test scores on teacher-created exams. The arrangement was reversed the following term. The students 
with the laptops created a 12-slide online presentation. Using repeated-measures ANOVA, the authors found no overall differences between the two groups in achievement (as expected, since both groups were given the same treatment, just at different times), but statistically significant differences in performance existed during the periods in which students had access to the laptops with multimedia and presentation software. Siegle and Foster could not conclude whether the differences in achievement were due to possession of the laptops, the use of multimedia software, or the creation of presentation slides. One student they interviewed attributed the increased performance due to the increased review of the material needed to create the presentation. The study, however, overlooked certain discrepancies in the experimental design, including the difficulty level and nature of the course material, and differing multimedia software programs distributed to each classroom.

Use of specialized educational software may not only benefit achievement, but also address gender differences in attitudes towards science. Levine (1994) found that students using Rediscover Science, a multimedia program for middle school science, not only performed significantly better on the U.S. National Assessment for Educational Progress (NAEP) and the IEA science test than their counterparts in the control group, who used only traditional instructional materials (a difference of approximately one-third of a standard deviation), but girls who used the software appeared to have a more positive attitude towards science, closing the gap that existed in the control group between boys and girls. Levine attributed this heightened interest to increased engagement that enabled 
students to construct their own understanding through the simulations, explorations, tutorials, and tools that were provided by the software.

\section{Conclusion}

Since an analysis of available literature did not produce a definite conclusion on achievement attributable to students' use of ICT, additional research in various dimensions of ICT would contribute to the literature. The availability of electronic instructional tools for the science curriculum (e.g., software, websites, applets) is continually increasing; therefore, a periodical examination of ICT use in school subjects may offer an operational indication of the extent to which educational practitioners can view ICT as a useful tool (Pelgrum \& Plomp, 2002). For example, the proportion of students between 1995 and 1998 reporting never having used computers for mathematics decreased from $82 \%$ to $67 \%$ in Canada, and from $77 \%$ to $71 \%$ in Australia (Pelgrum \& Plomp); one could reasonably expect this ratio to have since further decreased in school.

Investments in ICT resources by school jurisdictions have increased the availability to computers for students, which, in turn, may influence how often computers are used in schools for learning purposes. However, Pelgrum (2001) states that "indicators of infrastructure tend to be obsolete by the time they are published" (p. 167), noting the change in computer:student ratios from data collected in the 1995 TIMSS and SITES 1998. He found that the typical country cut its student:computer ratios by slightly more than one-half during this period (i.e., the availability of computers for students doubled), perhaps attributable to national programs for educational ICT infrastructure expansion and the decreasing prices for computer equipment. For example, in 1995, the 
ratio was 14:1 in Canada but decreased to 7:1 three years later. Furthermore, the installation of computer equipment and network connectivity do not necessarily assure successful or productive use; available technology is often underused and poorly integrated into classroom practice (Ofsted, in Osborne \& Hennessy, 2003).

This thesis attempts to reveal some of the associations between ICT-related factors and science achievement that have emerged since the previous PISA assessment cycle. These variables may interact with student demographic variables and characteristics of the schools that the students attend.

Although increased access to ICT in schools has narrowed the digital divide between students of different immigrant status and SES, Attewell (2001) proposes that there are two digital divides, the first being access to computers and ICT, but the second relating to "the ways in which computers are used at school and at home" (p. 253). Both of these characteristics profile a student's use of ICT. Furthermore, cost-benefit analyses associated with ICT in teaching and learning have often been higher than traditional and proven methods; in light of the continuing decrease in acquiring ICT hardware and software, a reevaluation of findings is needed. The current study may suggest advantages to increased integration of ICT in science classes and use in students' daily contexts. 


\section{CHAPTER 3}

\section{METHOD}

This thesis uses data from the Programme for International Student Assessment (PISA), a large-scale assessment sponsored by the Organisation for Economic Cooperation and Development (OECD) that enables participating countries to evaluate the effectiveness of their educational policies and practices. In 2006, PISA was administered in 57 countries, including Australia and Canada. Each administration of PISA, which occurs every three years, focuses on a different domain, either reading, mathematical, or scientific literacy. The term literacy is used by PISA to describe a spectrum of competencies relevant to coping with adult life (Anderson, Milford, \& Ross, 2009). The PISA 2006 assessment provided the greatest emphasis on scientific literacy, although, to a lesser extent, measures were taken of the two other domains. Scientific literacy emphasizes the mastery of processes, the understanding of concepts, and the ability to function in various situations within each domain (OECD, 2006a). The results generated in this thesis are secondary data analyses, since they are conducted subsequent to, and independent of, the initial program that generated the data (Anderson, Milford, \& Ross).

\section{Data Collection}

Sample

A two-stage stratified sampling procedure was used to obtain the sample of 15year-old students within each country: (a) a systematic sample of schools with 15-yearold students within each geographic area; and (b) a sample of students within the school 
who were 15 years of age (where each student had an equal probability of being selected). Since students were randomly sampled from schools, and not from intact classrooms, different learning environments might be present due to differences in teaching styles. Therefore, classroom-level information could only be collected at either the student level or the school level (OECD, 2009). Each school sample of students consisted of approximately 35 students; however, if there were fewer than 35 students selected, the sample size of schools for that country was increased to ensure the national sample was adequate (see OECD, 2007). A minimum of 150 schools, consisting of at least 4,500 students, was sampled for each country (OECD, 2009). Hence students were nested within schools, and schools were nested within countries.

While the predetermined number of students per school was 35, a minimum of 20 students per school was expected to ensure accuracy in estimating variance components between and within schools (OECD, 2009). For each school, the response rate of selected students was a minimum of $50 \%$ to be considered a participating school, with a response rate of $80 \%$ of selected students in participating schools for each country (Bussière et al., 2007; OECD, 2009). Both Canada and Australia were countries that satisfied the minimum school response rate requirements (OECD, 2009). To validate the data set, the subsample from each country was then compared with the international pooled sample; through confirmatory factor analysis, comparisons for equivalence in factor loadings were made as a measure of cross-country validation (OECD, 2009).

Canada. PISA 2006 was a collaboration among Human Resources and Social Development Canada, Statistics Canada, and the Council of Ministers of Education, 
Canada (CMEC). According to Bussière et al. (2007), there were 22,203 participating students from 850 selected schools from all 10 provinces (none of the territories was sampled) in PISA 2006; however, the data set obtained from OECD contained 22,646 students nested within 846 schools. Canada's school response rate was $86.23 \%$, which was calculated by dividing the number of participating schools by the total number of schools sampled, and weighted based on 15-year-old enrolment numbers in each school (please refer to Appendix A in Bussière et al., 2007). A large sample was required to collect provincial-level data and allow for estimates for both official language groups. PISA 2006 was administered during school hours in April and May 2006, in either English or French, depending on school language programs. The correlation between the French and English versions of PISA 2006 was $r=0.92$; therefore, any language effects were negligible (OECD, 2009). Although the recommended sample size per school was 35, Canadian school samples varied between 1 and 225 students. At the low end, the variation may be due to sampling from remote regions of the country or low response rates for participation. At the high end, it is possible that schools sampled whole classes rather than using the randomized selection protocol. Since it was not possible to identify the exact reason for any one school, and to prepare the data for multilevel analysis, student- and school-level data collected from schools with a sample size under 10 students were deleted, representing $2.4 \%$ of the student sample. The final Canadian sample used in the analysis consisted of 22,121 students from 645 schools.

Australia. In Australia, PISA was administered by the Australian Council for Educational Research (ACER) in all six states and two territories. A total of 14,170 
students in 356 schools (222 government schools, 73 Catholic schools, and 61

independent schools) were randomly selected to participate, a weighted school participation rate of 98.85\% (OECD, 2009; Thomson \& De Bortoli, 2008). PISA 2006 was administered between late July and early September, 2006, with larger samples than required by OECD standards to obtain more reliable results for rural areas and indigenous cultures. Australian school samples varied between 3 and 59 students. Similar to the treatment of the Canada data set, student- and school-level data collected from schools with a sample size under 10 students were deleted, representing $0.6 \%$ of the student sample. The final Australian sample used in the analyses consisted of 14,084 students in 341 schools.

\section{Instruments}

PISA 2006 assessed student performance in scientific literacy, mathematics literacy, and reading literacy. The correlation between the national parameter estimates of the Australian and Canadian versions of PISA 2006 (English) was $r=0.96$ (OECD, 2009). The pool of items was divided into 13 clusters ( 7 science, 4 mathematics, and 2 reading) with each cluster representing 30 minutes of testing time. The testing material was organized into different combinations of test booklets of four clusters, with each booklet containing one, two, or four science item clusters, and the remainder drawn from reading or mathematics. OECD developed 13 different test booklets that were randomly assigned to participants; thus each participant was tested for a total of 120 minutes. Test items included multiple-choice items and open-ended questions, including short-response and constructed-response (OECD, 2007b). National submissions of items were reviewed 
using a structured process for possible inclusion (see OECD, 2009 for the review procedure). As data were collected from OECD member and partner countries with different national contexts, cross-country validation was important. For questionnaire items, Likert-type items were treated as if they were continuous using maximum likelihood estimation and covariance matrices (see OECD, 2009). All data used in this study are available for download (OECD, 2007a); see the PISA 2006 Technical Report (OECD, 2009) for more details.

The data used in this thesis were derived from three PISA 2006 questionnaires: (a) a mandatory student background questionnaire (which took approximately 30 minutes to complete); (b) an optional student information and communication technology (ICT) familiarity questionnaire (10 minutes); and (c) a school questionnaire completed by principals (20 minutes). Items used in the questionnaires were developed by experts in participating countries, and decisions about the nature of these items were steered jointly by governments on the basis of shared, policy-driven interests (OECD, 2007b).

The student background questionnaire collected demographic information and measures of science perspectives and experience. The demographic information from the questionnaire included in the present thesis encompassed students' gender, immigrant status, and their economic, social, and cultural status (ESCS; an index of SES derived from several measures). The science questions used focused on students' views on science, the environment, and science-related careers; means of teaching and learning of science; and reports on learning time (OECD, 2009). 
The student ICT familiarity questionnaire looked at how often and where students used computers, how long they had been using them, which tasks they performed on computers, and how confident they were using ICT. Students in Canada and Australia both answered this questionnaire. The items analyzed in the current thesis from this questionnaire were: students' experience with ICT, the frequency of ICT use at different locations, frequency of ICT software use, and students' confidence in carrying out ICTrelated tasks (OECD, 2009).

The school questionnaire covered school-related aspects, such as structure and organization of the school, staffing, school resources, accountability and admission practices, the teaching of science and environmental issues, and aspects of career guidance. Sections analyzed from the school questionnaire included structure and organization of the school (school size and the community in which it is located) and the school's ICT resources, which were: (a) the index of availability of computers ${ }^{4}$; (b) the overall ratio of computers to school size $\mathrm{e}^{5}$; and (c) the proportion of computers connected to the Internet. ${ }^{6}$

\section{Preliminary Analyses}

Prior to the main statistical analyses, preliminary analyses were conducted in that the data were recoded and scaled to facilitate interpretation of the results. For example,

\footnotetext{
${ }^{4}$ The index of availability of computers was obtained by dividing the total number of computers at school by the number of students at school (see OECD, 2009, p. 308).

5 The overall ratio of computers to school size was obtained by dividing the number of computers available for instruction at school by the number of students at school (OECD, 2009).

${ }^{6}$ The proportion of computers connected to the Internet was obtained by dividing the total number of computers connected to the Web by the total number of computers (OECD, 2009).
} 
some indices were inverted so that a higher value indicated a more positive response. Quasi-continuous and continuous indices were standardized in SPSS, with a mean of zero and a standard deviation of one, prior to being added to the model. Standardization allows results to be expressed in terms of changes in the outcome measure per standard deviation change in the predictor variable. Binary variables were added to multilevel models using grand-mean centring; this technique changes a raw score to a deviation score to facilitate interpretation (see Tabachnick \& Fidell, 2007).

Handling of Missing Data, Weighting, and Estimation Methods

HLM software can only handle missing data at level-1 (Heck \& Thomas, 1999). Listwise deletion was performed in SPSS to remove all cases with missing data. To best represent the sample population whilst minimizing bias, students attending schools with 10 or fewer students sampled were also removed from the level-1 data, as were the data from the corresponding schools at level-2. These schools did not meet the minimum sample specifications established by OECD (2009); however, they might have been included in the data set to represent geographically remote areas of the country. As well, normalized survey weights for students and schools in the sample were applied in the estimation settings of HLM to ensure that the data set for each country was representative of its population (i.e., the sum of the weights was equal to the number of students in the data set, and each school contributed equally to the analysis; see OECD, 2009). For the respecified constructs (ICT use and self-confidence), new values were calculated using the existing data (i.e., no data were imputed for any missing cases). 
Restricted maximum likelihood (REML) methods were used in HLM to estimate the fixed effects of a multilevel model. REML adjusts for bias when estimating variances because it estimates the random components averaged over all possible values of fixed effects, thereby adjusting for uncertainty about the fixed effects (de Leew \& Meijer, 2008; Raudenbush \& Bryk, 2002; Tabachnick \& Fidell, 2007).

\section{Main Analyses}

This section is organized into two subsections, according to the research questions of this thesis. The designs employed and data analysis methods for each research question are discussed.

To what extent do students in Canada and Australia differ in their access to, use of, and confidence with information and communication technology (ICT)?

ICT familiarity questionnaire items were first assembled into constructs or indices to answer this question. OECD included four constructs in the PISA 2006 data set: two related to ICT software use and two related to confidence performing certain tasks with ICT. The software constructs consisted of ICT Internet/entertainment use and ICT program/software use, while the confidence items reflected self-confidence in ICT Internet tasks and in ICT high-level tasks (see OECD, 2007). OECD scaled the indices using a partial credit model based on weighted maximum likelihood estimates (WLE) to obtain individual student scores. The standard procedure used by OECD involved analyzing equal-sized subsamples of students from each participating country, and then 
inverting the items for scaling so that positive WLEs on each index indicated higher frequencies of ICT use or positive attitudes towards computers.

Although the constructs specified by OECD were considered as predictor variables, it was thought that respecifying the constructs using the country-specific data would provide a contextual representation of ICT use and confidence. Exploratory factor analysis (EFA) was used to create the latent variables that underlay the questionnaire subitems for each country, and afterwards the new constructs were tested for reliability and suitability for use. Fabrigar, Wegener, MacCallum, and Strahan (1999) suggest that EFA is appropriate if "the goal is to arrive at a parsimonious representation among the original variables" (p. 275). A maximum likelihood EFA was chosen, since it has the advantage of testing the factor loadings and correlations among factors for statistical significance (Fabrigar et al.). To determine the type of rotation used, an intercorrelation table between the subitems was generated. Since there were correlations among the factors, an oblique rotation (e.g., promax rotation) was used. Furthermore, Fabrigar et al. recommend that, as a general approach to achieving solutions with simple structure, oblique rotations should be examined first as the basis for interpretation.

For all constructs and variables related to frequency of ICT use in different places, ICT software use, and confidence with ICT generated by EFA, descriptive statistics (e.g., mean and standard deviation) were calculated for each country. Where applicable, items within scales were reverse-scored so that a higher value represented a more positive response (5-point Likert-type scale for use of ICT; 4-point Likert-type scale for confidence with ICT). The descriptive statistics were also categorized by gender (within 
the country) and by country (using all data) to test differences in accessibility to ICT from different places, ICT software use, and confidence with ICT for statistical significance using independent samples $t$-tests. The effect sizes for the analyses were then calculated using Glass’ delta ( $\hat{\Delta}$; see Glass \& Hopkins, 1996, pp. 289-290).

To what extent are differences in scientific literacy predicted by student-level and schoollevel characteristics in Canada and Australia?

The data were prepared for multilevel linear modeling (MLM) with statistical software: SPSS for exploratory factor analysis (i.e., maximum likelihood factor analysis) and HLM (Hierarchical Linear Modeling) for multilevel linear modeling. ${ }^{7}$ MLM is a statistical technique appropriate for analyzing data organized hierarchically (Raudenbush \& Bryk, 2002), since it is assumed that observations within groups are dependent (de Leeuw \& Meijer, 2008).

A two-level model was used to simultaneously examine the associations that the school-level variables (i.e., level-2) and student-level variables (i.e., level-1) had on the outcome measures. Therefore, variance could be explained through predictors at the student level and/or at the school level (Guo, 2005). As the uppermost level of analysis, school-level predictors were fixed effects. Since the purpose of this research question was not to compare the countries, separate multilevel linear models were constructed for Australia and Canada.

\footnotetext{
${ }^{7}$ Hierarchical Linear Modeling (HLM) is the software package that was used in the analysis; multilevel linear modeling (MLM) refers to the standard analytical technique.
} 


\section{Outcome Measure}

The outcome measure (dependent variable) in this analysis, scientific literacy, was determined using the five plausible values (see OECD, 2007). Plausible values represent possible achievement scores a student would have obtained had he or she responded to a different set of items (Wu, 2005). To obtain a common metric for comparison, estimates of student performance for PISA were scaled using item response theory (Anderson, Lin, Treagust, Ross, \& Yore, 2007). One advantage of HLM is that it has the ability to internally execute the procedures and calculations necessary when using data with multiple-imputed values for a single outcome measure, by producing an estimated average value from the five plausible values, and the correct standard errors (Raudenbush, Bryk, Cheong, \& Congdon, 2004).

\section{Multilevel Model Development}

To build a model with the predictors of interest, an exploratory strategy described by Hox (cited in Tabachnick \& Fidell, 2007) was used. First, the simplest intercept model was generated to examine the intraclass correlation (ICC). Fixed level-1 predictors were added next, and the contribution of each predictor to the model was assessed individually, and excluded if it was not statistically significant. Lastly, the procedure was repeated for level-2 predictors, and the variance explained by the model was determined through a calculation of effect size. In a school-effects study, there are three steps in the development of a multilevel model: (a) determination of the intraclass correlation (ICC) through the null model; (b) estimation of a within-school or Level-1 model; and (c) estimation of a between-school or level-2 model (Lee, 2000). A background model, 
comprised of student demographic characteristics (ESCS, gender, and immigrant status) and school characteristics (school mean SES, school size, and community in which school is located), was generated to account for variables that were not measures of ICT.

The null model. The first step in MLM is to determine the ICC. The variance in the dependent variable (in this case, science achievement) is partitioned into two parts, variance that lies between students within one school (pooled over schools) and variance in science achievement that lies systematically between schools. The proportion of variance in the dependent variable may be modeled as a function of school characteristics, and the ICC is the proportion of the total variance that lies systematically between schools (Lee, 2000). Determination of the ICC is conducted with a null (intercepts-only) model. The null model is helpful in testing the null hypothesis that all schools have the same mean science achievement (i.e., whether or not there are mean differences between schools), since no student or school characteristics are considered (Lee; Tabachnick \& Fidell, 2007). The null model also provides an estimated science achievement score for all schools within the country (Heck \& Thomas, 1999). The model is statistically equivalent to a one-way random effects analysis of variance (ANOVA; see Raudenbush \& Bryk, 2002). If the ICC is greater than $10 \%$ of the total variance in the outcome, it is an indication that MLM techniques would be appropriate in a schooleffects study (Lee).

Addition of student-level predictors (level-1 fixed effects). The second step in a school-effects analysis is to estimate the within-school (Level-1) model by investigating characteristics of individual students associated with the outcome. In this study, science 
achievement was explored as a function of student characteristics, including gender, SES, and immigrant status, since previous research has suggested that these have effects on science achievement (e.g., Ma \& Klinger, 2000). Gender was coded as a binary variable (boys $=0$; girls $=1$ ). Immigrant status was recoded into a binary variable using SPSS (non-immigrant $=0$; immigrant $=1$ ). SES was represented by a composite variable computed by OECD known as the economic, social, and cultural status (ESCS) index. ${ }^{8}$ The output provided the variance explained by these predictors, from which the level-1 equation(s) could be generated. These student-level variables were initially treated as fixed effects, since they are intended to control for the ICT variables and may be correlated with each other. By doing so, an assumption being made is that the effect of each individual-level variable is homogeneous across schools (Heck \& Thomas, 1999).

The other student characteristics were related to ICT, which include: (a) computing experience; (b) frequency of use at home, at school, and at other places; (c) frequency of ICT use (browse the Internet, collaborate on the Internet, productivity software, entertainment software); and (d) confidence with ICT use (presentation software, basic tasks, advanced tasks). Please refer to Appendix A for a detailed listing of the variables.

To examine the absolute effect, each student-level variable was added separately to the null model to determine whether or not its relationship varied significantly across schools, independent of other variables (Ma \& Klinger, 2000). The contribution of each

\footnotetext{
${ }^{8}$ Student ESCS is the SES variable within the PISA framework, and is derived from five indices: parents' occupational status, parents' educational level, family wealth, cultural possessions, and home educational resources (OECD, 2009).
} 
predictor to the equation was expressed as a $t$-value (with degrees of freedom based on number of groups). Variables that had significant absolute effects (i.e., $p<.05$ ) were then introduced together to examine their relative effects in the presence of other variables. Thus the relative effect of the variable was adjusted for the shared effects of other variables (Ma \& Klinger). In this combined level-1 model, variables that were no longer statistically significant were removed one at a time, starting with the variable with the largest $p$-value in the model, until all remaining variables in the model were statistically significant. The end result was the relative effects level-1 model. When the variance of the relative effects model is compared to the null model, the proportional reduction in the within-group variance can be determined.

Addition of school-level predictors (level-2 intercept model). The procedure used to generate the relative fixed effects model was repeated with level-2 (school-level) variables. All level-2 predictors were treated as fixed effects. These variables were added to the relative effects level-1 model independently to test for absolute effects, and then those that had statistically significant absolute effects were tested for relative effects. This strategy was used to build a parsimonious multilevel linear model, by focusing on variables that had both absolute and relative effects on the outcome measure.

In this level-2 model, the school-level factors were added as explanatory variables. With the exception of school mean SES, the data were primarily obtained from the PISA 2006 school questionnaire, which was completed by the school principal or 
administrator. The school characteristics include school mean ESCS composition, ${ }^{9}$ location of school, school size, technology availability, and resources (e.g., proportion of computers available for student use, proportion of computers connected to the Internet, and the ratio of computers for instruction to school size). The location of each school was categorized into an ordinal variable based on the population size of the jurisdiction in which it was located (e.g., ranges from village or hamlet [population $<3000$ ] to large city [population >1 000 000]; refer to Appendix A for details), but was treated as an interval variable for MLM. School mean ESCS composition was based on data collected from the student questionnaire. School size was expressed as a continuous variable centred at the mean for the national sample, with each standard deviation change representing 100 students. Other variables were continuous values between 0 and 1 . All level-2 variables (school-level effects) were treated as fixed, since there were no higher-level variables in which they were free to vary. The analysis identified whether or not students' scientific literacy varied by school, after adjusting for differences in student ICT familiarity, student demographics, and differences in school characteristics.

The overall model considered the collective effect of all student-level variables related to ICT that influenced the mean differences in science achievement in both countries. All individual variables that had absolute effects were added to the model, and then those that were not statistically significant were individually removed until all remaining variables were statistically significant. The parsimonious level-2 model was

\footnotetext{
${ }^{9}$ According to Willms (2004), the average SES composition of a school has an effect on a student's achievement, over and above the effects associated with the student's own family SES.
} 
then added, and again, any variables that were not statistically significant were dropped. By comparing the residual variance of the overall model to the variance that existed in the null model, the proportion reduction in the between-group variance explained by school-level predictors and the effect size can be determined. Separate calculations were done for the within-groups (level-1) and between-groups (level-2) portions of the overall model, because residual variances were defined differently for the two levels (Tabachnick \& Fidell, 2007).

Effect sizes. The effect size for each overall model was calculated to determine how much of the total variance was attributable to the model; effect size is the ratio of systematic variance of the predictors to total variance. To calculate the estimated effect size for fixed predictors, the residual variance with the predictors (the overall model) is subtracted from the residual variance of the intercepts-only model (the null model) and divided by the residual variance without the predictor (see Tabachnick \& Fidell, 2007).

\section{Supplementary Analysis for Second Research Question}

Previous studies on achievement and student use of ICT (e.g., Pelgrum and Plomp, 2002; Wittwer \& Senkbeil, 2008) have treated the latter as discrete, rather than continuous, variables. For this analysis, the data set for each country was partitioned into categories based on values for: (a) access to ICT use at home, school, and other places; (b) the two respecified constructs of ICT use, frequency of Internet browsing, and frequency of Internet collaboration; and (c) the two respecified constructs of ICT confidence, and confidence with presentation software. For variables based on access to ICT, there were four categories: never (value of 0), monthly (value of 1), weekly (value of 
2), or frequently (value of 3 or greater). For ICT use, there were four categories: never (value under 2), rarely (value between 2.0 and 2.9), sometimes (value between 3.0 and 3.9), and frequently (value of 4.0 or greater). For confidence with ICT, there were three categories: limited (value under 2), moderate (value between 2 and 3, but excluding 3), and proficient (value of 3 or greater). HLM was used to generate an estimate of the scientific literacy using the plausible values using the data in each of the categories. To analyze the profiles, the standard error values were used to calculate the $95 \%$ confidence intervals for each level. The intervals were then compared with other levels within the group for overlap; any overlaps would indicate that the differences between levels were not statistically significant at the .05 level. 


\section{CHAPTER 4}

\section{RESULTS}

This chapter is organized into two sections according to the research questions posed in this thesis, with the results from Canada and Australia presented together to address each question. The first section presents descriptive statistics of the variables related to ICT access, use, and confidence, the respecification of constructs that were used in multilevel linear modeling (MLM) analyses, as well as analyses that compare access to, use of, and confidence with ICT based on gender and country differences. The second section focuses on the multilevel analysis and also profiles data to compare differences in scientific literacy based on access to, use of, and confidence with ICT within each country.

To what extent do students in Canada and Australia differ in their access to, use of, and confidence with information and communication technology (ICT)?

The analyses in this section focus on variables relating to three categories of items from the PISA 2006 ICT familiarity questionnaire: (a) access to ICT from various locations; (b) types of software used by students; and (c) students' confidence with various ICT tasks.

Access to ICT

Access to ICT was measured by comparing students in Australia and Canada on how frequently they used ICT at home, at school, and at other places. This frequency of use was also examined within countries by gender. In addition, access was measured at 
the school level by comparing ICT resources at schools located in the two countries with respect to (a) index of availability of computers; (b) overall ratio of computers to school size; and (c) proportion of computers connected to the Internet.

A descriptive statistics analysis of PISA 2006 revealed that, in Canada, 83\% of students surveyed used a computer at home almost every day, and $11 \%$ once or twice during the week; $21 \%$ reported daily usage at school, $31 \%$ once or twice per week, and $27 \%$ a few times per month. Approximately $9 \%$ of students used computers almost every day at places other than home and school, while $27 \%$ of students reported doing so once or twice a week.

In Australia, $75 \%$ of students surveyed used a computer at home almost every day, and $18 \%$ once or twice during the week; $26 \%$ reported daily usage at school, $49 \%$ once or twice per week, and $18 \%$ a few times per month. Approximately $5 \%$ of students used a computer at other places almost every day, while $20 \%$ of students did so once or twice a week.

Based on a five-point scale measuring overall frequency of use (see Table 1), student computer access at school was more frequent in Australia $(M=2.92)$ than in Canada $(M=2.44)$, a difference that was statistically significant $(t=-43.7, p<.001, \hat{\Delta}=$ $.42) .{ }^{10}$ On the other hand, students in Canada more frequently accessed computers at places other than home and school $(M=2.02)$ than students in Australia $(M=1.58)$; this difference was also significant $(t=33.4, p<.001, \hat{\Delta}=.39)$. While home use between

\footnotetext{
${ }^{10}$ Cohen (1988) provided a set of guidelines to interpret effect sizes: a value of .2 indicates a small effect; .5 , a medium effect, and .8 , a large effect.
} 
countries had the smallest mean difference, Canadian students were still more likely to access computers at home $(t=6.6, p<.001, \hat{\Delta}=.07)$.

The differences in access by gender were analyzed at a country-level basis. The independent samples $t$-test analyses revealed that, in Canada, boys used ICT more frequently than girls, regardless of location (e.g., at home, $t=3.0, p<.01, \hat{\Delta}=.04$; at school, $t=12.0, p<.001, \hat{\Delta}=.16$; at other places $t=14.4, p<.001, \hat{\Delta}=.19)$. In Australia, there was no statistically significant difference at home (i.e., girls used computers as frequently as boys; $t=1.6, p=\mathrm{ns}, \hat{\Delta}=.02$ ), but statistically significant differences existed at school $(t=5.8, p<.001, \hat{\Delta}=.10)$ and at other places $(t=13.5, p<$ $.001, \hat{\Delta}=.23$ ), favouring boys.

Analyses for three variables from the school-level data revealed that, although the proportion of computers connected to the Web was similar between Canada and Australia $(t=1.91, p=\mathrm{ns}, \hat{\Delta}=.10)$, in Australia, there were more computers available for instruction per student, and more computers overall based on school size $(t=-7.46, p<$ $.001, \hat{\Delta}=.57$; and $t=-5.86, p<.001, \hat{\Delta}=.36$, respectively). The effect sizes of analyses by gender suggest that the magnitude of the difference is quite small, most under onequarter of a standard deviation. The magnitude of the difference between countries is largest for access at school and at other places, whereas it is smallest for access at home. 
Table 1.

Descriptive statistics of ICT accessibility by students in Canada and Australia

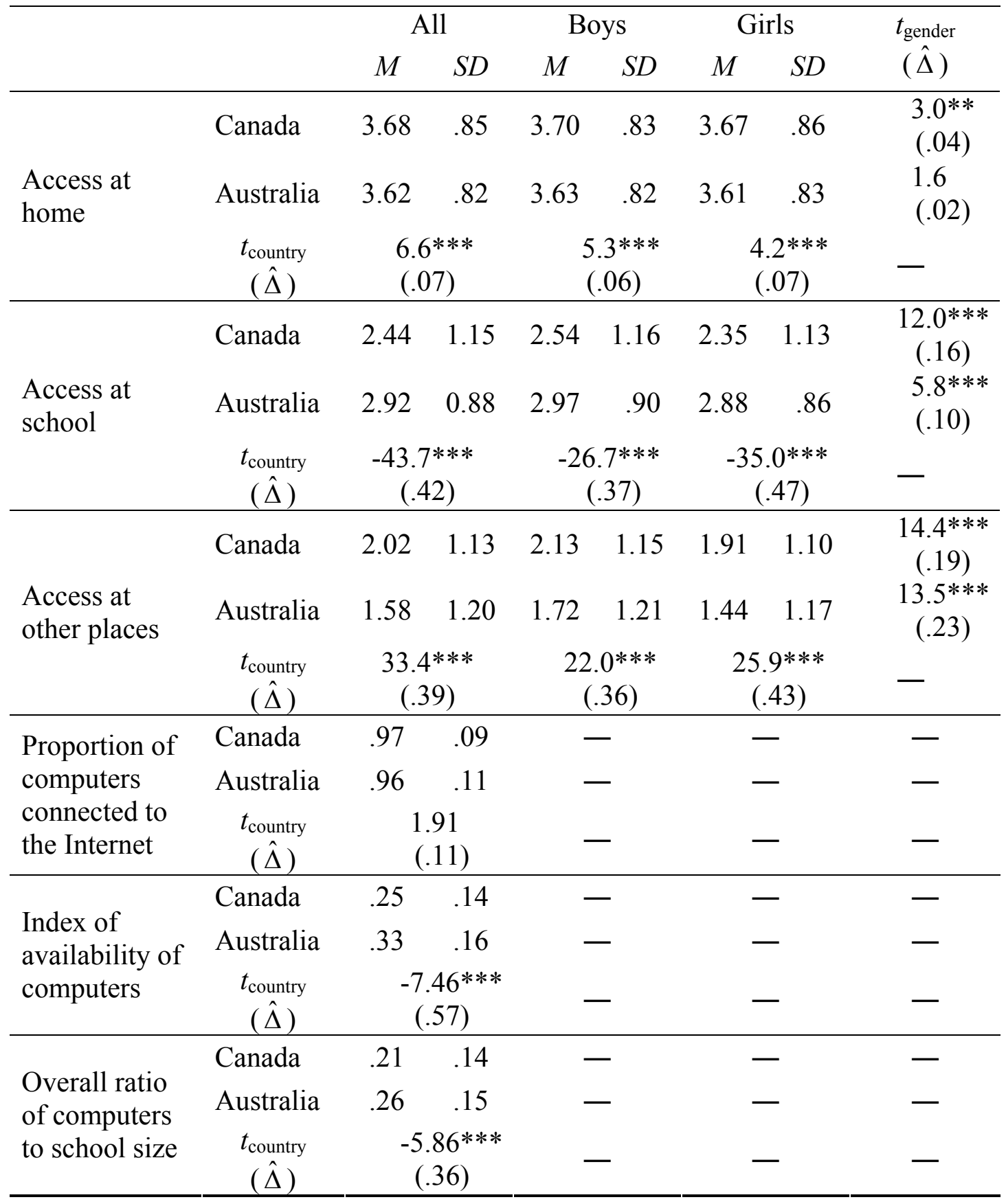

Note. $t_{\text {gender }}$ is based on differences between genders, whereas $t_{\text {country }}$ is based on differences between countries.

$* p<.05 . * * p<.01 . * * * p<.001$. 
Use of ICT

Use of ICT was measured by how frequently students performed a particular type of activity or software while engaged with ICT. One item (with 10 subitems) from the familiarity questionnaire was used to derive constructs related to frequency of ICT use for different purposes (see OECD, 2009). The specification of constructs by OECD, a process that used data from all countries, resulted in two constructs. However, exploratory factor analyses (maximum likelihood) were conducted separately with the data from each country, since different constructs could result, depending on contextual factors.

The optimal solution from the Canadian data contained two factors (Table 2), which would be best described as 'productivity use' (Factor 1) and 'entertainment use' (Factor 2). The subitems 'browse the Internet' and 'collaborate on the Internet' were at or near the threshold of .32 on both factors. ${ }^{11}$ (These variables were originally part of the 'ICT Internet/Entertainment' construct; see OECD, 2007). Hence the subitems were removed from the respecified constructs but retained as explanatory student-level predictors for multilevel linear modeling since these were the only constructs that measured Internet use. The internal consistency values of factors 1 and 2 were $.74(\alpha)$ and $.67(\alpha)$, respectively. The two factors combined for about $50 \%$ of the variability in ICT use, and loaded in a pattern consistent with frequency of students' ICT activities (as opposed to the OECD scales, which were organized by type of software).

\footnotetext{
${ }^{11}$ According to Tabachnick and Fidell (2007), only variables with loadings of .32 or above should be interpreted, a value representing $10 \%$ overlapping variance. The larger the value, the more the variable is a pure measure of the factor.
} 
The optimal solution from the Australian data contained two factors (Table 2), which would also be best described as 'entertainment use' (Factor 1) and 'productivity use' (Factor 2). Although the 'collaborate on Internet' subitem within the Australian data loaded at .32 (Table 2), the 'browse Internet' subitem did not load at all. Therefore, these two subitems were handled the same way as the Canadian data were (i.e., excluded from the respecified constructs but used as separate predictors). The internal consistency values of Factors 1 and 2 were both approximately .71 $(\alpha)$. Similar to Canada, the two factors combined for approximately $50 \%$ of the variability.

In summary, factor analyses of software use subitems resulted in two constructs, each construct composed of identical subitems, along with two separate predictors (i.e., browse Internet, collaborate on the Internet). Comparing the results from both countries, the total variation explained by a two-factor model was similar.

Gender and country differences. On a country-level basis, the gender comparisons revealed that boys used ICT more than girls, regardless of purpose, but differences were largest for entertainment use. The $t$-values were: (a) for entertainment, Canada: $t=28.2, p$ $<.001, \hat{\Delta}=.38$; Australia: $t=25.4, p<.001, \hat{\Delta}=.43$; (b) for productivity, Canada: $t=$ 5.5, $p<.001, \hat{\Delta}=.07$; Australia: $t=8.0, p<.001, \hat{\Delta}=.13$; (c) for Internet browsing, Canada: $t=2.4, p<.05, \hat{\Delta}=.04$; Australia: $t=2.7, p<.01, \hat{\Delta}=.04$; and (d) for Internet collaboration, Canada: $t=8.4, p<.001, \hat{\Delta}=.12$; Australia: $t=6.9, p<.001, \hat{\Delta}=.12$. The results are presented in Table 3. 
Table 2 .

Factor loadings for maximum likelihood factor analysis of student ICT software use in Canada and Australia

\begin{tabular}{|c|c|c|c|c|}
\hline & \multicolumn{2}{|c|}{ Canada } & \multicolumn{2}{|c|}{ Australia } \\
\hline & 1 & 2 & 1 & 2 \\
\hline Browse Internet & & .32 & - & - \\
\hline Play games & & .38 & .41 & \\
\hline Write documents & .48 & & & .54 \\
\hline Collaborate on Internet & .33 & & & .32 \\
\hline Use spreadsheets & .74 & & & .75 \\
\hline Download software & & .66 & .81 & \\
\hline Graphics programs & .44 & & & .39 \\
\hline Educational software & .78 & & & .66 \\
\hline Download music & & .73 & .79 & \\
\hline Write programs & .59 & & & .47 \\
\hline Email or chat rooms & & .60 & .55 & \\
\hline Percentage of variation explained & $35.6 \%$ & $14.7 \%$ & $35.5 \%$ & $14.8 \%$ \\
\hline Internal consistency & .74 & .67 & .71 & .71 \\
\hline
\end{tabular}

Note. Factor loadings under .32 were suppressed from the output. 
Table 3.

Independent-samples t-test analyses of respecified constructs relating to frequency of ICT software use of 15-year-old students in Canada and Australia

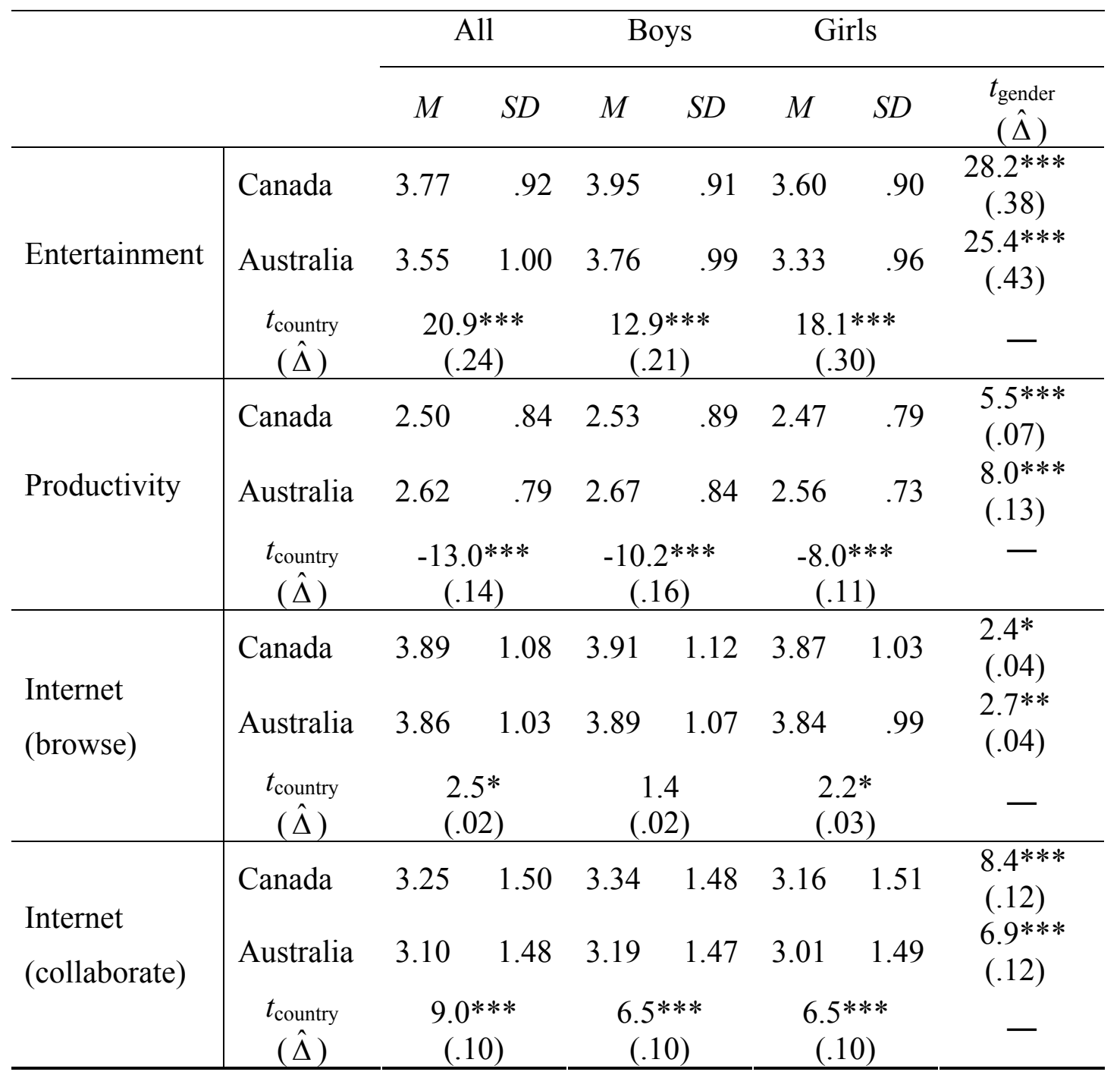

$* p<.05 . * * p<.01 . * * * p<.001$.

To analyze gender differences, independent samples $t$-test analyses were conducted by gender, using constructs that were respecified using the respective data from each country. Canadian students used ICT more commonly for entertainment purposes than their Australian counterparts overall $(t=20.9, p<.001, \hat{\Delta}=.24)$. When 
broken down by gender, the results were similar (boys: $t=12.9, p<.001, \hat{\Delta}=.21$; girls: $t$ $=18.1, p<.001, \hat{\Delta}=.30)$. Conversely, Australian students used ICT more commonly for productivity purposes than Canadian students overall $(t=-13.0, p<.001, \hat{\Delta}=.14)$, which did not change when gender was considered (boys: $t=-10.2, p<.001, \hat{\Delta}=.16$; girls: $t=$ $-8.0, p<.001, \hat{\Delta}=.11)$. For Internet browsing, an activity that could be classified into either of the first two categories, Canadian students were more frequent users overall $(t=$ $2.5, p<.05, \hat{\Delta}=.02)$, but statistically significant differences were found only for girls $(t$ $=2.2, p<.05, \hat{\Delta}=.03)$. Lastly, for Internet collaboration, there were differences overall $(t=9.0, p<.001, \hat{\Delta}=.10)$, but also between boys $(t=6.5, p<.001, \hat{\Delta}=.10)$ and girls $(t$ $=6.5, p<.001, \hat{\Delta}=.10)$. The effect sizes of gender and country analyses suggest that the magnitude of the difference is quite small, most under one-third of a standard deviation. (The exception was the difference in gender within countries with regards to ICT entertainment use).

\section{Confidence with ICT}

Since the data for students' attitudes towards ICT were collected in the same manner as software use, the methods and analyses were similar to the ones described in the previous section. Students' attitudes were measured using one questionnaire item with 16 subitems from the ICT Familiarity Questionnaire. Again, exploratory factor analyses (maximum likelihood) were conducted separately with the data from each country.

For both the Canadian and Australian data, all of the subitems loaded above .40, which suggests that students' response patterns in both countries were quite similar to 
each other (Table 4). In both countries, the two resultant factors explained over $50 \%$ of the variation. However, there was inconsistency with one subitem, self-confidence using presentation software, which loaded onto Factor 1 (Australia) and Factor 2 (Canada). After removing this subitem from the construct, but retaining it as a separate explanatory variable, the internal consistency values of Factor 1 (Australia) and Factor 2 (Canada) decreased slightly to $\alpha=.88$ and $\alpha=.78$, respectively. The two constructs could be best described as 'basic-level tasks' (Factor 1) and 'advanced-level tasks' (Factor 2).

Gender and country differences. Within each country but separated by gender (Table 5), girls were more confident than boys for the basic tasks (in Canada, $t=-8.6, p<$ $.001, \hat{\Delta}=.12$ ); in Australia, $t=-6.0, p<.001, \hat{\Delta}=.09$ ) and for presentation software (in Canada, $t=-5.3, p<.001, \hat{\Delta}=.07$; in Australia, $t=-11.6, p<.001, \hat{\Delta}=.18)$, but boys were more confident than girls for the advanced tasks (in Canada, $t=7.9, p<.001, \hat{\Delta}=$ .11 ; in Australia, $t=6.7, p<.001, \hat{\Delta}=.11)$.

Student confidence was then compared overall on a country-level basis, and by gender (Table 5). For confidence with basic tasks, Canadian students were more confident than Australian students overall $(t=6.1, p<.001, \hat{\Delta}=.06)$ and by gender (boys: $t=3.4, p<.001, \hat{\Delta}=.05$; girls: $t=5.5, p<.001, \hat{\Delta}=.10$ ). There were no statistically significant differences between countries for advanced tasks, either overall or by gender. In addition, significant differences were found in confidence with presentation software, favouring Australia (overall: $t=-25.9, p<.001, \hat{\Delta}=.24$; boys: $t=-14.4, p<$ .001, $\hat{\Delta}=.19$; and girls: $t=-23.7, p<.001, \hat{\Delta}=.30$ ). The differences in confidence 
between gender and between countries are small when effect sizes are compared, particularly with basic and advanced tasks.

Table 4.

Factor loadings for maximum likelihood factor analysis of student ICT self-confidence in Canada and Australia

\begin{tabular}{|c|c|c|c|c|}
\hline & \multicolumn{2}{|c|}{ Canada } & \multicolumn{2}{|c|}{ Australia } \\
\hline & 1 & 2 & 1 & 2 \\
\hline Chat & .72 & & .61 & \\
\hline Anti-virus & & .56 & & .59 \\
\hline Edit photos & & .56 & & .51 \\
\hline Database & & .73 & & .72 \\
\hline Copy data to CD & .47 & & .50 & \\
\hline Move files & .52 & & .69 & \\
\hline Search Internet & .79 & & .87 & \\
\hline Download files & .71 & & .63 & \\
\hline Attach files to email & .68 & & .70 & \\
\hline Word processor & .61 & & .70 & \\
\hline Spreadsheet & & .61 & & .44 \\
\hline Presentation $^{\mathrm{a}}$ & & .50 & .53 & \\
\hline Download music & .66 & & .55 & \\
\hline $\begin{array}{l}\text { Multimedia } \\
\text { presentation }\end{array}$ & & .72 & & .60 \\
\hline Emails & .80 & & .75 & \\
\hline $\begin{array}{l}\text { Web page } \\
\text { construction }\end{array}$ & & .46 & & .66 \\
\hline $\begin{array}{l}\text { Percentage of } \\
\text { variation explained }\end{array}$ & $39.3 \%$ & $11.4 \%$ & $41.2 \%$ & $9.9 \%$ \\
\hline Internal consistency & .88 & .80 & .89 & .78 \\
\hline
\end{tabular}

Note. Factor loadings under .32 were suppressed from the output.

${ }^{a}$ Presentation was removed in calculating reliability because of its differential loading in the two countries. 
Table 5.

Independent-samples t-test analyses of respecified constructs relating to ICT attitudes of students in Canada and Australia

\begin{tabular}{|c|c|c|c|c|c|c|c|c|}
\hline & & \multicolumn{2}{|c|}{ All } & \multicolumn{2}{|c|}{ Boys } & \multicolumn{2}{|c|}{ Girls } & \multirow[b]{2}{*}{$\begin{array}{c}t_{\text {gender }} \\
(\hat{\Delta})\end{array}$} \\
\hline & & $M$ & $S D$ & $M$ & $S D$ & $M$ & $S D$ & \\
\hline \multirow{3}{*}{ Basic } & Canada & 4.85 & .35 & 4.83 & .41 & 4.88 & .29 & $\begin{array}{c}-8.6 * * * \\
(.12)\end{array}$ \\
\hline & Australia & 4.83 & .37 & 4.81 & .43 & 4.85 & .31 & $\begin{array}{c}-6.0 * * * \\
(.09)\end{array}$ \\
\hline & $\begin{array}{c}t_{\text {country }} \\
(\hat{\Delta})\end{array}$ & \multicolumn{2}{|c|}{$\begin{array}{l}6.1 * * * \\
(.06)\end{array}$} & \multicolumn{2}{|c|}{$\begin{array}{l}3.4 * * * \\
(.05)\end{array}$} & \multicolumn{2}{|c|}{$\begin{array}{l}5.5 * * * \\
(.10)\end{array}$} & - \\
\hline \multirow{3}{*}{ Advanced } & Canada & 4.23 & .59 & 4.27 & .63 & 4.20 & .56 & $\begin{array}{l}7.9 * * * \\
(.11)\end{array}$ \\
\hline & Australia & 4.22 & .58 & 4.26 & .61 & 4.19 & .53 & $\begin{array}{l}6.7 * * * \\
(.11)\end{array}$ \\
\hline & $\begin{array}{c}t_{\text {country }} \\
(\hat{\Delta})\end{array}$ & \multicolumn{2}{|c|}{$\begin{array}{l}0.9 \\
(.02) \\
\end{array}$} & \multicolumn{2}{|c|}{$\begin{array}{l}0.7 \\
(.02)\end{array}$} & \multicolumn{2}{|c|}{$\begin{array}{l}0.9 \\
(.02) \\
\end{array}$} & - \\
\hline \multirow{3}{*}{ Presentation } & Canada & 4.63 & .71 & 4.61 & .74 & 4.66 & .67 & $\begin{array}{c}-5.3 * * * \\
(.07)\end{array}$ \\
\hline & Australia & 4.80 & .53 & 4.75 & .60 & 4.86 & .44 & $\begin{array}{c}-11.6 * * * \\
(.18)\end{array}$ \\
\hline & $\begin{array}{c}t_{\text {country }} \\
(\hat{\Delta})\end{array}$ & \multicolumn{2}{|c|}{$\begin{array}{c}-25.9 * * * \\
(.24)\end{array}$} & \multicolumn{2}{|c|}{$\begin{array}{c}-14.4 * * * \\
(.19)\end{array}$} & \multicolumn{2}{|c|}{$\begin{array}{c}-23.7 * * * \\
(.30)\end{array}$} & - \\
\hline
\end{tabular}

$* * * p<.001$.

To what extent are differences in scientific literacy predicted by student-level and schoollevel characteristics in Canada and Australia?

The second research question is addressed in two sections: (a) the multilevel linear models using HLM software, followed by (b) ICT construct profiling. In the first section, the multilevel linear models include student demographic characteristics, such as gender; immigrant status; economic, social, and cultural status (ESCS); and computing experience, in addition to the variables and respecified constructs analyzed in the first 
research question. The models also consider school demographic characteristics, such as school size and community in which the school was located. The results from each country are described separately, with each culminating in a summary of the overall model. In the second section, ICT-related constructs and variables are profiled, since previous research has determined that there were differences in achievement based on levels of use. For this analysis, the data were sorted by frequency (for ICT use variables) or self-confidence (for confidence with ICT variables) to examine trends in the scientific literacy scores.

\section{Canada}

\section{Null Model}

The null model for scientific literacy scores in Canada, which partitions the variance into within-school and between-school variance, is presented in Table 6 .

Table 6.

Results of the null model for science achievement among students in Canada

\begin{tabular}{lcccc}
\hline Fixed effect & \multicolumn{1}{c}{$\gamma_{00}$ coefficient } & \multicolumn{2}{c}{$S E$} \\
\hline Scientific literacy & \multicolumn{3}{c}{535.8} & \\
\hline $\begin{array}{l}\text { Random effect } \\
\text { Variance } \\
\text { component }\end{array}$ & $d f$ & $\chi^{2}$ & $p$ \\
\hline $\begin{array}{l}\text { Between-school } \\
\text { variability } \\
\text { (intercept) }\end{array}$ & 1330.6 & 644 & 3429.8 & $<.001$ \\
$\begin{array}{l}\text { Within-school } \\
\text { variability }\end{array}$ & 7278.7 & & & \\
\hline
\end{tabular}

Note. Analyses were based on data for 22,121 students nested within 645 schools. Reliability $\lambda=.82 ; \mathrm{ICC}=.155$ 
Fixed effects. The weighted least squares estimate for scientific literacy in Canada (based on plausible values) is

$$
\hat{\gamma}_{00}=535.8
$$

This estimation has a standard error of 2.3 and yields a $95 \%$ confidence interval of

$$
535.8 \pm 1.96(2.3)=(531.2,540.4)
$$

Given that the OECD average of all participating countries is 500 with a standard deviation of 100, Canada performed well above average in scientific literacy.

Variance components. Table 6 also lists restricted maximum likelihood estimates of the variance components. At the student level, variance is calculated as

$$
\widehat{\operatorname{Var}}\left(r_{i j}\right)=\hat{\sigma}^{2}=7278.7
$$

At the school level, $\tau_{00}$ is the variance of the true school means, $\beta_{0 j}$, around the grand mean, $\gamma_{00}$. The estimated variability in these school means is

$$
\widehat{\operatorname{Var}}\left(\beta_{0 j}\right)=\widehat{\operatorname{Var}}\left(u_{0 j}\right)=\hat{\tau}_{00}=1330.6
$$

Thus significant variation does exist among schools in their scientific literacy scores. According to Table 6, 95\% of the schools were expected to fall within the range

$$
\hat{\gamma}_{00} \pm 1.96 \sqrt{\hat{\tau}_{00}}=(464.3,607.3)
$$

The $p$-value is less than .001 ; therefore, the null hypothesis is rejected, and the results indicate that average scientific literacy scores varied across the schools.

The intraclass correlation, which represents the proportion of variance in scientific literacy between schools, can be calculated as follows:

$$
\rho=\frac{\hat{\tau}_{00}}{\hat{\tau}_{00}+\hat{\sigma}^{2}}=\frac{1330.6}{1330.6+7278.7}=.155
$$


indicating that about $16 \%$ of the total variance is associated with schools as opposed to students. According to Heck and Thomas (1999), HLM uses maximum likelihood estimation to find the "most likely population parameter estimates that could have produced the observed sample covariance matrix" (p. 65). Based on the results, although the largest proportion of variance in scientific literacy scores is associated with the individual (about 84\%), the change in variance from the student-level variables is still statistically significant.

The reliability of the sample was obtained by averaging the individual school estimates.

$$
\hat{\lambda}=\frac{\sum \hat{\lambda}_{j}}{J}
$$

The output from HLM was $\hat{\lambda}=.82$, indicating that the sample means tended to be quite reliable as indicators of the true school means.

\section{Background Model}

The background model, a two-level linear model comprised of the student demographic variables and school mean ESCS and school location (all fixed), was generated. All predictors in this model (including gender) were statistically significant, with the exception of school location, which was removed. The reliability of this model was $\hat{\lambda}=.73$. Based on the change in the variance component as compared to the null model, the background variables explained about $4 \%$ of the within-school variance, and about $45 \%$ of the between-school variance. 


\section{Relative Effects Model}

The absolute effects of each variable were tested using fixed effects (see Appendix D for these results), and those with statistically significant effects on scientific literacy scores were then included to build a parsimonious fixed, relative effects multilevel model. This model is presented in Table 7, and the equations are presented in Appendix C.

Ten statistically significant student-level predictors and one school-level predictor were retained in the final relative effects model, including student ESCS and immigration status. The reliability of the model was $\hat{\lambda}=.70$. Gender was excluded from relative effects modeling since it was not statistically significant when tested for absolute effects. Students from more affluent and educated families performed better; for every one standard deviation increase in student ESCS, a student attained nearly 15 points higher in scientific literacy, when other variables in the model were held constant. Also, students from non-immigrant families tended to do better than students from immigrant families, but compared to the absolute effects results, the effects were reduced in the presence of ICT-related variables.

There was also a positive effect between students who had prior experience using computers and scientific literacy, a change of +6.21 points per standard deviation increase. (All values reported refer to the change in the scientific literacy score per standard deviation [SD] increase in the predictor variable.) Having confidence with basic ICT skills and presentation software had beneficial effects on scientific literacy, but frequent use of ICT (whether for entertainment or productivity purposes) had negative 
effects in the relative effects model (-11.56 and -9.57 points per SD, respectively), except for students browsing the Internet ( +9.75 points per SD). Students who used computers primarily at other places, scored lower. Use of ICT at home was not statistically significant, nor was use at school.

Table 7.

Overall relative effects model with fixed effects, multilevel linear model for scientific literacy among students in Canada

\begin{tabular}{|c|c|c|c|}
\hline Level 1/Student-level effects & Gamma & $S E$ & $t$ \\
\hline Socioeconomic status & 14.72 & 1.66 & $8.9^{* * *}$ \\
\hline Immigrant status & -19.97 & 3.89 & $-5.1 * * *$ \\
\hline Experience with computers & 6.21 & 1.11 & $5.6^{* * *}$ \\
\hline $\begin{array}{l}\text { Frequency of computer access } \\
\text { from other places }\end{array}$ & -11.47 & 1.48 & $-7.8^{* * *}$ \\
\hline Browse the Internet & 9.75 & 1.35 & $7.2^{* * *}$ \\
\hline $\begin{array}{l}\text { Frequency of entertainment } \\
\text { software use }\end{array}$ & -11.56 & 1.74 & $-6.6 * * *$ \\
\hline $\begin{array}{l}\text { Frequency of productivity software } \\
\text { use }\end{array}$ & -9.57 & 1.37 & $-7.0 * * *$ \\
\hline $\begin{array}{l}\text { Confidence with presentation } \\
\text { software }\end{array}$ & 6.29 & 1.15 & $5.5^{* * *}$ \\
\hline Confidence with basic ICT skills & 17.05 & 1.78 & $9.6^{* * *}$ \\
\hline $\begin{array}{l}\text { Confidence with advanced ICT } \\
\text { skills }\end{array}$ & -3.25 & 1.52 & $-2.1^{*}$ \\
\hline
\end{tabular}

Level-2/School-level effects

\begin{tabular}{lrrr}
\hline Mean ESCS & 14.55 & 1.71 & $8.52 * * *$ \\
\hline$* p<.05 . * * p<.01 . * * * p<.001$. & \\
Proportion of variance explained (effect size) & \\
at the student-level $\quad .13$ & \\
at the school-level & .55 \\
\hline
\end{tabular}


There was one statistically significant level-2 predictor, MEANESCS, which is positively related to scientific literacy.

The proportion of variance explained at level-2 is

$$
\frac{\hat{\tau}_{00}(\text { random ANOVA })-\hat{\tau}_{00}(\text { level }-1)}{\hat{\tau}_{00}(\text { random ANOVA })}=\frac{1330.6-599.1}{1330.6}=.550
$$

Altogether, 55\% of the true between-school variance in scientific literacy is accounted for by the full model. Thus the addition of school mean ESCS to the existing level-1 model collectively explained much of the variance that would render schools more homogeneous in scientific literacy.

The proportion reduction in variance can be determined by comparing the $\hat{\sigma}^{2}$ estimates from the level-1 model, $\hat{\sigma}^{2}\left(\right.$ level-1), and the null model, $\hat{\sigma}^{2}$ (random ANOVA), which did not contain any predictors.

The proportion variance explained at level-1 is

$$
\frac{\hat{\sigma}^{2}(\text { random ANOVA })-\hat{\sigma}^{2}(\text { level-1 })}{\hat{\sigma}^{2}(\text { random ANOVA })}=\frac{7278.7-6338.3}{7341.7}=.129
$$

It can be seen that the statistically significant level-1 predictors reduced the within-school variance by $13 \%$. Relative to the null model, computer use at the student level, in addition to SES and immigrant status, accounted for $13 \%$ of the variance; however, the overall model accounted for approximately $55 \%$ of the between-school variance. 


\section{Australia}

\section{Null Model}

The null model for scientific literacy in Australia, which partitions the variance into within-school variance and between-school variance, is presented in Table 8.

Table 8.

Results of the null model for science achievement among students in Australia

\begin{tabular}{|c|c|c|c|c|}
\hline \multirow{2}{*}{\multicolumn{2}{|c|}{$\begin{array}{l}\text { Fixed effect } \\
\text { Scientific literacy }\end{array}$}} & \multirow{2}{*}{$\frac{\gamma_{00} \text { coefficient }}{530.0}$} & \multicolumn{2}{|c|}{$S E$} \\
\hline & & & & \\
\hline Random effect & $\begin{array}{l}\text { Variance } \\
\text { component }\end{array}$ & $d f$ & $\chi^{2}$ & $p$ \\
\hline $\begin{array}{l}\text { Between-school } \\
\text { variability } \\
\text { (intercept) }\end{array}$ & 1552.7 & 340 & 2915.8 & $<.001$ \\
\hline $\begin{array}{l}\text { Within-school } \\
\text { variability }\end{array}$ & 7845.4 & & & \\
\hline
\end{tabular}

Note. Analyses were based on data for 14,084 students nested within 341 schools.

Reliability $\lambda=.88 ; \mathrm{ICC}=.165$

Fixed effects. The weighted least squares estimate for scientific literacy scores

(based on plausible values) in Australia is

$$
\hat{\gamma}_{00}=530.0
$$

This estimation has a standard error of 2.9 and yields a $95 \%$ confidence interval of

$$
530.0 \pm 1.96(2.9)=(524.2,535.7)
$$

Like Canada, students in Australia performed well above the OECD average in scientific literacy. 
Variance components. Table 8 also lists restricted maximum likelihood estimates of the variance components. At the student level,

$$
\widehat{\operatorname{Var}}\left(r_{i j}\right)=\hat{\sigma}^{2}=7845.4
$$

At the school level, $\tau_{00}$ is the variance of the true school means, $\beta_{0 j}$, around the grand mean, $\gamma_{00}$. The estimated variability in these school means is

$$
\widehat{\operatorname{Var}}\left(\beta_{0 j}\right)=\widehat{\operatorname{Var}}\left(u_{0 j}\right)=\hat{\tau}_{00}=1552.7
$$

Significant variation does exist among schools in their scientific literacy scores. According to Table $8,95 \%$ of the schools were expected to fall within the range

$$
\hat{\gamma}_{00} \pm 1.96 \sqrt{\hat{\tau}_{00}}=(452.1,606.6)
$$

The $p$-value is less than .001 ; therefore, the null hypothesis is rejected, and the results indicate that average scientific literacy scores varied across the schools.

The intraclass correlation, which represents the proportion of variance in scientific literacy between schools, can be calculated as follows:

$$
\rho=\frac{\hat{\tau}_{00}}{\hat{\tau}_{00}+\hat{\sigma}^{2}}=\frac{1552.7}{1552.7+7845.4}=.165
$$

This result indicates that approximately $17 \%$ of the total variance is between schools. This variance signifies that approximately $83 \%$ of the total variance in scientific literacy can be attributed to students in Australia, while $17 \%$ of the total variance can be attributed to the schools that they attend. The reliability of the sample was obtained by averaging the individual school estimates. 


$$
\hat{\lambda}=\frac{\sum \hat{\lambda}_{j}}{J}
$$

The output from HLM was $\hat{\lambda}=.88$, indicating that the sample means tend to be quite reliable as indicators of the true school means.

\section{Background Model}

The background model, a two-level linear model comprised of the student demographic variables and school characteristics (all fixed), was generated. Gender and school location were not statistically significant predictors at the .05 level and thus were removed. The reliability of this model was $\hat{\lambda}=.78$. Based on the change in the variance component as compared to the null model, the background variables explained less than $1 \%$ of the within-school variance, and about $57 \%$ of the between-school variance.

\section{Relative Effects Model}

The absolute effects of each variable were tested using fixed effects (see Appendix D for these results), and those with statistically significant effects on scientific literacy were then entered to build a parsimonious fixed, relative effects multilevel model. This model is presented in Table 9, with the equations presented in Appendix C.

There were 11 student-level predictors and two school-level predictors in the relative effects model that were statistically significant. The reliability of the model was $\hat{\lambda}=.77$. Gender did not have statistically significant absolute effects in Australian students' scientific literacy, and therefore was not included in the relative effects model. Students with higher levels of ESCS had a positive effect $(+18.11$ points per SD 
increase), while non-immigrant students, on average, performed slightly better as well $(+7.30$ points per SD increase).

Students with prior experience in computer use scored higher in scientific literacy (+8.22 points per SD increase). Regardless of the type of ICT activity (with the exception of browsing the Internet) performed, scientific literacy scores decreased with use; however, like Canada, students in Australia who browsed the Internet more frequently scored higher $(+8.06$ points per SD increase). Confidence with the use of basic ICT tasks (including presentation software) was positively associated with scientific literacy $(+8.64$ points per SD increase). Confidence with advanced ICT tasks had no effects on scientific literacy in the relative effects model, although it was significant when it was analyzed for absolute effects.

The places where students used computers also predicted scientific literacy. More frequent use of computers at home or school had a positive relationship $(+5.94$ and +3.30 points, respectively), whereas use in other places had a negative relationship (-9.12 points). 
Table 9.

Overall relative effects model with fixed effects for scientific literacy among Australian students

\begin{tabular}{|c|c|c|c|}
\hline Level 1/Student-level effects & Gamma & $S E$ & $t$ \\
\hline Socioeconomic status & 18.11 & 1.18 & $15.3 * * *$ \\
\hline Immigrant status & -7.30 & 3.10 & $-2.4^{*}$ \\
\hline Computing experience & 8.22 & 1.27 & $6.5 * * *$ \\
\hline $\begin{array}{l}\text { Frequency of computer access from } \\
\text { home }\end{array}$ & 5.94 & 1.74 & $3.4 * * *$ \\
\hline $\begin{array}{l}\text { Frequency of computer access from } \\
\text { school }\end{array}$ & 3.30 & 1.15 & $2.9 * *$ \\
\hline $\begin{array}{l}\text { Frequency of computer access from } \\
\text { other places }\end{array}$ & -9.12 & 1.07 & $-8.6 * * *$ \\
\hline Browse the Internet & 8.06 & 1.13 & $7.1 * * *$ \\
\hline $\begin{array}{l}\text { Frequency of entertainment software } \\
\text { use }\end{array}$ & -11.64 & 1.58 & $-7.4 * * *$ \\
\hline $\begin{array}{l}\text { Frequency of productivity software } \\
\text { use }\end{array}$ & -9.04 & 1.35 & $-6.7 * * *$ \\
\hline $\begin{array}{l}\text { Confidence using presentation } \\
\text { software }\end{array}$ & 8.64 & 1.37 & $6.3 * * *$ \\
\hline Confidence with basic-level tasks & 12.72 & 1.62 & $7.8 * * *$ \\
\hline \multicolumn{4}{|l|}{ Level 2/School-level effects } \\
\hline Mean ESCS & 15.12 & 2.1 & $7.3 * * *$ \\
\hline $\begin{array}{l}\text { Proportion of computers connected } \\
\text { to Internet }\end{array}$ & -12.57 & 4.1 & $-3.1 * *$ \\
\hline \multicolumn{4}{|l|}{$* p<.05 . * * p<.01 . * * * p<.001$} \\
\hline \multicolumn{4}{|c|}{ Proportion of variance explained (effect size) } \\
\hline at the student-level & & & \\
\hline at the school-level & & & \\
\hline
\end{tabular}


The proportion of variance explained at level-2 is

$$
\frac{\hat{\tau}_{00}(\text { random ANOVA })-\hat{\tau}_{00}(\text { level }-1)}{\hat{\tau}_{00}(\text { random ANOVA })}=\frac{1552.7-611.2}{1552.7}=.606
$$

Altogether, $61 \%$ of the true between-school variance in scientific literacy is accounted for by the final model.

The proportion reduction in variance can be determined by comparing the $\hat{\sigma}^{2}$ estimates

from the level-1 model, $\hat{\sigma}^{2}$ (level-1), and the null model, $\hat{\sigma}^{2}$ (random one-way ANOVA), which was free of predictors.

The proportion variance explained at level-1 is

$$
\frac{\hat{\sigma}^{2}(\text { random ANOVA })-\hat{\sigma}^{2}(\text { level- } 1)}{\hat{\sigma}^{2}(\text { random ANOVA })}=\frac{7845.4-6777.7}{7845.4}=.136
$$

The overall results show that $14 \%$ of the variance was explained at the student level; $61 \%$ of the variance was explained with the additional contribution of school-level variables. The statistically significant variables at level-2 were school mean ESCS and ratio of school computers connected to the Internet. Hence although the standard deviation from the descriptive statistics analysis was small, having more school computers connected to the Internet is negatively related to scientific literacy, while school mean ESCS is positively related.

\section{ICT Profiles and Scientific Literacy}

Data for ICT use and ICT confidence for each country were organized based on student responses from the questionnaire. This section presents the scientific literacy 
scores from the plausible values associated with each student according to how frequently the student used ICT at a specific place, how frequently he or she used a particular category of software, and by how confident he or she was with a particular ICT activity. The scientific literacy scores were calculated between each level to identify any trends. The $95 \%$ confidence interval was used to compare the scientific literacy scores between the levels within each group.

Access to ICT

As evidenced by the multilevel models, there were differences in students' scientific literacy scores based on how frequently they accessed ICT at a particular place (Table 10). In both countries, students who used ICT at home frequently (i.e., at least several times per week) scored significantly higher than students in the other three groups (moderate, infrequent, or never). The estimates ${ }^{12}$ were 536 and 530 for Canada and Australia, respectively. At school, the relationship appears to be curvilinear in Canada, where it rises from 519 to 542 between never and infrequent, but drops to 534 with moderate access. In Australia, the scores continually increase with frequent use, but like in Canada, the biggest change in scores occurs between never (476) and infrequent (515). The difference in scores between these two levels is significant, since there was no overlap between these levels. Finally, the pattern for ICT use at other places had a curvilinear relationship in both countries, with the largest decrease occurring between

\footnotetext{
${ }^{12}$ Although estimates of scientific literacy are described in the text, the tables in this section provide the $95 \%$ confidence intervals for the estimates (i.e., the upper and lower bounds of the true value).
} 
moderate and frequent access (541 to 516 in Canada, and 530 to 510 in Australia). This difference in scores was also significant, according to the $95 \%$ confidence intervals.

Table 10.

Upper and lower bounds ${ }^{\mathrm{a}}$ of scientific literacy scores of students in Canada and Australia based on how frequently they use ICT at home, school, or other places

\begin{tabular}{lcccccc}
\hline & \multicolumn{2}{c}{ Home } & \multicolumn{2}{c}{ School } & \multicolumn{2}{c}{ Other Places } \\
\cline { 2 - 7 } & Canada & Australia & Canada & Australia & Canada & Australia \\
\hline Never & $477-521$ & $438-498$ & $509-529$ & $442-510$ & $534-554$ & $519-535$ \\
Monthly & $473-513$ & $451-491$ & $534-550$ & $505-525$ & $546-558$ & $538-550$ \\
Weekly & $504-532$ & $467-499$ & $526-542$ & $517-533$ & $535-547$ & $522-538$ \\
Frequently & $532-540$ & $524-536$ & $527-539$ & $522-534$ & $510-522$ & $502-518$ \\
\hline
\end{tabular}

${ }^{\mathrm{a}} 95 \%$ confidence intervals, calculated using the standard error values generated by HLM.

Use of ICT

The data were first sorted into smaller sets based on how frequently students used a particular type of software (e.g., entertainment, productivity, Internet). In general, although the scores were different in each country, the general trends between levels were similar.

There was a curvilinear relationship between scientific literacy and how often students used ICT for entertainment (Table 11). Scores were highest for students who infrequently used ICT for entertainment compared to the other three user groups (never users; moderate users; and frequent users). For example, in Canada, scores peaked at 551 for infrequent use, but were the lowest at 521 for the frequent users; in Australia, scores peaked at 534 (infrequent users), contrasting to the 519 mean score of frequent users. 
Once the $95 \%$ confidence intervals are considered, there was little overlap between the moderate and frequent levels.

For productivity software, a similar pattern was observed, where moderate and frequent users scored lower than students who never and infrequently used ICT for this purpose. The trend was different for Internet browsing, where students who browsed the Internet frequently scored higher, but the scores remained stagnant between the moderate and frequent use levels (e.g., in Canada, it remained at 537; in Australia, the score dipped slightly from 531 to 529). However, the 'never' and 'infrequent' levels were significantly different. Lastly, there was considerable overlap in the $95 \%$ confidence intervals for Internet collaboration; therefore, the frequency of this activity appears to be relatively unrelated to scientific literacy scores. 
Table 11.

Upper and lower bounds ${ }^{\mathrm{a}}$ of scientific literacy scores of students in Canada and Australia based on how frequently they use ICT for entertainment, productivity, and to use the Internet

\begin{tabular}{llllllllll}
\hline & \multicolumn{2}{c}{ Entertainment } & \multicolumn{2}{c}{ Productivity } & \multicolumn{2}{c}{ Internet (browse) } & \multicolumn{2}{c}{$\begin{array}{c}\text { Internet } \\
\text { (collaborate) }\end{array}$} \\
\cline { 2 - 9 } & Canada & Australia & Canada & Australia & Canada & Australia Canada & Australia \\
\hline Never & $521-549$ & $502-527$ & $535-547$ & $511-527$ & $469-497$ & $456-480$ & $533-549$ & $518-534$ \\
Infrequent & $543-559$ & $526-542$ & $538-550$ & $530-542$ & $512-528$ & $496-520$ & $525-545$ & $524-540$ \\
Moderate & $533-545$ & $524-540$ & $513-529$ & $514-530$ & $529-545$ & $523-539$ & $527-539$ & $516-532$ \\
Frequent & $521-533$ & $513-525$ & $482-502$ & $470-490$ & $531-543$ & $523-535$ & $529-537$ & $519-531$ \\
\hline
\end{tabular}

${ }^{\mathrm{a}} 95 \%$ confidence intervals, calculated using the standard error values generated by HLM. 


\section{Confidence with ICT}

The effects of confidence towards ICT on scientific literacy scores were different from those observed with ICT software use. In all cases, scientific literacy scores increased with confidence. The extent of the change was smaller for advanced tasks than it was for both basic tasks and presentation software (Table 12). For confidence with basic tasks, low confidence users averaged 415 , rising to 460 for medium users and 536 for high confidence users in Canada. In Australia, the values were 401, 442, and 530, respectively. The $95 \%$ confidence intervals did not overlap between the medium and high levels in either country.

For self-confidence with presentation software in Canada, it rose from 494 to 524 and then 540, respectively. Similarly, for Australia, the scores rose from 442 (low confidence) to 489 (medium) to 534 (high confidence). All three levels were significantly different, as the $95 \%$ confidence intervals did not overlap each other.

For advanced tasks in both countries, the largest magnitude increase in scientific literacy score estimates occurred between the low and medium confidence levels (e.g., from 488 to 534 in Canada; from 453 to 516 in Australia). While the 95\% confidence intervals overlapped between the medium and high levels in Canada, there was no overlap in Australia, nor was there any overlap between the low and medium levels in either country. 
Table 12.

Upper and lower bounds ${ }^{\mathrm{a}}$ of scientific literacy scores of students in Canada and Australia based on confidence with basic ICT tasks, advanced ICT tasks, and presentation software

\begin{tabular}{lcccccc}
\hline & \multicolumn{2}{c}{ Basic } & \multicolumn{2}{c}{ Advanced } & \multicolumn{2}{c}{ Presentation } \\
& Canada & Australia & Canada & Australia & Canada & Australia \\
\hline Low & $379-451$ & $351-451$ & $474-502$ & $431-475$ & $486-502$ & $422-462$ \\
Medium & $440-480$ & $422-462$ & $528-540$ & $508-524$ & $518-530$ & $477-501$ \\
High & $532-540$ & $524-536$ & $529-541$ & $526-538$ & $534-546$ & $528-540$ \\
\hline
\end{tabular}

${ }^{\mathrm{a}} 95 \%$ confidence intervals, calculated using the standard error values generated by HLM. 


\section{CHAPTER 5}

\section{DISCUSSION}

This study examined two research questions around the relationship of ICT and scientific literacy in two countries, Canada and Australia. This chapter begins with a discussion of the results for the two research questions. The remainder of the chapter addresses the implications of the findings to research and practice.

To what extent do students in Canada and Australia differ in their access to, use of, and confidence with information and communication technology (ICT)?

\section{Access to ICT}

PISA 2006 sought data on places where students most frequently used ICT: at home, at school, or at other places. Although no examples of "other places" were given in the questionnaire, places outside of home or school would likely include public libraries, coffee shops, and Internet kiosks at shopping centres. In both countries, access from home was most common, followed by access at school, and then access from other places. Differences in frequency of access may be explained by the proportion of time students spend in each place (e.g., if they spend most of their time at home where there is a computer available, they would be more likely to access ICT from there).

Another important consideration is the availability of ICT and computers at each place; ICT availability is an external factor that may be limited by students' parents and their teachers. For example, at home, student access to ICT may be monitored and restricted by parents, perhaps encouraging more productive uses. Similarly, at school, 
access to ICT is generally determined by (a) how often teachers plan lessons that include the use of ICT, (b) the teachers' discretion of which activity that students complete while using ICT, and (c) curricular demands. Levin and Arafeh (2002) found that there are wide variances in teacher attitudes about the Internet and its use from classroom to classroom, and this variation undoubtedly results in different levels of access to ICT, regardless of other factors.

With respect to gender, mean differences in access to ICT at home between boys and girls was smallest in both countries, followed by access at school, and then at other places. (In all cases, boys were more frequent users.) Looker and Thiessen (2003) found that physical access at home is similar for both genders, which may suggest that the increasing number of computers being purchased by households has allowed girls to have increased accessibility to ICT. However, the discrepancy between genders with regards to use at school was lesser in Australia than in Canada. This result corroborates the Australian results from Thomson and De Bortoli (2007), who found that the differences between boys and girls and their access to computers at home or at school were negligible. Therefore, why do boys access ICT more frequently at school than girls? Although the effect of personal choice may influence access to ICT at school, Ilomäki and Rantanen (2007) suggest that gender inequality can diminish if technology is used in combination with learning at school. However, some courses are more oriented towards ICT than others (e.g., computer programming). Due to boys' interest in these courses, which are generally technical in nature and taken as electives, they may have additional opportunities to access ICT at school (see Volman, van Eck, Heemskerk, \& Kuiper, 
2005). Given the equal availability of ICT at school, it is important to continue exploring the small but persistent gender differences in access to ICT at school.

Use of ICT

Both Canadian and Australian students were frequent users of ICT, particularly for entertainment and Internet-related activities. This finding is a continuing trend: in PISA 2003, OECD (2005) found that Canadian students were among the most frequent users of ICT internationally. Furthermore, another development since PISA 2003 is the increasing importance of the Internet in students' daily lives, particularly for entertainment, social communication, and school work: in PISA 2006, over $70 \%$ of Canadian students connected to the Internet at least once a week to browse Web sites, download music, send email, and chat (please refer to Appendix B).

The results also align with ICT applications frequently incorporated into teaching practices, according to the Canadian data from the 2003-2004 Information and Communications Technologies in Schools Survey (abbreviated ICTSS; Plante \& Beattie, 2004). In that study, while word processing was, by far, most frequently used $(82.1 \%$ of secondary schools), use of the Internet or intranet to disseminate information was second (40.5\%). Conversely, ICT activities that were more specialized in nature or required technical skills — typically categorized as productivity software-were less frequently used by students. For instance, computer programming might only be used by students in vocational programs or those who were taking the course as an elective.

Cross-country comparisons revealed that Canadian students used ICT more frequently than their Australian counterparts for entertainment purposes, while the 
converse was true when using ICT for productivity purposes. One possible explanation for this difference between countries might be Australia's National Goals for Schooling in the Twenty-first Century program, which emphasized increased ICT integration in daily lessons and use of computers at school to prepare students before they left school (MCEETYA, 1999). Such integration might include the instruction of productivity software. Since it has been acknowledged that Canada does not have a comprehensive plan for learning with ICT (e.g., Canadian Council for Learning, 2009), it is possible that students attending schools in provinces that have specific ICT curricula (e.g., Alberta, British Columbia, Saskatchewan, and Nova Scotia; see Wallin, Anderson, \& Penner, 2009) may use software differently from students in other provinces where ICT use is not mandated. However, this explanation is speculation, and additional indicators would be required to test this hypothesis.

Gender effects still existed in most productivity and entertainment software. In both Canada and Australia, boys tended to use computers more frequently for activities relating to entertainment, while girls tended to use computers more frequently for activities relating to productivity. For example, two specific activities where boys still dominated in usage were downloading software and playing games, while two specific activities where girls dominated were writing documents and email or chat rooms (see Appendix B). These results agree with previous studies that point out that boys traditionally use the computer for entertainment purposes (whose stimulating nature can entice users to spend more time). For example, Lupart and Cannon (2002) found that 
boys spent more time surfing the Internet and playing games, while girls spent more time writing emails and completing assignments.

\section{Confidence with ICT}

Although there were differences in ICT software use between students in Canada and Australia, there were more similarities with respect to confidence with ICT. The confidence with basic ICT tasks, of which most were Web-based (e.g., 'search Internet', 'emails'), was quite similar between the two countries, and since these tasks require less technical skill, this decreased technical skill might have resulted in students being more confident with these basic tasks. Generally, students in both countries were less confident with productivity applications (i.e., applications from the advanced ICT tasks construct) than with basic tasks.

Therefore, a relationship may exist between the learning difficulty or required competence of a software program and student confidence with the software. From previous studies, students who had access to a computer at home were more confident in performing tasks (e.g., Ainley, Enger, \& Searle, 2008). Increased access to ICT in less restrictive environments may allow students to learn technical skills on their own (rather than being shown how to do it) and, as a result, become more confident with more complex ICT tasks.

Gender differences existed in the measures of confidence with ICT. Boys were more confident than girls in both basic and advanced tasks, a finding that remained constant from PISA 2003 (OECD, 2005; Thomson \& De Bortoli, 2007). Differences may be attributed to personal initiatives to become proficient with ICT (e.g., Ilomäki \& 
Rantanen, 2007). Similarly, Lowe, Krahn, and Sosteric (2003) found that gender differences existed with regards to use of ICT for technical applications: boys were more likely than girls to use ICT at school and at home for activities such as databases, spreadsheets, graphics, desktop publishing, and computer programming. To become more confident with ICT, especially for technical purposes, students would need to devote more time to using ICT.

To what extent are differences in scientific literacy predicted by student-level and schoollevel characteristics in Canada and Australia?

This section discusses results in the context of the relative effects model (i.e., effects on scientific literacy), and is organized according to student-level and school-level variables. Within each section, discussions focus on variables that were not direct measures of ICT (e.g., demographic characteristics), followed by variables related to ICT. Student Characteristics

Demographics. Of the three student demographic characteristics included in this study, student ESCS and immigrant status had large effects on scientific literacy. According to the multilevel model, non-immigrants and those students with high ESCS performed best. Gender, however, was not a statistically significant predictor, which suggests that previous gaps in science achievement may have closed. Reiterating Bussière, Knighton, and Pennock’s (2007) findings with the same dataset, no significant differences existed between boys and girls with respect to achievement in scientific 
literacy in Canada. The findings, therefore, are a sign that education programs in Canada are providing science education to both genders equally well.

Students' ESCS, a measure of family background and wealth, was positively associated with scientific literacy, as in previous studies (e.g., Ram, in Anderson, Milford, \& Ross, 2009). The ownership and use of a personal computer is a measure of a student's cultural possessions and home educational resources, which may be viewed as essential by parents with higher levels of education and income, since computers may give their children an educational and economic advantage (Lowe et al., 2003). Based on a multiple regression analysis, Lytton and Pyryt (1998) found that between 39\% and 45\% of the variation in elementary students' academic achievement could be attributed to socioeconomic status (e.g., family income and disadvantage index), values well above other measures such as student-body and school factors, which ranged from 5-12\% and 3$6 \%$, respectively. Moreover, in previous research, parental education level has had a larger effect on achievement than other student-level variables; mothers with less than a high school degree increased the chances that children would have a disadvantaged home life and lower academic achievement (Baker \& LeTendre, 2005; Pelgrum \& Plomp, 2002).

Immigrant status was a significant predictor, where non-immigrants performed better than immigrants (first- and second-generation). Although these identifiers were aggregated in this thesis as immigrant or non-immigrant, Bussière et al. (2007) also reported that non-immigrant students outperformed second-generation immigrant students, despite the latter having been born and having received all of their education in 
Canada. The authors reasoned that more similarities existed between second- and firstgeneration immigrants than between non-immigrants and second-generation immigrants. The findings in this thesis for Canada and Australia, however, contrast with Hsu (cited in Anderson et al., 2009), who found that in Canada, first-generation students (i.e., students born in Canada to immigrant parents) outperformed both non-immigrants and secondgeneration immigrants in mathematics literacy (PISA 2003). Additionally, OECD (2006b) found little difference between performance of immigrant and non-immigrant students in Canada and Australia. One possible explanation for this divergence is that different domains were being measured (mathematics or reading literacy) in previous PISA studies. A future study using PISA 2015 data (the next round with scientific literacy as the major cognitive domain) would shed more light on this hypothesis.

Computing experience. The findings also suggest that students with more computing experience in Canada and Australia achieved higher scientific literacy scores (i.e., the longer students reported having used ICT, the better they performed in science), although the predictor may be confounded with other social context variables, such as student ESCS or school ICT availability (see Fuchs \& Woessmann, 2004). For example, Lowe et al. (2003) found that students from more economically-advantaged families were more likely to have used a computer in the 12 months preceding their study, and more often at home. Although students who were raised in environments with higher levels of ESCS may have been using computers at an earlier age (e.g., the students' parents purchased a computer for their use at home), the effect of prior experience with computers remains statistically significant even after controlling for ESCS in the overall 
model. Therefore, as ICT usage in Canada and Australia continues to increase over time, future research that considers the inevitable ceiling effect of computer access shall ultimately determine the value of this predictor to science achievement.

\section{ICT-related Student Variables}

ICT access. In both Canada and Australia, frequent access to ICT at home may be beneficial to scientific literacy (i.e., at least a few times per week), a finding that aligns with previous research (e.g., Fuchs \& Woessmann, 2004; Ravitz, Mergendoller, \& Rush, 2002). Specifically, Fuchs and Woessmann found that use at home was associated with significantly higher scores in mathematics and reading if the computer was equipped with an Internet connection (and thus used for Web-based activities). In contrast, Wittwer and Senkbeil (2008) found that frequency of home use was not related to mathematical competence; however, the authors argued that their finding was based on a model including additional determinants of school performance, for which other studies (e.g., OECD, 2005) did not account, such as factors that usually covary with students' computer use (see Jackson et al., 2006). Therefore, the types of activities performed with ICT might be more important in explaining the variation in scientific literacy than access to ICT itself.

While frequent access of ICT at school in Australia also had beneficial effects on scientific literacy, access from school was not statistically significant in Canada. Through profiling analysis, different patterns emerged; the relationship between access to ICT at school to scientific literacy was curvilinear in Canada, while in Australia it was linear. One possible interpretation is the different programs of study between countries and the 
extent of ICT integration (e.g., MCEETYA, 1999). Since students in Australia might have used ICT more often at school, they might have been able to take advantage of science learning materials available on computers, such as educational software or Web sites. In Canada, ICT-related activities might not be focusing on learning objectives measured by scientific literacy. However, the overall score in scientific literacy for Australia was lower; future exploration may be needed to examine other influencing factors.

Both countries showed significant differences between students who never used ICT at school and those who did. Therefore, even infrequent use of ICT at school may benefit students' learning. Fuchs and Woessmann (2004), who reached the same conclusion, suggested that the curvilinear relationship may be due to a true causal effect of computer use, where some computerized instruction would be beneficial for student learning, thus constituting a valuable input in the students' learning process; however, at higher intensities of computer use at school, the negative effects of computer and Internet use set in, by crowding out more effective methods of teaching and learning.

Finally, profiling revealed that students who rarely used ICT at other places scored highest in scientific literacy. Students who have a computer at home may not need to rely on access from schools or other places (see Wittwer \& Senkbeil, 2008), but the ambiguity of "other places" does not distinguish between places that have an educational purpose (e.g., libraries) and those that do not (e.g., coffee shops). One explanation for these results is that students who rarely use ICT at other places are students who visit 
libraries to do research, but students who do not have access to ICT at home use it for all types of activities, academic and non-academic.

Use of ICT. In Canada and Australia, both productivity and entertainment software use were negatively associated with scientific literacy, and increased Internet browsing was positively associated. This finding was somewhat unexpected because ICT-integrated curricula generally identify productivity software as a component of students' preparation for the workforce (and thus should be beneficial), while entertainment software is generally used for leisure purposes. However, others have suggested (e.g., Papanastasiou, Zembylas, \& Vrasidas, 2005; Pelgrum \& Plomp, 2002), excessive use of ICT may not improve (and may actually stifle) achievement. Therefore, the findings provide support for previous research that attempted to link science achievement to regular use of ICT.

Analyses were conducted to determine if similar patterns existed with respect to software usage. Unsurprisingly, excessive entertainment use resulted in the lowest scores, perhaps as a result of inadequate time spent for test preparation (i.e., crowding of offline studying and productive time using ICT)

One possible interpretation for the lower scores with increased use of productivity software is the inability to distinguish whether or not the software was used for educational purposes. For example, Fuchs and Woessmann (2004) found that students who had educational software to use at home performed significantly better in mathematics. However, in their study, they did not consider productivity and entertainment software that were not related to Internet activities. One can only conclude 
from the multilevel linear model and ICT profiling analysis that students who used productivity software frequently (i.e., more often than once a week) scored lower in scientific literacy than those who used it at a lower frequency without regards to the type of software.

A similar conclusion can be made about browsing on the Internet, namely, that the types of Web pages viewed cannot be determined, only that frequent browsing is positively associated with scientific literacy. The results support the findings of Jackson et al. (2006), who found that students earned higher grades on standardized achievement tests with increased long-term Internet use. Profiling for this category revealed that students who browsed the Internet at a moderate-to-frequent level scored highest in scientific literacy. Fuchs and Woessmann (2004) found that, while student performance improved with Internet use at home, the relationship was curvilinear with the extent of Internet use at school. In conjunction with their findings, there may be an optimal level of Internet use that peaks near the 'moderate' level.

Confidence with ICT. Students who reported higher confidence with basic ICT tasks had significantly higher levels of scientific literacy in both countries. (Examples of such tasks include chat and email; copying and downloading files; and word processing.) Even when other student-level demographic characteristics were accounted for in the relative model, a strong relationship still existed. High confidence with basic tasks may signify that acquiring these skills may provide pedagogical benefits. When the data were categorized by increasing levels of confidence, scientific literacy improved significantly 
between levels. These activities, which have widespread applicability to daily life, may therefore not only benefit scientific literacy, but extend to other areas as well.

In contrast, confidence with advanced ICT tasks was not statistically significant in the relative effects model for Australia. In Canada, there was a small negative effect for students who reported higher confidence with advanced tasks. (Examples of advanced ICT tasks include the use of databases, spreadsheets, and anti-virus software.) One possible explanation why confidence with basic ICT tasks was a better predictor in the models (than advanced ICT tasks) is the increased variability in this measure. For instance, a student who is highly confident performing advanced ICT tasks is likely to also be highly confident at basic ICT tasks, but the converse is not necessarily true. Ravitz et al. (2002) found a positive relationship between computer proficiency in a variety of tasks (at home and at school) and achievement, which support the findings of this thesis, although the authors did not distinguish between general and specialized ICT tasks. Categorized by level of confidence, the majority of students with medium-to-high levels of confidence with advanced tasks scored highest.

Wittwer and Senkbeil (2008) found that there were differences in achievement if high-confidence ICT users (which they termed smart users) acquired the skills on their own, since they were engaged in problem-solving activities, as opposed to those who acquired skills with the help of others. Although their hypothesis cannot be examined in the current study, since such profile data were not collected in PISA 2006, it highlights the need to consider the implications of increased confidence with advanced tasks on achievement. 
Lastly, increased confidence using presentation software had a positive effect on science achievement in both the multilevel analyses and profiles of confidence with ICT, thus lending support to Siegle and Foster's (2001) findings, where students who completed learning activities specifically using presentation software scored higher on the achievement tests. However, this finding supposes, once again, that frequent use leads to increased self-confidence. Presentation software has been valued as an essential learning tool with cognitive benefits, since it can organize information into concept maps. Concept mapping requires identifying important concepts, arranging those concepts spatially, identifying relationships among those concepts, and labelling the nature of the relationships among those concepts (Jonassen, Howland, Marra, \& Crismond, 2008).

In summary, the findings from the multilevel analysis largely corroborate those from the ICT profiling analysis. However, since ICT can be used for a variety of purposes, and questionnaire items did not ask students how frequently they used ICT to learn science, the findings are limited to identifying significant predictors of scientific literacy.

\section{School-level Factors}

In the relative effects multilevel linear model, all effects within a level are adjusted for each other. In both Canada and Australia, while the majority of the variance in scientific literacy was at the student level (rather than at the school level), the multilevel linear models were able to explain more of the school-level variance. This subsection describes the school-level factors that were statistically significant in the overall model for each country. 
General school characteristics. The background variable models provided some indication of the variance in scientific literacy explained by school characteristics. In Canada, $45 \%$ of the between-school variance was attributed to these variables alone, while in Australia, it was $57 \%$. Since a large portion of between-school variance was explained by these background variables at the student and school levels, the findings indicate that, within each country, schools were mainly attended by groups of students with similar socio-economic backgrounds, and the SES of the schools that students attended was predictive of their performance (Anderson, Lin, Treagust, Ross, \& Yore, 2007).

School mean ESCS had a significant effect on science achievement in both countries, which suggests that existing inequalities between schools cannot be disregarded. As noted by Corbett and Willms (2002), school mean ESCS had effects over and above student ESCS, as evidenced in the current study. For example, in Canada, the school mean ESCS was the only outstanding school-level predictor of science achievement. (Other school characteristics, such as the school location and school size, had very little effect on science achievement in the relative effects model and were dropped from the model.) Therefore, physical external factors do not matter as much as the relative affluence of the neighbourhood in which the school is located.

ICT school characteristics. Differences in school ICT resources may be shaped by school characteristics. For example, Ravitz et al. (2002) found that the relationship between school size and investments in technological infrastructure was not direct, with urban and rural students both disadvantaged compared to suburban students. One possible 
explanation is that larger schools tend to be better funded than smaller schools (perhaps due to funding allocations made on a per-student basis), and thus are able to provide more resources to students. Anderson et al. (2007) state that, "schools with a more advantageous intake often have better educational resources" (p. 609).

In Canada, none of the predictors relating to availability of computer resources (e.g., proportion of computers available for student use, proportion of computers connected to the Internet) had significant effects on scientific literacy in the relative effects model. Since the school-level measures of ICT are based on ratios rather than absolute numbers, the findings suggest that little variability exists between Canadian schools, regardless of school size or location. Special government initiatives for rural communities to improve broadband connectivity may have helped in providing access to rural areas or areas with lower SES. For example, there are more Internet-connected workstations per student capita in rural areas than in urban areas in Saskatchewan (Wallin et al., 2009).

While increased connectivity did not appear to have any significant effects on scientific literacy in Canada, it did in Australia. The proportion of computers connected to the Internet had a negative relationship to scientific literacy in Australia. Although this finding was contradictory to the student-level predictor on Internet browsing, similar results have been reported by Fuchs and Woessmann (2004), who found that the measure of Internet connectivity on school computers (i.e., availability) had negligible effects on mathematics achievement. 
One explanation for this finding may be the dependence on the type of ICT activities prescribed by the teacher. After all, an Internet-connected computer has the capacity to perform all activities that a non-connected computer can, in addition to Webbased tasks. Therefore, an increased ratio of computers connected to the Internet should benefit students, as students would be able to browse the Internet at school more frequently. However, the mere availability of Internet-connected computers may not have a positive link to scientific literacy if their primary use was not for Internet-related activities. Furthermore, the Internet platform has evolved to a degree that browsing is not the only activity in existence. Social networking, video conferencing through a webcam, playing a multiplayer game, or posting comments on an electronic message board are now part of the Internet experience. Measuring students' time spent on Internet-based activities while at school (as a proportion of total ICT use) may clarify the effects of Internet connectivity at school.

The relative non-significance of school ICT resources in these models may suggest that their values as predictors of achievement may be decreasing (e.g., McFarlane $\&$ Sakellariou, 2002). Furthermore, when the effect sizes from the analyses of ICT access and use were calculated, differences between gender and countries were found to be small (based on guidelines from Cohen, 1988), despite being statistically significant. To conclude, Lowe et al. (2003) state that we "may have reached the point where school computers have become so ubiquitous that their ability to reproduce inequalities or to reduce them is minimal. Thus the family context becomes the determining factor in how useful computers will be in a student's future educational or work career" (p. 152). 
Implications for Future Research

In this section, three limitations associated with this analysis are discussed as a lens through which to situate implications for future research. The first limitation revolves around the difficulty of identifying the causes for the results obtained. The second limitation concerns the lack of classroom-level data. The third limitation relates to the incongruence of data collected from the ICT familiarity questionnaire, with consequent suggestions to improve the quality of the data.

As with other secondary data analyses, one limitation of this study is the crosssectional nature of PISA (i.e., all variables are measured and collected at one point in time). This arrangement does not make it possible to determine cause-and-effect relationships (e.g., by measuring students' prior ability). As such, any association between computer access, use, and confidence with science achievement cannot be taken as evidence of the impact of computers on learning. For example, it is possible that factors related to ICT may influence scientific literacy indirectly through another variable that correlates strongly with achievement (e.g., student interest in science). Therefore, an experimental study that considers the effects of student interest when learning with ICT would strengthen this relationship.

Second, since students were randomly sampled within schools, it is not possible to conduct analyses of specific variables at the classroom level; therefore, analyses of the data were limited to school-level and country-level comparisons (see Anderson et al., 2007). As a result, classroom-level characteristics that could contribute to variability in science achievement, such as different teaching strategies and activities during class, 
cannot be determined from this analysis alone. Instead, the variation in the outcome measures can only be attributed to the student level and the school level. As a result, future research should aggregate data to allow for analysis at the classroom level in addition to the school and country levels.

Finally, exploration of the effects of ICT use and confidence were limited in this thesis because the two items from the PISA 2006 ICT familiarity questionnaire central to this thesis (frequency of use and confidence with ICT tasks) had incongruent subitems. To address issues with the quality of the data, three changes are suggested:

1. align the use and confidence measures to identical subitems, which would allow more direct correlations between the two measures and permit more direct comparisons on specific uses of ICT;

2. ask students how much time they spend during a computer session (see Lupart \& Cannon, 2002); this measure may be just as relevant as how many times they have used a computer over a fixed period of time; and

3. measure confidence by the ability to generate end products with ICT, rather than measuring confidence with a specific type of software (e.g., how confident a student can use ICT to write an essay or letter, as opposed to how confident they are using word processing software). This modification would not only direct the focus towards learning with ICT, as opposed to learning about ICT (Jonassen et al., 2008), but would be more representative of the range of competencies that PISA attempts to measure (Anderson et al., 2009). 


\section{Implications for Practice}

This section describes three possible implications for practice from the findings that may help to improve scientific literacy scores. First, teachers should be encouraged to make use of Internet resources, particularly with students from low SES or immigrant backgrounds. Second, while teachers need to include the use of ICT in lesson planning, it should be used at a level that is not excessive. Finally, if ICT is to be an integrated part of learning, teachers require additional professional development so that it is relevant in every course.

First, since there appears to be a relationship between Internet use and higher achievement, teachers need to plan lessons that involve students in Web-based activities more frequently. Such lessons may prove especially advantageous to students with lower SES or immigrant students. Levin and Arafeh (2002) found that students' enthusiasm of Internet use for schoolwork was not sufficiently exploited by teachers. Students stated that educators and administrators - who establish the tone for Internet use in schoolshave not responded to the new ways students use the Web to communicate and access information, and argued that the quality of access (e.g., limited use to certain times of the day, or certain places in the building) limit their use. Furthermore, students in Levin and Arafeh's study said that more engaging Internet activities (relevant to their lives) would increase their attitude towards school and learning.

Approaches to instructional designs need to consider the integration of ICT. The traditional focus of study, consisting of curriculum, teaching, and learning, has been modified by the presence of ICT, which increases the complexity of these processes since 
it mediates instruction, provides direct communication, and supports collaboration and direct authorship (Reynard, 2009). Therefore, outcome measures should reflect processbased instructional design rather than content-driven design. However, use of ICT in schools for general purposes should be done in moderation, to ensure students experience a range of teaching and learning methods (e.g., Fuchs \& Woessmann, 2004).

Finally, teachers need to be familiar with ICT to integrate it successfully into the classroom (Papanastasiou et al., 2005). Reynard (2009) suggested that teachers need to be better equipped to use technology to ensure students have a more consistent experience across classes. To address gender differences in access and use, teachers need to view ICT as a tool that can be used in more disciplines, rather than a discrete, specialized subject. Only then can the true impact of ICT on student learning outcomes emerge. In conclusion, the findings from this thesis suggest that students' use of ICT at a low-to-moderate level can be beneficial to scientific literacy, particularly if the activities are relevant to students who scored lower in scientific literacy, such as immigrant students and students from disadvantaged backgrounds. However, one factor that is just as important is the computer skills possessed by teachers, since a strong set of skills may be conducive to meaningful integration of ICT into daily lessons. It is posited that teachers' computer skills, in combination with the proper thinking fostered by computer applications, would optimize student achievement. 


\section{REFERENCES}

Ainley, J., Enger, L., \& Searle, D. (2008). Students in a digital age: Implications of ICT for teaching and learning. In J. Voogt, \& G. Knezek (Eds.), International handbook of information technology in primary and secondary education (pp. 6380). New York: Springer.

American Association for the Advancement of Science [AAAS]. (1998). Blueprints for reform: Project 2061. New York: Oxford University Press.

Anderson, J. O., Lin, H.-S., Treagust, D. F., Ross, S. P., \& Yore, L. D. (2007). Using large-scale assessment datasets for research in science and mathematics education: Programme for International Student Assessment (PISA). International Journal of Science and Mathematics Education, 5, 591-614.

Anderson, J. O, Milford, T., \& Ross, S. P. (2009). Multilevel modeling with HLM: Taking a second look at PISA. In M. C. Shelley II, L. D. Yore, \& B. Hand (Eds.), Quality research in literacy and science education (p. 263-286). New York: Springer.

Attewell, P. (2001). The first and second digital divides. Sociology of Education, 74, 252259.

Australian Bureau of Statistics. (2008). Household use of information technology, Australia, 2007-08. Retrieved March 9, 2009, from http://www.abs.gov.au/Ausstats/abs@.nsf/mf/8146.0

Baker, D. P., \& LeTendre, G. K. (2005). National differences, global similarities: World culture and the future of schooling. Stanford, CA: Stanford University Press. 
Batterham, R. (2000). The chance to change: Final report by the chief scientist. Canberra, ACT, Australia: Commonwealth of Australia.

Becker, H. J. (2000). Who's wired and who's not: Children's access to and use of computer technology. The Future of Children, 10, 44-75.

Bussière, P., Knighton, T., \& Pennock, D. (2007). The performance of Canada's youth in science, reading and mathematics: 2006 first results for Canadians aged 15 (Catalogue No. 81-590-XIE). Ottawa, Ontario, Canada: Statistics Canada.

Bybee, R. W., \& Fuchs, B. (2006). Preparing the 21st century workforce: A new reform in science and technology education. Journal of Research in Science Teaching, $43,349-352$.

Canadian Council on Learning. (2009). State of e-learning in Canada. Ottawa, Ontario, Canada: Author.

Cohen, J. (1988). Statistical power analysis for the behavioral sciences (3rd ed.). New York: Academic Press.

Corbett, B. A., \& Willms, J. D. (2002). Information and communication technology: Access and use. Education Quarterly Review, 8(4), 8-15.

Council of Ministers of Education, Canada [CMEC]. (1997). Common framework of science learning outcomes, $K$ to 12 . Toronto, Ontario, Canada: Author.

Council of Ministers of Education, Canada [CMEC]. (2008). Education in Canada. Toronto, Ontario, Canada: Author.

de Leew, J., \& Meijer, E. (2008). Introduction to multilevel analysis. In J. de Leew \& E. Meijer (Eds.), Handbook of multilevel analysis (pp. 1-75). New York: Springer. 
Dobson, T. M., \& Willinsky, J. (2009). Digital literacy. In D. R. Olson \& N. Torrence (Eds.), The Cambridge handbook of literacy (pp. 286-312). New York: Cambridge University Press.

Fabrigar, L. R., Wegener, D. T., MacCallum, R. C., \& Strahan, E. J. (1999). Evaluating the use of exploratory factor analysis in psychological research. Psychological Methods, 4, 272-299.

Fensham, P. J. (1992). Science and technology. In P.W. Jackson (Ed.), Handbook of research on curriculum (pp. 789-829). New York: Macmillan.

Fuchs, T., \& Woessmann, L. (2004). Computers \& student learning: Bivariate and multivariate evidence on the availability and use of computers at home and at school (CESifo Working Paper 1321). Munich, Germany: CESifo.

Glass, G. V., \& Hopkins, K. D. (1996). Statistical methods in education and psychology (3rd ed.). Boston: Allyn \& Bacon.

Gobert, J. D. (2005). Leveraging technology and cognitive theory on visualization to promote students' science. In J. K. Gilbert (Ed.), Visualization in science education (pp. 73-90). Dordrecht, the Netherlands: Springer.

Government of Canada. (2002). Knowledge matters - Skills and learning for Canadians. Hull, Québec, Canada: Human Resources Development Canada.

Guo, S. (2005). Analyzing grouped data with hierarchical linear modelling. Children and Youth Services Review, 27, 637-652.

Heck, R. H., \& Thomas, S. L. (1999). An introduction to multilevel modeling techniques. Mahwah, NJ: Lawrence Erlbaum Associates. 
Ilomäki, L., \& Rantanen, P. (2007). Intensive use of ICT in school: Developing differences in students' ICT expertise. Computers and Education, 48, 119-136.

Jackson, L. A., von Eye, A., Biocca, F. A., Barbatsis, G., Zaho, Y., \& Fitzgerald, H. E. (2006). Does home Internet use influence the academic performance of lowincome children? Developmental Psychology, 42, 1-7.

Jonassen, D., Howland, J., Marra, R. M., \& Crismond, D. (2008). Meaningful learning with technology (3rd ed.). Upper Saddle River, NJ: Pearson Prentice Hall.

Kay, R. (2008). Exploring gender differences in computer-related behaviour: Past, present and future. In T. Kidd \& I. L. Chen (Eds.), Social information technology: Connecting society and cultural issues (pp. 12-30). Hershey, PA: Information Science Reference.

Knox, K., \& Schmidt, B. (2006, November). A wake-up call on science literacy: Canada's future depends on it. Policy Options, 27(9), 74-77.

Kulik, J. A. (1994). Meta-analytic studies of findings on computer-based instruction. Technology assessment in education and training. Hillsdale, NJ: Erlbaum.

Lee, V. E. (2000). Using hierarchical linear modeling to study social contexts: The case of school effects. Educational Psychologist, 35, 125-141.

Levin, D., \& Arafeh, S. (2002). The digital disconnect: The widening gap between Internet-savvy students and their schools. Washington, DC: Pew Internet \& American Life Project.

Levine, T. (1994). A computer-based program can make a difference: The case of the rediscover science program. Studies in Educational Evaluation, 20, 283-296. 
Linn, M. C. (2003). Technology and science education: Starting points, research programs, and trends. International Journal of Science Education, 25, 727-758.

Llewellyn, D. (2005). Teaching high school science through inquiry. Thousand Oaks, CA: Corwin Press.

Looker, E. D., \& Thiessen, V. (2003). The digital divide in Canadian schools: Factors affecting student access to and use of information technology (Catalogue No. 81597-XIE). Ottawa, Ontario, Canada: Statistics Canada.

Lowe, G. S., Krahn, H., \& Sosteric, M. (2003). Influence of socioeconomic status and gender on high school seniors' use of computers at home and at school. Alberta Journal of Educational Research, 49, 138-54.

Lupart, J., \& Cannon, E. (2002). Computers and career choices: Gender differences in Grades 7 and 10 students. Gender, Technology and Development, 6, 233-248.

Lytton, H., \& Pyryt, M. (1998). Predictors of achievement in basic skills: A Canadian effective schools study. Canadian Journal of Education, 23, 281-301.

Ma, X., \& Klinger, D. A. (2000). Hierarchical linear modelling of student and school effects on academic achievement. Canadian Journal of Education, 25, 41-55.

Mappin, D. (1995). Canada's SchoolNet initiative. Educational Technology Research and Development, 43, 94-95.

McFarlane, A., \& Sakellariou, S. (2002). The role of ICT in science education. Cambridge Journal of Education, 32, 219-232.

Ministerial Council on Education, Employment, Training and Youth Affairs [MCEETYA]. (1999). Adelaide declaration on national goals for schooling in the 
twenty-first century [Electronic version]. Carlton South, Victoria, Australia: Author. Available from http://www.mceetya.edu.au/mceetya/ Ministerial Council on Education, Employment, Training and Youth Affairs [MCEETYA]. (2008). Melbourne declaration on the educational goals for young Australians [Electronic version]. Carlton South, Victoria, Australia: Author. Available from http://www.mceetya.edu.au/mceetya/

Mullis, I. V. S., Martin, M. O., Gonzalez, E. J., \& Chrostowski, S. J. (2004). TIMSS 2003 international mathematics report: Findings from IEA's Trends in International Mathematics and Science Study at the fourth and eighth grades. Chestnut Hill, MA: Boston College, TIMSS \& PIRLS International Study Center.

Norris, S. P., \& Phillips, L. M. (2009). Scientific literacy. In D. R. Olson \& N. Torrence (Eds.), The Cambridge handbook of literacy (pp. 271-285). New York: Cambridge University Press.

Organisation for Economic Cooperation and Development [OECD]. (2001). Learning to change: ICT in schools. Paris: OECD Publications.

Organisation for Economic Cooperation and Development [OECD]. (2005). Are students ready for a technology-rich world? What PISA studies tell us. Paris: OECD Publications.

Organisation for Economic Cooperation and Development [OECD]. (2006a). Assessing scientific, reading and mathematical literacy: A framework for PISA 2006. Paris: OECD Publications. 
Organisation for Economic Cooperation and Development [OECD]. (2006b). Where immigrant students succeed - A comparative review of performance and engagement in PISA 2003. Paris: Author.

Organisation for Economic Cooperation and Development [OECD]. (2007a). PISA 2006 [Data file]. Paris: Author. Available from http://www.pisa.oecd.org Organisation for Economic Cooperation and Development [OECD]. (2007b). PISA 2006: Science competencies for tomorrow's world, Vol. 1: Analysis. Paris: OECD Publications.

Organisation for Economic Cooperation and Development [OECD]. (2009). PISA 2006 technical report [Electronic version]. Paris: OECD Publications. Available from http://www.pisa.oecd.org

Osborne, J., \& Hennessy, S. (2003). Literature review in science education and the role of ICT: Promise, problems and future directions [Electronic version]. Bristol, UK: Futurelab. Available from http://www.futurelab.org.uk

Osborne, J., Simon, S., \& Collins, S. (2003). Attitudes toward science: A review of the literature and its implications. International Journal of Science Education, 25, 1049-1079.

O’Sullivan, B. (1999). Global change and educational reform in Ontario and Canada. Canadian Journal of Education, 24, 311-325.

Papanastasiou, E. C., Zembylas, M., \& Vrasidas, C. (2005). An examination of the PISA database to explore the relationship between computer use and science achievement. Educational Research and Evaluation, 11, 529-543. 
Pelgrum, W. J. (2001). Obstacles to the integration of ICT in education: Results from a worldwide educational assessment. Computers and Education, 37, 163-178.

Pelgrum, W. J., \& Plomp, T. (2002). Indicators of ICT in mathematics: Status and covariation with achievement measures. In D. F. Robitaille and A. E. Beaton (Eds.), Secondary analysis of the TIMSS data (pp. 317-330). Dordrecht, the Netherlands: Kluwer Academic Publishers.

Pelgrum, W. J., \& Plomp, T. J. (Eds.). (1993). The IEA study of computers in education: Implementation of an innovation in 21 education systems. Oxford, UK: Pergamon Press.

Plante, J., \& Beattie, D. (2004). Connectivity and ICT integration in Canadian elementary and secondary schools: First results from the Information and Communications Technologies in Schools Survey, 2003-2004 (Catalogue No. 81595-MIE2004017). Ottawa, Ontario, Canada: Statistics Canada.

Ramirez, F. O., Luo, X., Schofer, E., \& Meyer, J. W. (2006). Student achievement and national economic growth. American Journal of Education, 113, 1-29.

Raudenbush, S. W., \& Bryk, A. S. (2002). Hierarchical linear models: Applications and data analysis methods (2nd ed.). Newbury Park, CA: Sage.

Raudenbush, S. W., Bryk, A. S., Cheong, Y. F., \& Congdon, R. (2004). HLM 6: Hierarchical Linear and Nonlinear Modeling (Version 6.0) [Computer software]. Lincolnwood, IL: Scientific Software International.

Raudenbush, S. W., Cheong, Y. F., \& Fotiu, R. P. (1995). Synthesizing cross-national classroom effects data: alternative models and methods. In M. Binkley, K. Rust, \& M. Winglee (Eds.), Methodological issues in comparative educational studies: 
The case of the IEA reading literacy study (pp. 243-286). Washington, DC: U.S. Department of Education, National Center for Education Statistics.

Ravitz, J., Mergendoller, J., \& Rush, W. (2002, April). Cautionary tales about correlations between student computer use and academic achievement. Paper presented at the annual meeting of the American Educational Research Association, New Orleans, LA.

Reynard, R. (2009, May). Technology's impact on learning outcomes: Can it be measured? [Electronic version]. Technologic Horizons in Education. Retrieved May 15, 2009, from http://www.thejournal.com/articles/24383

Reynolds, D., Treharne, D., \& Tripp, H. (2003). ICT—-the hopes and reality. British Journal of Educational Technology, 34, 151-167.

Siegle, D., \& Foster, T. (2001). Laptop computers and multimedia and presentation software: Their effects on student achievement in anatomy and physiology. Journal of Research on Technology in Education, 34, 29-37.

Smith, D. V., \& Gunstone, R. F. (2009). Science curriculum in the market liberal society of the twenty-first century: 'Re-visioning' the idea of Science for All. Research in Science Education, 39, 1-16.

Tabachnick, B. G., \& Fidell, L. S. (2007). Using multivariate statistics (5th ed.). New York: Allyn \& Bacon.

Thomson, S., \& De Bortoli, L. (2007). PISA 2003 Australia: ICT use and familiarity at school and home (ACER Monograph 62) [Electronic version]. Camberwell, Victoria, Australia: Australian Council for Educational Research. Available from http://www.acer.edu.au/ozpisa/ 
Thomson, S., \& De Bortoli, L. (2008). Exploring scientific literacy: How Australia measures up: the PISA 2006 survey of students' scientific, reading and mathematical literacy skills [Electronic version]. Camberwell, Victoria, Australia: ACER Press. Available from http://www.acer.edu.au/ozpisa/

Tytler, R. (2007). Re-imagining science education: Engaging students in science for Australia. Camberwell, Victoria, Australia: ACER Press.

Volman, M., van Eck, E., Heemskerk, I., \& Kuiper, E. (2005). New technologies, new differences. Gender and ethnic differences in pupils' use of ICT in primary and secondary education. Computers and Education, 45, 35-55.

Wallin, D. C., Anderson, H., \& Penner, C. (2009). Rural education: A review of provincial and territorial initiatives [Electronic version]. Winnipeg, Manitoba, Canada: Manitoba Education, Citizenship and Youth. Available from http://www.edu.gov.mb.ca/k12/docs/reports/rural_ed/

Willis, S., \& Tranter, B. (2006). Beyond the 'digital divide': Internet diffusion and inequality in Australia. Journal of Sociology, 42, 43-59.

Wittwer, J., \& Senkbeil, M. (2008). Is students' computer use at home related to their mathematical performance at school? Computers and Education, 50, 1558-1571.

World Bank. (2008). World development indicators database. Retrieved July 31, 2008, from http://siteresources.worldbank.org/DATASTATISTICS/Resources/GNIPC.pdf. $\mathrm{Wu}, \mathrm{M}$. (2005). The role of plausible values in large-scale surveys. Studies in Educational Evaluation, 31, 114-128. 


\section{APPENDIX A \\ VARIABLES USED IN MULTILEVEL LINEAR MODELING}

A summary of student-level and school-level variables used in the analyses is presented in Tables A1 and A2. They originated from the PISA 2006 student questionnaire and ICT familiarity component questionnaire, and represent a variety of ICT-related measures based on prior student experiences with computers, student performance on the PISA, and school data associated with computer resources. Please refer to OECD (2009) for more details on these measures. The student demographic characteristics (gender, socioeconomic status, and immigrant status) were included into the models as controlled predictors; the descriptive statistics for these variables are presented in Table A3.

Other items from the school questionnaire relating to ICT (e.g., lack of computer availability, lack of computer software, lack of access to the Internet) were excluded from these analyses because these responses were predictive judgments made by school officials, and were not based on the actual availability of school resources when the data were collected. 
Table A1.

Student ICT characteristics (level-1 explanatory variables) used in the multilevel linear models

\begin{tabular}{|c|c|c|c|}
\hline Predictors & Description & $\begin{array}{l}\text { Variable(s) used to } \\
\text { form predictor } \\
\text { (PISA variable) }\end{array}$ & Coding/comment \\
\hline $\begin{array}{l}\text { SCIEACH (outcome } \\
\text { variable) }\end{array}$ & $\begin{array}{l}\text { Scientific literacy } \\
\text { (achievement) }\end{array}$ & $\begin{array}{l}\text { PV1SCIE through } \\
\text { PV5SCIE (plausible } \\
\text { values) }\end{array}$ & $\begin{array}{l}\text { OECD-scaled with a } \\
\text { mean of } 500 \text { and a } \\
\text { standard deviation } \\
\text { of } 100\end{array}$ \\
\hline FEMALE $^{1}$ & Sex of student & SC04Q01 & $\begin{array}{l}\text { Dichotomous: } 0= \\
\text { male; } 1=\text { female }\end{array}$ \\
\hline $\mathrm{ESCS}^{1}$ & $\begin{array}{l}\text { Economic, social, } \\
\text { and cultural status } \\
\text { index }\end{array}$ & ESCS & $\begin{array}{l}\text { OECD-scaled index } \\
\text { with a mean of zero } \\
\text { and a standard } \\
\text { deviation of one }\end{array}$ \\
\hline $\mathrm{IMMIG}^{1}$ & $\begin{array}{l}\text { Immigrant status of } \\
\text { student }\end{array}$ & IMMIG & $\begin{array}{l}\text { Recoded; } \\
\text { dichotomous: } 0= \\
\text { non-immigrant; } 1= \\
\text { immigrant }\end{array}$ \\
\hline COMPEXP & $\begin{array}{l}\text { Experience with use } \\
\text { of ICT }\end{array}$ & IC02Q01 & $\begin{array}{l}\text { Standardized; } 1= \\
\text { less than one year; } 2 \\
=\text { one year or more } \\
\text { but less than three } \\
\text { years; } 3=\text { three } \\
\text { years or more but } \\
\text { less than five years; } \\
4=\text { five years or } \\
\text { more }\end{array}$ \\
\hline BROWSNET & $\begin{array}{l}\text { How often student } \\
\text { browsed the Internet }\end{array}$ & IC04Q01 & $\begin{array}{l}\text { Reverse-coded and } \\
\text { standardized }\end{array}$ \\
\hline COLLNET & $\begin{array}{l}\text { How often student } \\
\text { collaborated on the } \\
\text { Internet }\end{array}$ & IC04Q04 & $\begin{array}{l}\text { Reverse-coded and } \\
\text { standardized }\end{array}$ \\
\hline
\end{tabular}




\begin{tabular}{|c|c|c|c|}
\hline ENTFREQ $^{2}$ & $\begin{array}{l}\text { How often student } \\
\text { used ICT software } \\
\text { for entertainment }\end{array}$ & $\begin{array}{l}\text { IC04Q02, IC04Q06, } \\
\text { IC04Q09, IC04Q11 }\end{array}$ & $\begin{array}{l}\text { Each variable was } \\
\text { reverse-coded, then } \\
\text { averaged together } \\
\text { and standardized }\end{array}$ \\
\hline PRODFREQ $^{2}$ & $\begin{array}{l}\text { How often student } \\
\text { used ICT software } \\
\text { for productivity }\end{array}$ & $\begin{array}{l}\text { IC04Q03, IC04Q05, } \\
\text { IC04Q07, IC04Q08, } \\
\text { IC04Q10 }\end{array}$ & $\begin{array}{l}\text { Each variable was } \\
\text { reverse-coded, then } \\
\text { averaged together } \\
\text { and standardized }\end{array}$ \\
\hline PPTCONF & $\begin{array}{l}\text { Student confidence } \\
\text { using presentation } \\
\text { software (e.g., } \\
\text { Microsoft } \\
\text { PowerPoint) }\end{array}$ & IC05Q12 & $\begin{array}{l}\text { Reverse-coded and } \\
\text { standardized }\end{array}$ \\
\hline BASICONF $^{3}$ & $\begin{array}{l}\text { Student confidence } \\
\text { performing basic- } \\
\text { level ICT tasks }\end{array}$ & $\begin{array}{l}\text { IC05Q01, IC05Q05, } \\
\text { IC05Q06, IC05Q07, } \\
\text { IC05Q08, IC05Q09, } \\
\text { IC05Q10, IC05Q13, } \\
\text { IC05Q15 }\end{array}$ & $\begin{array}{l}\text { Each variable was } \\
\text { reverse-coded, then } \\
\text { averaged together } \\
\text { and standardized }\end{array}$ \\
\hline $\mathrm{ADVCONF}^{3}$ & $\begin{array}{l}\text { Student confidence } \\
\text { performing } \\
\text { advanced-level ICT } \\
\text { tasks }\end{array}$ & $\begin{array}{l}\text { IC05Q02, IC05Q03, } \\
\text { IC05Q04, IC05Q11, } \\
\text { IC05Q14, IC05Q16 }\end{array}$ & $\begin{array}{l}\text { Each variable was } \\
\text { reverse-coded, then } \\
\text { averaged together } \\
\text { and standardized }\end{array}$ \\
\hline HOMEUSE & $\begin{array}{l}\text { How frequently } \\
\text { students use a } \\
\text { computer at home }\end{array}$ & IC03Q01 & $\begin{array}{l}\text { Reverse-coded and } \\
\text { standardized; } 1= \\
\text { never; } 2=\text { once a } \\
\text { month or less; } 3=\mathrm{a} \\
\text { few times a month; } \\
4=\text { once or twice a } \\
\text { week; } 5=\text { almost } \\
\text { every day }\end{array}$ \\
\hline SCHUSE & $\begin{array}{l}\text { How frequently } \\
\text { students use a } \\
\text { computer at school }\end{array}$ & IC03Q02 & $\begin{array}{l}\text { Reverse-coded and } \\
\text { standardized; } 1= \\
\text { never; } 2=\text { once a } \\
\text { month or less; } 3=\text { a } \\
\text { few times a month; } \\
4=\text { once or twice a } \\
\text { week; } 5=\text { almost } \\
\text { every day }\end{array}$ \\
\hline
\end{tabular}




\begin{tabular}{lll}
\hline OTHERUSE & $\begin{array}{l}\text { How frequently } \\
\text { students use a } \\
\text { computer at other }\end{array}$ & IC03Q03 \\
places & $\begin{array}{l}\text { Reverse-coded and } \\
\text { standardized; } 1= \\
\text { never; } 2 \text { once a }\end{array}$ \\
& month or less; $3=\mathrm{a}$ \\
& few times a month; \\
& $4=$ once or twice a \\
& week; $5=$ almost \\
& every day \\
\hline
\end{tabular}

${ }^{1}$ used as control variables

${ }^{2}$ usage frequency of ICT activities:

- ICT Internet/entertainment: research (IC04Q01), games (IC04Q02), Internet collaboration (IC04Q04), downloading software from the Internet (IC04Q06), downloading music from the Internet (IC04Q09), online communication (IC04Q11)

- ICT program/software use: word processing (IC04Q03), spreadsheets (IC04Q05), graphics (IC04Q07), educational software (IC04Q08), programming (IC04Q10)

${ }^{3}$ self-confidence with ICT tasks:

- Internet tasks: chat online (IC05Q01), copy data to a CD (IC05Q05), moving files (IC05Q06), searching the Internet (IC05Q07), downloading files from the Internet (IC05Q08), email file attachments (IC05Q09), downloading music from the Internet (IC05Q13), write and send emails (IC05Q15)

- High-level tasks: using antivirus software (IC05Q02), editing photographs (IC05Q03), creating a database (IC05Q04), use a word processor (IC05Q10), use a spreadsheet (IC05Q11), create a presentation (IC05Q12), create a multimedia presentation (IC05Q14), construct a web page (IC05Q16) 
Table A2.

School characteristics (level-2 explanatory variables) used in the multilevel linear models

\begin{tabular}{|c|c|c|c|}
\hline Predictors & Description & $\begin{array}{l}\text { PISA variable(s) } \\
\text { used to form } \\
\text { predictor }\end{array}$ & Coding/comment \\
\hline MEANESCS $^{\top}$ & $\begin{array}{l}\text { mean SES } \\
\text { composition of } \\
\text { school }\end{array}$ & ESCS & $\begin{array}{l}\text { Aggregated data from student } \\
\text { ESCS }\end{array}$ \\
\hline $\mathrm{URBAN}^{1}$ & $\begin{array}{l}\text { community in } \\
\text { which school is } \\
\text { located }\end{array}$ & SC07Q01 & $\begin{array}{l}\text { Coded as } 1=\text { village }[\text { fewer than } \\
3,000 \text { people]; } 2=\text { small town } \\
{[3,000 \text { to } 15,000] ; 3=\text { town }} \\
{[15,000 \text { to } 100,000] ; 4=\text { city }} \\
{[100,000 \text { to } 1,000,000] ; 5=} \\
\text { large city [over } 1,000,000]\end{array}$ \\
\hline SCHLSIZE $^{1}$ & $\begin{array}{l}\text { School size } \\
\text { (enrolment) }\end{array}$ & SCHSIZE & $\begin{array}{l}\text { Standardized; centred on the } \\
\text { sample mean, with each } \\
\text { standard deviation representing } \\
100 \text { students }\end{array}$ \\
\hline COMPWEB & $\begin{array}{l}\text { proportion of } \\
\text { computers } \\
\text { connected to the } \\
\text { Internet }\end{array}$ & COMPWEB & $\begin{array}{l}\text { Standardized with a mean of } 0 \\
\text { and a standard deviation of } 1\end{array}$ \\
\hline RATCOMP & $\begin{array}{l}\text { index of availability } \\
\text { of computers }\end{array}$ & RATCOMP & $\begin{array}{l}\text { Standardized with a mean of } 0 \\
\text { and a standard deviation of } 1\end{array}$ \\
\hline IRATCOMP & $\begin{array}{l}\text { overall ratio of } \\
\text { computers to school } \\
\text { size }\end{array}$ & IRATCOMP & $\begin{array}{l}\text { Standardized with a mean of } 0 \\
\text { and a standard deviation of } 1\end{array}$ \\
\hline
\end{tabular}

\footnotetext{
${ }^{1}$ used as control variables
} 
Table A3.

Mean and standard deviation of student demographic variables from PISA 2006 for students in Canada and Australia

\begin{tabular}{|c|c|c|c|c|c|}
\hline & & \multicolumn{2}{|c|}{ Canada } & \multicolumn{2}{|c|}{ Australia } \\
\hline & & $M$ & $S D$ & $M$ & $S D$ \\
\hline \multicolumn{6}{|c|}{ Student-level variables } \\
\hline Gender $($ female $=1)$ & FEMALE & .51 & .50 & .49 & .50 \\
\hline Socioeconomic status & ESCS & .30 & .81 & .19 & .78 \\
\hline Immigrant status & IMMIG & .12 & .33 & .20 & .40 \\
\hline Computing experience & COMPEXP (scaled) & 3.77 & .58 & 3.79 & .54 \\
\hline \multicolumn{6}{|c|}{ School-level variables } \\
\hline $\begin{array}{l}\text { Population of municipality } \\
\text { in which school is located }\end{array}$ & RURAL (scaled) & 2.84 & 1.30 & 3.66 & 1.24 \\
\hline
\end{tabular}




\section{APPENDIX B \\ DESCRIPTIVE STATISTICS FOR ICT USE AND CONFIDENCE ITEMS}

There are differences in terms of which activities were more frequently used: activities that may be considered entertainment (e.g., playing games, downloading music) were more popular with Canadian students, while productivity applications (e.g., word processing, spreadsheets) were more popular with Australian students (see Table B1). Activities that could be classified under either of these categories (e.g., browse Internet, collaborate on Internet) were relatively similar in both countries. Compared to productivity software, Internet and entertainment software were used more frequently in both countries. The results suggest that the average student in Canada or Australia used email or chat rooms most frequently (i.e., almost every day). In contrast, the least frequently used computer programs were educational software and programming software. 
Table B1.

Proportion of students in Australia and Canada reporting frequent ${ }^{\mathrm{a}}$ use of various ICT tasks

\begin{tabular}{lcc}
\hline Subitem & Canada (\%) & Australia (\%) \\
\hline Browse Internet & 70.7 & 72.1 \\
Play games & 57.6 & 50.1 \\
Write documents & 56.8 & 72.4 \\
Collaborate on Internet & 50.8 & 47.7 \\
Use spreadsheets & 17.0 & 23.0 \\
Download software & 47.2 & 48.0 \\
Graphics programs & 36.3 & 37.0 \\
Educational software & 10.4 & 13.3 \\
Download music & 73.7 & 65.2 \\
Write programs & 15.9 & 12.5 \\
Email or chat rooms & 84.8 & 79.0 \\
\hline
\end{tabular}

Note. $\mathrm{N}=22,121$ for Canada; $\mathrm{N}=14,084$ for Australia.

${ }^{a}$ Frequent use is defined as 'almost every day' or 'a few times each week' (OECD, 2005).

The statistics for confidence using ICT, are presented in Table B2 for Canada and Australia, respectively. Students were quite confident for most tasks (i.e., reported that they can do the listed tasks by themselves), but for tasks where they were reported not being able to do themselves, indicated that they could do it if given help from somebody (as compared to the remaining options, knowing what it is but cannot do it, or not familiar with the task). According to Table B2, students were most confident using a word processor, and least confident using databases. 
Table B2.

Self-confidence of students in Canada and Australia with various ICT tasks

\begin{tabular}{|c|c|c|c|c|}
\hline \multirow[b]{2}{*}{ Subitem } & \multicolumn{2}{|c|}{ Canada } & \multicolumn{2}{|c|}{ Australia } \\
\hline & $\begin{array}{l}\text { Can do it by } \\
\text { myself }(\%)\end{array}$ & $\begin{array}{l}\text { Can do it with } \\
\text { help }(\%)\end{array}$ & $\begin{array}{l}\text { Can do it by } \\
\text { myself (\%) }\end{array}$ & $\begin{array}{l}\text { Can do it with } \\
\text { help }(\%)\end{array}$ \\
\hline Chat & 94.6 & 2.8 & 89.7 & 5.2 \\
\hline Anti-virus & 53.7 & 27.9 & 46.8 & 30.0 \\
\hline Edit photos & 65.4 & 22.6 & 63.8 & 24.9 \\
\hline Database & 28.0 & 29.5 & 27.8 & 30.1 \\
\hline Copy data to CD & 82.8 & 11.4 & 82.7 & 11.7 \\
\hline Move files & 87.1 & 8.6 & 88.8 & 7.6 \\
\hline Search Internet & 95.8 & 2.6 & 95.5 & 3.2 \\
\hline Download files & 88.2 & 8.1 & 85.3 & 10.0 \\
\hline Attach files to email & 87.7 & 7.7 & 85.9 & 9.0 \\
\hline Word processor & 91.3 & 5.7 & 91.3 & 6.0 \\
\hline Spreadsheet & 50.1 & 31.5 & 60.3 & 27.4 \\
\hline Presentation & 74.4 & 16.9 & 85.5 & 10.5 \\
\hline Download music & 89.8 & 6.0 & 83.4 & 10.5 \\
\hline Multimedia presentation & 50.2 & 34.1 & 56.1 & 33.4 \\
\hline Emails & 94.8 & 3.1 & 92.8 & 4.7 \\
\hline Web page construction & 50.1 & 32.9 & 34.3 & 40.0 \\
\hline
\end{tabular}

Note. The sample consisted of 22,121 students in Canada and 14,084 students in Australia. 


\section{APPENDIX C \\ MULTILEVEL MODELING EQUATIONS}

For the outcome variable SCIEACH, a multilevel null model was generated for both Canada and Australia, and can be summarized as follows:

$$
\text { Level } 1 \text { model: } Y_{i j}=\beta_{0 j}+r_{i j}, r_{i j} \sim N\left(0, \sigma^{2}\right) .
$$

Level 2 model: $\beta_{0 j}=\gamma_{00}+\mu_{0 j}, \mu_{0 j} \sim N\left(0, \tau_{00}\right)$.

Combined model: $Y_{i j}=\gamma_{00}+\mu_{0 j}+r_{i j}$.

In the level-1 model, $Y_{i j}$ represents the outcome variable (SCIEACH), $\beta_{0 j}$ is the average science achievement for school $j$, and $r_{i j}$ is the error term representing a unique effect associated with student $i$ in school $j$. Statistically, $r_{i j}$ measures the level-1 random effect in a normal distribution with a mean of zero and a constant level-1 variance, $\sigma^{2}$ (for details, please refer to Raudenbush \& Bryk, 2002).

In the level- 2 model, $\gamma_{00}$ is the intercept, which represents the grand mean of the outcome variable, and $\mu_{0 j}$ is the error term representing a unique effect with school $j$. Statistically, $\mu_{0 j}$ measures the level-2 random effect in a normal distribution with a mean of zero and a constant level-2 variance, $\tau_{00}$ (Raudenbush $\&$ Bryk, 2002). 


\section{Canada}

Level-1 model:

$$
\begin{aligned}
& \mathrm{SCIEACH}=\beta_{0 j}+\beta_{1 j}(\mathrm{ESCS})_{i j}+\beta_{2 j}(\mathrm{IMMIG})_{i j}+\beta_{3 j}(\mathrm{COMPEXP})_{i j}+\beta_{4 j}(\text { OTHERUSE })_{i j}+ \\
& \beta_{5 j}(\mathrm{BROWSNET})_{i j}+\beta_{6 j}(\mathrm{ENTFREQ})_{i j}+\beta_{7 j}(\mathrm{PRODFREQ})_{i j}+\beta_{8 j}(\mathrm{PPTCONF})_{i j}+ \\
& \beta_{9 j}(\mathrm{BASICONF})_{i j}+\beta_{10 j}(\mathrm{ADVCONF})_{i j}+r_{i j}
\end{aligned}
$$

Level-2 model:

$$
\begin{aligned}
& \beta_{0 \mathrm{j}}=\gamma_{00}+\gamma_{01}(\text { MEANESCS })_{\mathrm{j}}+u_{0 j} \\
& \beta_{1 j}=\gamma_{10} \\
& \beta_{2 j}=\gamma_{20} \\
& \beta_{3 j}=\gamma_{30} \\
& \beta_{4 j}=\gamma_{40} \\
& \beta_{5 j}=\gamma_{50} \\
& \beta_{6 j}=\gamma_{60} \\
& \beta_{7 j}=\gamma_{70} \\
& \beta_{8 j}=\gamma_{80} \\
& \beta_{9 j}=\gamma_{90} \\
& \beta_{10 j}=\gamma_{100}
\end{aligned}
$$

The overall relative effects regression model:

$$
\begin{aligned}
& \text { SCIEACH }=\gamma_{00}+\gamma_{01}(\text { MEANESCS })_{j}+\gamma_{10}(\text { ESCS })_{i j}+\gamma_{20}(\text { IMMIG })_{i j}+\gamma_{30}(\text { COMPEXP })_{i j}+ \\
& \gamma_{40}(\text { OTHERUSE })_{i j}+\gamma_{50}(\text { BROWSNET })_{i j}+\gamma_{60}(\text { ENTFREQ })_{i j}+\gamma_{70}(\text { PRODFREQ })_{i j}+ \\
& \gamma_{80}(\text { PPTCONF })_{i j}+\gamma_{90}(\text { BASICONF })_{i j}+\gamma_{100}(\text { ADVCONF })_{i j}+u_{0 j}+r_{i j}
\end{aligned}
$$




\section{Australia}

Level-1 model:

$$
\begin{aligned}
& \text { SCIEACH }=\beta_{0 j}+\beta_{1 j}(\text { ESCS })_{i j}+\beta_{2 j}(\text { IMMIG })_{i j}+\beta_{3 j}(\text { COMPEXP })_{i j}+\beta_{4 j}(\text { HOMEUSE })_{i j}+ \\
& \beta_{5 j}(\text { SCHUSE })_{i j}+\beta_{6 j}(\text { OTHERUSE })_{i j}+\beta_{7 j}(\text { BROWSNET })_{i j}+\beta_{8 j}(\text { ENTFREQ })_{i j}+ \\
& \beta_{9 j}(\text { PRODFREQ })_{i j}+\beta_{10 j}(\text { PPTCONF })_{i j}+\beta_{11 j}(\text { BASICONF })_{i j}+r_{i j}
\end{aligned}
$$

Level-2 model:

$$
\begin{aligned}
& \beta_{0 \mathrm{j}}=\gamma_{00}+\gamma_{01}(\text { MEANESCS })_{j}+\gamma_{02}(\text { COMPWEB })_{\mathrm{j}}+u_{0 j} \\
& \beta_{1 j}=\gamma_{10} \\
& \beta_{2 j}=\gamma_{20} \\
& \beta_{3 j}=\gamma_{30} \\
& \beta_{4 j}=\gamma_{40} \\
& \beta_{5 j}=\gamma_{50} \\
& \beta_{6 j}=\gamma_{60} \\
& \beta_{7 j}=\gamma_{70} \\
& \beta_{8 j}=\gamma_{80} \\
& \beta_{9 j}=\gamma_{90} \\
& \beta_{10 j}=\gamma_{100} \\
& \beta_{11 j}=\gamma_{110}
\end{aligned}
$$

The overall relative effects regression model:

$$
\begin{aligned}
& \text { SCIEACH }=\gamma_{00}+\gamma_{01}(\text { MEANESCS })_{j}+\gamma_{02}(\text { COMPWEB })_{j}+\gamma_{10}(\text { ESCS })_{i j}+\gamma_{20}(\text { IMMIG })_{i j}+ \\
& \gamma_{30}(\text { COMPEXP })_{i j}+\gamma_{40}(\text { HOMEUSE })_{i j}+\gamma_{50}(\text { SCHUSE })_{i j}+\gamma_{60}(\text { OTHERUSE })_{i j}+ \\
& \gamma_{70}(\text { BROWSNET })_{i j}+\gamma_{80}(\text { ENTFREQ })_{i j}+\gamma_{90}(\text { PRODFREQ })_{i j}+\gamma_{100}(\text { PPTCONF })_{i j}+ \\
& \gamma_{110}(\text { BASICONF })_{i j}+u_{0 j}+r_{i j}
\end{aligned}
$$




\section{APPENDIX D}

\section{ABSOLUTE EFFECTS MODELS}

Individual absolute effects for each student-level and school-level predictor were tested by addition to the null model. The results for Canada are presented in Table D1; the results for Australia are presented in Table D2.

Table D1.

Final estimation of absolute effects (fixed); two-level hierarchical linear model for scientific literacy among students in Canada

\begin{tabular}{|c|c|c|c|c|}
\hline Level 1/Student-level effects & & Gamma & $S E$ & $t$ \\
\hline Gender & FEMALE & -4.01 & 2.15 & -1.9 \\
\hline Socioeconomic status & ESCS & 20.67 & 1.61 & $12.8 * * *$ \\
\hline Immigrant status & IMMIG & -24.55 & 4.08 & $-6.0 * * *$ \\
\hline Experience with computers & COMPEXP & 11.41 & 1.05 & $10.9 * * *$ \\
\hline $\begin{array}{l}\text { Frequency of computer access } \\
\text { from home }\end{array}$ & HOMEUSE & 7.22 & 1.24 & $5.8 * * *$ \\
\hline $\begin{array}{l}\text { Frequency of computer access } \\
\text { from school }\end{array}$ & SCHUSE & -1.00 & 1.29 & -.8 \\
\hline $\begin{array}{l}\text { Frequency of computer access } \\
\text { from other places }\end{array}$ & OTHERUSE & -14.13 & 1.21 & $-11.7 * * *$ \\
\hline Browse the Internet & BROWSNET & 6.50 & 1.36 & $4.8^{* * *}$ \\
\hline Collaborate on Internet & COLLNET & -2.82 & 1.08 & $-2.6 * *$ \\
\hline $\begin{array}{l}\text { Frequency of entertainment } \\
\text { software use }\end{array}$ & ENTFREQ & -8.47 & 1.34 & $-6.3 * * *$ \\
\hline $\begin{array}{l}\text { Frequency of productivity software } \\
\text { use }\end{array}$ & PRODFREQ & -11.90 & 1.28 & $-9.3 * * *$ \\
\hline $\begin{array}{l}\text { Confidence using presentation } \\
\text { software }\end{array}$ & PPTCONF & 11.22 & 1.16 & $9.7 * * *$ \\
\hline Confidence with basic ICT skills & BASICONF & 16.76 & 1.38 & $12.2 * * *$ \\
\hline $\begin{array}{l}\text { Confidence with advanced ICT } \\
\text { skills }\end{array}$ & ADVCONF & 2.43 & 1.15 & $2.1 * *$ \\
\hline
\end{tabular}




\begin{tabular}{|c|c|c|c|c|}
\hline Level 2/School-level effects & & Gamma & $S E$ & $t$ \\
\hline School mean ESCS & MEANESCS & 14.55 & 1.71 & $8.5 * * *$ \\
\hline $\begin{array}{l}\text { Size of municipality in which } \\
\text { school is located }\end{array}$ & URBAN & 5.63 & 1.86 & $3.0 * *$ \\
\hline $\begin{array}{l}\text { Proportion of computers connected } \\
\text { to Internet }\end{array}$ & RATCOMP & -1.93 & 2.34 & -.8 \\
\hline School size & SCHLSIZE & .93 & .38 & $2.4^{*}$ \\
\hline Availability of computers & COMPWEB & .37 & 1.60 & -.2 \\
\hline Computers: School size ratio & IRATCOMP & -1.76 & 2.37 & -.8 \\
\hline
\end{tabular}

Note. Analyses were based on data for 22,121 students nested within 645 schools.

$* p<.05 . * * p<.01 . * * * p<.001$. 
Table D2.

Final estimation of absolute effects (fixed); two-level hierarchical linear model for science achievement among Australian students

\begin{tabular}{|c|c|c|c|c|}
\hline Level 1/Student-level effects & & Gamma & $S E$ & $t$ \\
\hline Gender & FEMALE & -0.14 & 3.12 & -.1 \\
\hline Socioeconomic status & ESCS & 24.69 & 1.22 & $20.2 * * *$ \\
\hline Immigrant status & IMMIG & -9.99 & 3.15 & $-3.2 * *$ \\
\hline Experience with computers & COMPEXP & 16.41 & 1.36 & $12.1 * * *$ \\
\hline $\begin{array}{l}\text { Frequency of computer access from } \\
\text { home }\end{array}$ & HOMEUSE & 12.33 & 1.94 & $6.4^{* * *}$ \\
\hline $\begin{array}{l}\text { Frequency of computer access from } \\
\text { school }\end{array}$ & SCHUSE & 2.79 & 1.22 & $2.3 * *$ \\
\hline $\begin{array}{l}\text { Frequency of computer access from } \\
\text { other places }\end{array}$ & OTHERUSE & -8.53 & 1.06 & $-8.1 * * *$ \\
\hline Browse the Internet & BROWSNET & 8.54 & 1.18 & $7.2 * * *$ \\
\hline Collaborate on Internet & COLLNET & .11 & 1.40 & .1 \\
\hline $\begin{array}{l}\text { Frequency of entertainment software } \\
\text { use }\end{array}$ & ENTFREQ & -4.15 & 1.29 & $3.2 * *$ \\
\hline $\begin{array}{l}\text { Frequency of productivity software } \\
\text { use }\end{array}$ & PRODFREQ & -7.05 & 1.27 & $-5.6 * * *$ \\
\hline $\begin{array}{l}\text { Confidence using presentation } \\
\text { software }\end{array}$ & PPTCONF & 18.42 & 1.26 & $14.6 * * *$ \\
\hline Confidence with basic-level tasks & BASICONF & 19.50 & 1.67 & $11.7 * * *$ \\
\hline $\begin{array}{l}\text { Confidence with advanced-level } \\
\text { tasks }\end{array}$ & ADVCONF & 9.79 & 1.35 & $7.3 * * *$ \\
\hline
\end{tabular}




\begin{tabular}{|c|c|c|c|c|}
\hline \multicolumn{2}{|l|}{ Level 2/School-level effects } & \multirow{2}{*}{$\begin{array}{c}\text { Gamma } \\
13.82\end{array}$} & \multirow{2}{*}{$\frac{S E}{2.90}$} & \multirow{2}{*}{$\frac{t}{4.8^{* * *}}$} \\
\hline School mean ESCS & MEANESCS & & & \\
\hline Size of municipality in which scho & $1 \mathrm{URBAN}$ & 3.22 & 2.87 & 1.1 \\
\hline \multicolumn{5}{|l|}{ is located } \\
\hline School size & SCHLSIZE & -.17 & .69 & -.25 \\
\hline Proportion of computers connected & COMPWEB & -12.21 & 3.69 & $-3.3 * * *$ \\
\hline \multicolumn{5}{|l|}{ to Internet } \\
\hline Availability of computers & RATCOMP & 2.76 & 3.35 & .8 \\
\hline Computers: school size ratio & IRATCOMP & 1.97 & 3.22 & 6 \\
\hline
\end{tabular}

Note. Analyses were based on data for 14,084 students nested within 341 schools. $* p<.05 . * * p<.01 . * * * p<.001$. 